\title{
Hepatocyte Polarity
}

\author{
Aleksandr Treyer ${ }^{1}$ and Anne Müsch ${ }^{1,{ }^{*}}$ \\ ${ }^{1}$ Albert Einstein College of Medicine, Department of Developmental and Molecular Biology, \\ Bronx, New York
}

\section{Abstract}

Hepatocytes, like other epithelia, are situated at the interface between the organism's exterior and the underlying internal milieu and organize the vectorial exchange of macromolecules between these two spaces. To mediate this function, epithelial cells, including hepatocytes, are polarized with distinct luminal domains that are separated by tight junctions from lateral domains engaged in cell-cell adhesion and from basal domains that interact with the underlying extracellular matrix. Despite these universal principles, hepatocytes distinguish themselves from other nonstriated epithelia by their multipolar organization. Each hepatocyte participates in multiple, narrow lumina, the bile canaliculi, and has multiple basal surfaces that face the endothelial lining. Hepatocytes also differ in the mechanism of luminal protein trafficking from other epithelia studied. They lack polarized protein secretion to the luminal domain and target single-spanning and glycosylphosphatidylinositol-anchored bile canalicular membrane proteins via transcytosis from the basolateral domain. We compare this unique hepatic polarity phenotype with that of the more common columnar epithelial organization and review our current knowledge of the signaling mechanisms and the organization of polarized protein trafficking that govern the establishment and maintenance of hepatic polarity. The serine/threonine kinase LKB1, which is activated by the bile acid taurocholate and, in turn, activates adenosine monophosphate kinase-related kinases including AMPK1/2 and Par1 paralogues has emerged as a key determinant of hepatic polarity. We propose that the absence of a hepatocyte basal lamina and differences in cell-cell adhesion signaling that determine the positioning of tight junctions are two crucial determinants for the distinct hepatic and columnar polarity phenotypes.

\section{Introduction}

Hepatocytes, like other epithelia, are situated at the interface between the organism's exterior and the underlying internal milieu and organize the vectorial exchange of macromolecules between these two spaces. To mediate this function, epithelial cells, including hepatocytes, are polarized with distinct luminal and basolateral domains that are segregated by tight junctions. Lateral surfaces are engaged in cell-cell contacts while the basal domains mediate the interaction with the underlying extracellular matrix (ECM). Despite these universal principles, hepatocytes distinguish themselves from other nonstriated epithelia by their multipolar organization. Each hepatocyte participates in multiple, narrow lumina, the bile canaliculi, and has multiple basal surfaces that face the endothelial lining. Hepatic cells also differ from all other epithelia studied to date in their strategy to target luminal proteins in the biosynthetic pathway. They only transport polytopic membrane proteins directly from the Golgi to the bile canalicular domain but lack polarized protein secretion into the luminal domain and target single-spanning and

(C) 2013 American Physiological Society.

*Correspondence to anne.muesch@einstein.yu.edu. 
glycosylphosphatidylinositol (GPI)-anchored bile canalicular membrane proteins via transcytosis from the basolateral domain.

Our knowledge of principal mechanisms for the establishment and maintenance of epithelial polarity are largely derived from culture models of the more common columnar epithelia tissues such as the kidney, intestine, breast, or thyroid. In particular, Mardin Darby Canine kidney (MDCK) cells, originating from distal kidney tubules have evolved as a widely used model system to study all aspects of polarity from morphology to protein trafficking. By contrast, few hepatic cell lines exist that develop polarity and they are less amenable to experimental manipulation than the columnar epithelial lines. In this review, we will introduce and evaluate the tools that have been utilized for the study of hepatic polarity and will give an outlook on emerging new technologies and approaches. Experimental limitations are the likely reason why the study of hepatic epithelial polarity has lagged behind that of columnar epithelia (305). Consequently, we still have only limited knowledge of which molecular features are common and which are distinct between the two epithelial polarity phenotypes. This is an important question for understanding the potential of hepatoblasts to differentiate into either hepatocytes or biliary cells (also called cholangiocytes or ductal epithelial cells). The latter make up the liver bile ducts and are of columnar polarity.

In the following sections, we will highlight the unique features of the hepatic polarity phenotype and discuss molecular mechanisms for epithelial morphogenesis and the organization of the polarized trafficking machinery. We will include polarity features that have been elucidated in nonhepatic epithelial cells when they are also relevant for hepatocytes, but the emphasis is on findings that were made in hepatocytes and hepatic culture models. Furthermore, we will discuss how these findings either mirror or contrast with what we know for columnar epithelial cells. Finally, we will illustrate how multiple liver diseases are intimately linked to hepatocyte polarity, either because their underlying reasons are polarity defects or because disease-causing agents highjack polarity proteins to enter hepatic cells.

\section{The Liver-the Functions of Hepatocytes}

Liver. In the beginning of the 20th century, Ambrose Bierce humorously described it as a large red organ thoughtfully provided by nature to be bilious with, noting as well the ancients' belief that the liver bore emotion and life itself. Thus, it was long established historically, although perhaps not always scientifically, that the liver has a specific role in digestion and, moreover, in some all-encompassing bodily function that we presently know as homeostasis. Indeed, the liver is the largest metabolic organ in the human body, responsible for production of bile acid, salt, pigment, cholesterol, and nearly all plasma proteins, catabolism and absorption of nutrients, elimination of toxic compounds, and processing of a large variety of viscerally produced hormones and cytokines. The liver's blood circuit is a unique system where venous blood from the gut, pancreas, and the spleen, as well as arterial blood from the hepatic artery is delivered to the liver's highly branched network of fenestrated blood vessels known as the sinusoids. It is here, that the delivered blood mixture has a near-direct access to the liver's parenchymal epithelial cells- the hepatocytes. Processed blood is delivered from the sinusoids to the central veins that then empty into the vena cava inferior. The free access of blood to the parenchyma is made possible by the high permeability of the endothelial lining of the sinusoids, and, at the same time by the plate-like arrangement of the hepatic parenchyma, which is formed by single- or double-cell thick layers of brick-like hepatocytes, with the faces of the plates set effectively exposed to the sinusoidal space. Thus, the organization of hepatocytes provides that each cell has an extensive basal façade for epithelial-blood interface and maintains the sites of 
cell-cell adhesion laterally, along its perimeter. There is yet another functionally distinct domain on the hepatocyte plasma membrane, known as the apical, or, canalicular domain, which makes up a narrow lumen between two adjacent hepatocytes and serves as a site of bile secretion. The luminal domains of every hepatocyte couplet are continuous with those of the next, and the combined luminal structures extend throughout the length of hepatic plates, forming a network of bile canaliculi. The bile canaliculi deliver bile secreted by hepatocytes to the interlobular bile ducts, which are larger tubules encased by the connective tissue of the portal tracts, which incidentally also house the hepatic arterioles and portal venules, and which, in turn, empty into the larger ducts that join as the common bile duct of the gastrointestinal tract, a minore ad maius (Fig. 1).

\section{The Hepatic Polarity Phenotype}

Hepatocytes have to sustain two countercurrent flow systems- the synthesis and secretion of bile, and the uptake, processing, and secretion of sinusoidal blood components, including ones of the bile itself returning through the portal venous blood. Their capacity to do so is provided by the highly polarized state of healthy adult hepatocytes. The polarity of a hepatocyte is multifaceted. It is manifested primarily by polarized plasma membrane domain structure, identity, and distribution, but is rooted in intracellular pathways that control polarized trafficking of proteins and cytoskeletal dynamics. Table 1 lists some of the best studied hepatocyte membrane proteins that are targeted to and/or function at either the bile canalicular or sinusoidal (and lateral) cell surface.

Domain segregation is a recurring theme in polarized epithelial cells, since most epithelial tissues serve as an interface between two different physiological environments. Interestingly, however, hepatic polarity constitutes a unique example of epithelial morphology, as most other polarized nonstriated epithelia, including the cholangiocytes of the interlobular bile ductules, manifest a much more prevalent columnar type of apicobasal polarity. Tissues with columnar morphology, as the classification may imply, are comprised of tightly packed cell monolayers with a continuous apical surface occluded by a belt of tight junctions at the geometrical apex of the monolayer. The basolateral domain in columnar cells provides adhesion between neighboring cells via desmosomes, adherens junctions, and the aforementioned tight junctions, and conducts anchoring and signaling functions through the interaction with the ECM components of the basal lamina. This type of polarity is physiologically advantageous to the formation of larger luminal surface areas, such as those found in the gut, kidney, and respiratory airway epithelia, and has been extensively reviewed (56) (Fig. 1, biliary cells).

The canalicular domains of hepatocytes, on the other hand, develop on the perimeter of the cells at the sites of lateral cell-cell contacts (Fig. 1, hepatocytes), albeit via similar tightjunction occlusion principles as do the columnar apical domains (238). The canaliculus may be shared with more than one neighboring cell and may encircle the entire perimeter of the hepatocyte. In vivo canalicular size is relatively small compared to those in hepatic tissue culture model systems, yet it accounts for 13\% of the total hepatocyte surface area, courtesy of its extensive microvilli $(143,484)$. A remarkable aspect of the canalicular structure is its extremely dynamic turnover, which has been estimated at $10 \% / \mathrm{min}$ for the outer membrane leaflet, presumably due to the fact that the release of phospholipid vesicles from the canalicular membrane is the primary source of phospholipids secreted in bile (87).

A further distinguishing characteristic of hepatocyte morphology has to do with the basolateral domain. The basal surfaces of hepatocytes are flanked by subendothelial sinusoidal spaces (better known as the space of Disse) that allow the access of hepatocytes to the sinusoidal blood flow (Fig. 1, hepatocytes). Neither the sinusoidal endothelium, nor 
the hepatocytes themselves provide a dense basal lamina that is found in most epithelial tissues, although a sparse basement membrane-like deposition of various collagens, fibronectin, and proteoglycans is found around adult hepatocytes $(293,303,491)$. A dense basal lamina is also present in the liver, but is confined to the portal areas housing vasculature and bile ducts. Thus, in the liver, there is a distinct correlation between the presence and strength of the basal lamina and the corresponding columnar versus hepatic polarization of the epithelium it supports, particularly since ECM is thought to be necessary for proper differentiation of all hepatic cell types $(303,382,415)$.

\section{The acquisition of hepatic polarity during development}

Although hepatic and biliary epithelia develop with their respective and distinct polarity phenotypes, both tissues differentiate from common precursors in the vertebrate embryo. Let us briefly consider the important embryological steps that are involved in the formation of the adult liver, which are quite well documented in references (110) and (510) in detail.

The liver is one of the organs that develop from the endoderm. At the three-germ layer stage of the embryo, the ventral endoderm develops a Wnt signaling gradient, which functionally divides the cells of the endoderm along the anterior-posterior axis into the hind-, mid-, and foregut regions, with Wnt respectively decreasing toward the latter (395). The resulting foregut becomes the site of future liver development, the absence of Wnt signaling being a requirement for hepatogenic competence (194). In addition to its hepatogenetic function, the foregut also gives rise to the pancreas, the gall bladder, and the lungs.

The first step toward true hepatic delineation is the expression of FoxA and GATA transcription factors, both of which promote transcription of serum albumin gene-a principal hepatic hallmark, and of a hepatic-specified transcription factor HNF4a (42-44, 161). Two signaling mechanisms begin to act on the foregut to further induce hepatic development-Fibroblastic Growth factor (FGF) coming from the cardiogenic mesoderm, and Bone Morphogenetic Protein (BMP) coming from the septum transversum, both producing hepatic gene expression and massive proliferation by embryonic day 9 in mice $(61,214,381)$. The proliferating cells of the hepatic endoderm proceed to thicken laterally and, by day 11 , delaminate and invade the neighboring mesenchyme of the septum transversum. The resulting bulbous conglomerate of hepatoblasts is known as the liver bud, which continues to expand, and assumes hematopoetic functions (the liver being the primary hematopoetic organ during embryogenesis). During the progression of the liver bud, the structure becomes vascularized and receives a wide array of growth factors and cytokines from the mesenchyme it eventually invades. Importantly, these growth factor pathways have been found to be active during liver regeneration and in vitro differentiation as well (37, $316,436)$.

Finally, by embryonic day 13.5 in mice, or 7 weeks in humans, the bipotent hepatoblasts of the liver bud begin to differentiate into hepatocytes and cholangiocytes. The differentiation of cholangiocytes is associated with signaling via Notch and transforming growth factor beta (TGF $\beta)(80,234,282)$. Hepatocytes, on the other hand, differentiate following stimulation with Oncostain $\mathrm{M}$ and transforming growth factor alpha (216). Hepatcotye growth factor, primarily required for proliferation and migration of hepatic cells, may also play a role in proper differentiation and organization of hepatic tissue $(218,314)$. The markers commonly used to determine the identity of hepatic tissues are cytokeratine (CK) 19 for cholangiocytes, and CK8, CK18, and albumin for hepatocytes (459).

So, what happens in the developing liver in terms of polarity? Our understanding of when and how the mammalian fetal liver polarizes has thus far been limited to temporally static 
analysis of murine liver samples. However, the work of Hubbard, Hughes, and several other groups yields some basis for a comprehensive picture of liver polarity during development.

Although hepatoblasts are essentially nonpolarized cells and do not see much contact with each other due to being heavily interspersed with hematopoetic stem cells, the first signs of their undergoing membrane differentiation may be observed in fetal rat liver at embryonic day 12 , where small zones of attachment appear on the few directly apposed cells. These zones serve as the sites for the emergence of canalicular structures, which by embryonic day 13 are detectable by electron microscopy as fissures with irregular microvilli $(23,324,494)$. Biliary epithelium also emerges at embryonic day 14 , as cuboidal biliary cells can be observed around the portal vein in a structure known as the ductal plate. Following day 17, as the hematopoetic stem cell populations decrease, hepatocytes increasingly proliferate and fill the liver, forming extensive cell-cell contacts, and the first contiguous canalicular structures (494). These early canalicular domains appear dilated, and are thought of as common apical structures for several hepatocytes at a time. Central lumen-sharing hepatocyte clusters (see Fig. 2), which form during developmental and regenerating processes, are often referred to as acini (not to be confused with the conventional definition of the liver acinus as the parenchyma centered around the terminal branches of the hepatic artery and the portal vein that give rise to the zones of the liver lobule). Embryonic day 17 also marks a change in biliary morphology, starting a process known as ductal plate remodeling. As part of this remodeling, biliary epithelium circumnavigating the portal vein becomes sequestered into biliary tracts by the portal mesenchyme. True bile canalicular profiles become apparent by embryonic day 21, and continue to develop for about 2 weeks postnatally (123). Ductal plate remodeling is also complete around embryonic day 21 (149, 263).

Surface identity of embryonic hepatocytes is delineated quite early on in development, as early as their initial differentiation. The dynamics of these early domain constituents are not synchronized, and the distribution of different surface proteins that mark basolateral and canalicular domains varies for prenatal, neonatal, and adult hepatocytes. Nonetheless, canalicular proteins such as dipeptidyl peptidase IV and HA 4, both widely used in vivo and in primary culture models as canalicular markers, as well as basolateral proteins such as asialoglycoprotein receptor (ASOR) and CE-9 have been observed at their respective domains starting at embryonic day $14(23,24,123)$.

\section{Hepatic polarity in liver regeneration}

One of the most notable features that make the liver unique is its well-known and uncanny capacity for regeneration following the loss of up to $70 \%$ of its mass. The phenomenon was first observed in rabbit liver resection studies by Hermann Tillmanns at the end of the 19th century, although insinuations at hepatic regeneration date back to ancient Greek literature. Modern studies have elucidated a number of temporal and molecular steps of regeneration following partial hepatectomy via surgical resection or damage with hepatotoxic agents such as dimethyl-nitrosamine and carbon tetrachloride. The molecular mechanisms of mammalian liver regeneration are well reviewed in references $(122,316)$, and we will, on our part, go over the process while focusing on the morphology and polarity dynamics in the regenerating liver.

Following partial hepatectomy, all tissues of the resected liver begin to proliferate, with the hepatocytes being the first (DNA synthesis peaking at $24 \mathrm{~h}$ postsurgery) and the other cell types following suit (DNA synthesis peaking 3-4 days postsurgery). All hepatocytes have the potential to undergo cell division. However, there is a specific dynamic to their proliferation in context of the space between the portal and central venules of the remaining liver lobule mass. Hepatocytes nearest the central veins generally stay dormant, while those 
nearest the portal blood supply divide, progressively filling up the space toward the central vein. Almost immediately after the start of the proliferation, the periportal hepatocytes appear to have diminished canalicular networks. Furthermore, the canalicular structures of the periportal hepatocytes at this stage resemble the multicellular acini that are observed during embryonic liver development, complete with a dilated central lumen shared between several hepatocytes at a time (422). After hepatocytes have significantly divided (around 3 days post-partial hepatectomy), and filled the space between the portal and central veins, the emerging hepatic plates generally appear multicellular in thickness and the canalicular acini remain abundant. By day 7 postsurgery, the regenerated hepatic plates appear as normal single-cell thick structures with predominantly typical honeycomb network and very few acini. Work of Stamatoglou and Odin and Obrink suggests that in regeneration, similarly to embryonic polarity development, polarized markers such as intercellular adhesion molecule C-CAM, fibronectin receptor AGp110, and zonula occludens-1 tight junction protein may be diminished or mislocalized $(340,341)$. At the same time, observations by Hubbard and Stamatoglou suggest that hepatocytes maintain canalicular domain identity and segregation during proliferation (25). Taken together, it is apparent that hepatic polarity is generally maintained in regenerating hepatocytes, it resembles rather the embryonic stages, where junctional complexes are apparent but not fully matured and thus unable to maintain strict domain occlusion.

But why do regenerating hepatocytes proliferate and polarize in a way that seems somewhat counterintuitive to the maintenance of their metabolic function? Recent modeling and validation of hepatocyte division following chemical hepatectomy suggest that, proliferating hepatocytes may initially assume random orientation in the recovering liver mass, but must ultimately align with the cytokine-producing sinusoidal endothelium to assume proper hepatic plate structure (187). Thus, without the sinusoidal cues, as would be the case for surgical hepatectomy, hepatocyte proliferation appears unstructured until sufficient parenchymal density is achieved and the sinusoids reemerge.

All these suggest that the observed changes in hepatic plate structure and domain marker distribution are part of a facultative reorganization that allows for hepatocytes to grow back quickly and enmasse, before engaging proper secretory and metabolic function provided by the typical hepatic morphology. However, it is necessary to note, that establishment of polarity is not an after-effect that follows proliferation, but is an integral part of hepatic regeneration. As mentioned previously, domain specificity and tight junction maintenance is necessary for hepatic acini clustering and for the prevention of mixing between the canalicular and sinusoidal spaces. Furthermore, mouse liver knockouts for $\mathrm{Cdc} 42$, a rhoGTPase family member that interacts with Par3-Par6-aPKC polarity complex that in turn maintains cell-cell junctions, develop aberrations in both the hepatic plate and canalicular structures, are significantly slower to proliferate post-partial hepatectomy with attenuated DNA synthesis peaks, and engage in excessive lipid accumulation, which may be indicative of cytoskeletal and trafficking defects (503).

In conclusion, we want to emphasize once more that there are extensive parallels between the morphogenetic events that lead to the organization of hepatocytes into cords that is characteristic of the mature liver during embryonic development and during liver regeneration, suggesting that the regenerating liver re-calls the embryonic differentiation program. As we will see in Section "Hepatocellular carcinoma," during the early stages of transformation, hepatocytes revert to the embryonic organization of hepatocyte ascini (Fig. $2)$. 


\section{In vitro Models for Hepatocyte Polarity}

\section{Primary hepatocyte cultures}

Enzymatic digestion of the liver allows the isolation of hepatocytes. In the standard protocol, the bulk of cells collected upon collagenase treatment of a perfused liver consists of hepatocytes that are plated out mostly as nonpolarized cells. About $20 \%$ of the cells, however, are hepatocyte couplets, which restore the bile canalicular-like space between them upon plating and have been utilized to study signaling mechanisms that govern the reestablishment of the canalicular domain and the trafficking of canalicular proteins (154, 155). Although hepatocyte couplets can be further enriched for by centrifugal elutriation to represent up to $60 \%$ to $70 \%$ of all viable cells in a preparation, their usefulness is limited by their short lifespan that prevents manipulations such as recombinant protein expression or protein depletion.

When maintained as monolayers primary hepatocytes on substrates coated with ECM protein such as collagen or fibronectin exhibit a spread morphology and remain nonpolarized without distinguishable surface domains or junctional complexes. They also rapidly lose expression of many of their differentiation markers including albumin and most of their bile acid influx and efflux transporters. Remarkably, when overlaid with gelifying collagen-I or Matrigel (a laminin and collagen containing ECM extracted from EngelbrethHolm-Swarm tumor in mice) even a week after being maintained as a monolayer, rat hepatocytes repolarize and form extensive, functional bile canaliculi lined with tight junctions that accumulate fluorescent bile acid analogues $(112,310)$. Sandwich cultures between double layers of ECM have become robust and reproducible in vitro models for hepatic polarity that can be maintained for up to 40 days $(111,261,312)$. They have been employed to elucidate signaling pathways that govern differentiation, including bile canaliculi formation $(33,37,134,274,312)$ and even to study protein trafficking of bile salt export pump-yellow fluorescent protein (BSEP-YFP) from the perinuclear area to the canalicular membrane (L. Homolya and I. Arias, personal communication). However, the gelled ECM top support represents a mass transfer barrier that hinders the diffusion of solutes from the culture medium and hampers live imaging studies. To alleviate such limitations, "ECM-free" and optically transparent synthetic sandwich cultures have been developed in which the natural ECM has been replaced by bioactive polymeric films that contain sugar ligands [such as galactose which interacts with the sinusoidal ASOR $(75,108)$ ] or cell adhesion peptides $(92,375)$. Still, like most primary cultures the hepatocyte sandwich cultures require animal sacrifices, are laborious to establish and exhibit some variability. Therefore, hepatic cell lines have been developed as alternatives.

\section{Hepatic cell lines}

Immortalization is associated with cell transformation, which frequently involves loss of epithelial cell polarity. Therefore, few model cell lines exist that allow the investigation of polarity for any epithelial tissue. Hepatic cell lines that maintain luminal/basolateral cell surface polarity with hepatic organization and assemble cell-cell junctional complexes are limited to (i) the human hepatoma lines HepG2 and HepG2R, (ii) hybrids of the rat hepatoma Fao cell line, and (iii) the AML12 line derived from livers of transgenic mice overexpressing TGFa. Typically, polarized hepatic lines do not develop bona fide bile canaliculi, that is, arrange the luminal domains of neighboring cells into a continuous lumen between the lateral domains of neighboring cells, but rather form intercellular lumina between two or three cells (Figs. 3 and 4A).

HepG2-This is a human line established from a differentiated hepatocellular carcinoma (HCC) $(90,226)$. It is the most widely used line for polarity studies because of its human 
origin and because it can be easily manipulated by transfection. HepG2 cells accumulate the fluorescent bile acid derivative cholylglycylamidofluorescein in their bile canaliculi-like lumina, indicating that they are capable of vectorial transport and have been shown to possess functional bile acid efflux transporters at their luminal domains $(57,96)$. HepG2 cells also maintain the trafficking mode for luminal proteins that is characteristic of hepatocytes in vivo (413). As discussed in more detail below, hepatocytes target newly synthesized single-membrane-spanning luminal proteins via transcytosis from the sinusoidal surface to the bile canalicular-like domain. However, only $20 \%$ to $40 \%$ of HepG2 cells in a monolayer polarize with bile canaliculi-like structures (462). The polarity of HepG2 cells has been improved by growing them as multilayers on predeposited ECM, resulting in elongated canalicular structures that appear as ascini involving multiple cells (182).

HepaRG-These cells (160) exhibit a heterogeneous phenotype with hepatocyte-like and biliary-like cells. The hepatic population features functional expression of both sinusoidal and canalicular drug transporters and have retained regulatory pathways controlling transporter levels (230). These features, associated with high expression of drug metabolizing enzymes in HepaRG cells, have made them interesting for the study of hepatic drug detoxification pathways. Their bipotent nature has also made them of interest for differentiation studies (162).

WIFB-These cells were derived from hybrid cells obtained by fusion of nonpolarized rat hepatic Fao cells (101) with human fibroblasts $(68,200,402)$. Similar to HepG2 cells, they polarize and target bile canalicular and sinusoidal proteins as observed in hepatocytes in Vivo $(199,200)$, and are capable of cholylglycylamidofluorescein accumulation in their lumina (50). However, they show far more extensive polarization than HepG2 cells. WIFB cells develop polarity in more than $90 \%$ of the monolayer, allowing for the biochemical analysis of polarity features (200). Unlike HepG2 cells, they establish gap junctions (72), which might regulate the establishment of other hepatocyte cell-cell junctions (see below). On the downside, their hybrid nature and the fact that they have not been manipulated other than by adeno- or retrovirus transduction, has hampered the popularity of WIFB cells as a research tool for hepatic polarity studies.

Can 3-1 and Can 10 (357)-These lines were generated by culture of Fao cells in spheroids, which promotes extensive cell-cell contacts and led to the appearance of zones of polarized cells that could subsequently be isolated in monolayer cultures. Can 3-1 cells form functional bile canaliculi-like domains in $95 \%$ of the monolayer when cultured at high density while Can 10 cells establish long branched bile canaliculi structures in which the luminal poles of ten or more cells are joined. This makes Can 10 the first hepatic cell line with functionally highly developed bile canaliculi that resemble those in vivo (Fig. 4B). Their advantage over WIFB cells is their nonhybrid nature. They are attractive tools for the elucidation of polarization pathways because their gene expression profile can be compared to that of their parental nonpolarized Fao line. There are currently no published data available on protein and lipid transport in these lines, so their full potential as research tools still remains to be explored.

AML12-The AML12 line (497) establishes bile canalicular-like domains between neighboring cells. Transmission electron microscopy analysis revealed luminal microvilli and tight junctions. There is, however, little information about the polarized distribution of polarity proteins and no data on protein trafficking in AML12 cells, which have been mostly utilized for the study of cell signaling $(53,499)$. 
In summary, the tools and wealth of information accumulated for HepG2 and WIFB cell studies make these two cell lines the primary choice for in vitro hepatic polarity studies. The reader is referred to an excellent recent review that evaluates the advantages and disadvantages of the above-mentioned and additional hepatic cell lines for the study of various aspects of hepatic physiology (96).

\section{Models to study simple columnar versus hepatic polarity}

As discussed in Sections "The acquisition of hepatic polarity during development and "Hepatic polarity in liver regeneration", during liver development, regeneration of the adult liver or during neoplastic growth (see Section "Hepatocellular carcinoma"), hepatocytes are frequently found in an acinar organization that had been interpreted as columnar phenotpye $(343,422,423)$. Hepatic acini disappear when the liver plate is properly (re-)established. The available data have thus led to the hypothesis that hepatic differentiation involves columnar intermediates. The capability of liver cells to switch between columnar and hepatic polarity phenotypes is further suggested by liver regeneration studies that have shown that hepatocytes can give rise to biliary cells and vice versa $(311,358,359,501)$. The question of what mediates the branching into either polarity phenotype has not been widely posed, but there are several culture models available to address it.

Primary hepatocytes-Michalopoulos and colleagues devised a protocol to establish organoid liver cultures from isolated rat hepatocytes (315). By growing hepatocytes in collagen-coated pleated surface roller bottles (for sufficient aeration), the authors could reconstruct a multilayered liver tissue composed of a superficial monolayer of biliary epithelial cells with classical cobblestone morphology, an intermediate layer of polarized hepatocytes that formed bile canaliculi interspersed with connective tissue and a basal layer of endothelial cells. While the nonepithelial cell types are likely contaminants of the hepatocyte preparation, Michalopoulos et al. demonstrated that the biliary layer was indeed derived from the hepatocyte parenchyma (313). They further determined that the receptor tyrosine kinase ligands epidermal and hepatocyte growth factors are required for the maturation of the biliary layer at the surface of the organoid, while the steroid dexamethasone was essential for the phenotypic maturation of the hepatocytes (314). With the ability to selectively manipulate the cell types in the organoid, particularly the maturation of biliary epithelia from hepatocyte precursors, liver organoid cultures represent a promising tool to unravel signaling pathways that govern the development of the two epithelial cell types of the liver (267). It will be difficult, however, from the plethora of changes in cell fate and differentiation to dissect out signaling events that relate to changes in the polarity phenotype. Hepatic cell lines with either flexible polarity phenotypes or with defined columnar polarity might be better suited to yield initial insights into this question.

Hepatic cell lines-WIFB cell polarization appears to mimic the two-step process proposed for the developing liver. Upon plating at low confluency, they initially adopt simple columnar polarity. Then, over a 2-week period, columnar cells first lose their luminal domains to become nonpolarized and proliferate before they subsequently repolarize with hepatic polarity $(84,97)$. This feature makes WIFB cells a good model for high-throughput approaches to identify compounds/molecules that block the transition from columnar-tohepatic polarity (Fig. 4A).

Cassio and colleagues, who had selected polarized clones derived from Fao hepatoma cells grown as spheroids did not only establish lines that exhibit hepatic polarity (Can 3-1, Can 10) but with Can 11-3-5 also generated a Fao-derived line that develops columnar polarity (357). Given their common parental precursor a comparison of the gene expression profile between the Can3-1 and Can 11-3-5 lines might reveal key determinants of the two polarity 
phenotypes. Likewise, a HepG2 clone that exhibits columnar polarity has been developed, which can be compared with the parental line (414).

Van Ijzendoorn and colleagues established experimental conditions under which HepG2 cells can be coaxed into forming acinar-like lumina shared by multiple cells (182) and develop complicated branching luminal structures (441). This makes them a useful tool to study the transition from isolated bile canalicular pockets between two cells to larger ascini and elaborate bile canalicular networks.

Nonhepatic cell lines-Utilizing the kidney-derived epithelial line MDCK as a model, our group discovered with Par1b the first candidate protein to regulate the branching of the columnar and hepatic epithelial differentiation programs. Par1b/MARK2/EMK1 is one of four mammalian paralogues of Par1, a serine/threonine kinase originally identified as polarity determinant in the one-cell embryo of Caenorhabditis elegans (227). Evidence from Drosophila has since indicated an essential role for Par1 in the maintenance of a columnar monolayered follicle epithelium $(86,104)$. Par1 also promotes the organized remodeling of cell layers during morphogenetic processes such as gastrulation movement in Xenopus (246, 347) and vulva morphogenesis in C. elegans (196). Others and we found Parlb essential for the morphogenesis of polarizing MDCK cells. Inhibition of PAR1b-function disrupted various aspects of epithelial polarization, notably the establishment of a luminal surface domain, the development of a columnar cell shape and the organization of an epithelialspecific microtubule array $(81,83,429)$. Additional findings from our group suggested a role for Parlb not just in lumen formation per se but also in defining lumen position and epithelial architecture. Interestingly, we found that recombinant expression of wild-type Par1b promotes two hallmarks of the hepatic epithelial phenotype in MDCK cells, a model for columnar epithelia. Parlb-overexpessing MDCK cells exhibited bile canaliculi-like lateral rather than apical lumina and switched from a direct to an indirect mode of luminal protein targeting (84) (Fig. 3, MDCK-Parlb cells). Thus, the elucidation of Par1b-signaling pathways in MDCK cells will likely yield key mechanisms for the differentiation into either the columnar or hepatic epithelial phenotype.

\section{Signaling Molecules and Pathways for Hepatic Polarity}

The acquisition of epithelial polarity is but one aspect of a complex hepatic differentiation program that is initiated by a sequentially operating set of signaling pathways. This complexity makes it difficult to pinpoint the signaling events that explicitly shape epithelial polarization and only a few key molecules have been characterized for their role in polarity. Most, if not all of them, function in part by regulating hepatic protein traffic, which we will elaborate on in more detail later.

\section{HNF-4a}

HNF4- $\alpha$ (hepatocyte nuclear factor 4 alpha) is a transcription factor essential for expression of a large array of genes that define hepatocyte function (265). In addition, HNF-4a is required for the expression of many genes whose products are involved in cell junction assembly and cell adhesion (420). Reduced expression of the latter proteins, among them Ecadherin, ZO1, and CEACAM1, likely accounts for the fact that livers deficient in HNF-4a not only exhibited metabolic defects but also an abnormal morphology (355). Hepatocytes from these livers were small, failed to make proper cell-cell contacts, and lacked normal bile canaliculi. In addition to cell-cell adhesion molecules, they also featured reduced expression of connexins 32 and 26 that might participate in junction assembly in hepatocytes. Interestingly, overexpression of HNF-4a in cultured fibroblasts was sufficient to convert these cells to an epithelial phenotype. Surprisingly, however, when HNF-4a deficient hepatocytes where grown in vitro as primary cultures their wild-type cell morphology and 
polarity were restored, which prompted the authors to suggest an additional noncell autonomous role for HNF-4a (177). Because the absence of HNF-4a has also been associated with signs of stress response, such response may have contributed to the deficiencies observed in HNF-4a-null livers.

\section{Oncostatin M}

Oncostatin M (OSM) is an interleukin-6-related cytokine and glucocorticoid that is produced and secreted by the hemopoietic cells that are interspersed with the fetal hepatocytes [reviewed in reference (321)]. Members of the IL-6 family that also include leukemia inhibitory factor, ciliary neutrotrophic factor, and cardio-trophin-1, are known as potent inducers of tissue differentiation. As such, OSM functions as a paracrine mediator of hepatocyte maturation. OSM binds to the gp130 receptor at the hepatocyte membrane and induces multiple signaling cascades including activation of the transcription factors STAT3 (205) and HNF-4a (217) and of the G-protein K-Ras (184). HNF-4a activation likely contributes to OSM-mediated heptoacyte polarization. In addition, the OSM-mediated activation of Ras-signaling promotes cell-cell adhesion (297). Cultured murine hepatic cells derived from a midembryonic stage form cadherin-dependent adherens junction when treated with OSM. This effect was blocked by dominant-negative Ras, and in cultured cells derived from K-Ras-knockout mice. K-Ras deficiency abolished OSM-induced formation of adherens junction without an apparent effect on the expression of hepatic differentiation markers. Ectopic expression of K-Ras cDNA restored the polarization signal. Hoekstra and co-workers identified an additional OSM signaling pathway relevant for hepatic polarity (458). They showed that addition of OSM to HepG2 cells increased the number of cells that polarized with bile canalicular-like domains and sped up the kinetics of polarization marked by an increased membrane flow from a subapical endosomal compartment (SAC) to the luminal pole. The authors had previously observed a similar effect upon activation of protein kinase A (PKA) $(493,505)$. OSM functions in this pathway by inducing the expression of the cell cycle inhibitor p27 KIP that keeps cells in G1. Forced G1-S phase transition indeed rendered the cells insensitive to OSM-mediated lumen formation. The authors further determined that G1-S transition prevented an OSM-mediated recruitment of PKA to the centrosome and prevented the PKA-activated transport route to the luminal surface that is important for luminal surface biogenesis (462). Thus, OSM-mediated activation of p27 KIP couples centrosome-associated signaling pathways to luminal pole directed membrane traffic, which is essential for the genesis of bile canalicular-like luminal domains. Lazaro et al. reported that OSM treatment promoted the formation of bile canaliculi in primary cultures of fetal human hepatocytes, suggesting that the signaling pathway for lumen formation in HepG2 cells might be relevant in vivo (259).

\section{LKB1 and LKB1-activated AMP-related kinases}

LKB1/Par4 is a ubiquitously expressed serine/threonine kinase that was first described as a polarity determinant in the one cell embryo of $C$. elegans (227). In humans, LKB1 inactivation is responsible for the Peutz-Jeghers syndrome, a rare genetic disease that leads to hamartomas of the gastrointestinal tract and dramatically increases patients' cancer risk at multiple sites. LKB1 is also frequently mutated in spontaneous lung and cervical cancers and for these reasons has been classified as a tumor suppressor, a rare distinction for a kinase [reviewed in references $(4,208)]$. LKB1 activates AMPK and 11 AMP-related kinases, including the four mammalian paralogues of Par1 (275). AMPK is best known for its role as energy sensor that regulates cell growth and proliferation through mammalian target of rapamycin signaling pathways (170). In fact, LKB1's inhibitory role on cell growth and metabolism offers an attractive explanation for its tumor suppressor function (438). On the other hand, an essential role for LKB1 in mammalian epithelial cell polarity as predicted from Par4's role in C. elegans, was not obvious in several epithelial cell lines analyzed 
$(38,401)$. Moreover, LKB1-deficient embryonic mice did not show polarity defects until day 7 of development, after important polarization events have already occurred (502). This might be due to the fact that at least some of the LKB1 targets, notably AMPK and Par1paralogues, have additional activating kinases $(197,444,498)$. Recently however, two studies, one in vivo (495) and one in vitro (134), have reported a major role for LKB1 in the development of hepatic polarity. The liver along with the pancreas and skeletal muscle indeed shows markedly higher expression of LKB1 than other adult tissues (382). Liverspecific deletion of LKB1 led to defective canaliculi in hepatocytes and a lack of open tubular bile ducts in the developing liver, which prevented the formation of a normal biliary tree and caused impaired bile acid clearance and accumulation of bile acids in serum and liver. The reason for the hepatocyte phenotype appeared to be the retention of the canicular bile salt export pump BSEP in intracellular pools. In addition, the amount of the bile acid influx transporters Oatp1 and Ntcp at the sinusoidal membrane was reduced. Thus, it is plausible that defects in protein trafficking to or their retention at the luminal pole could be the primary defect in LKB1-deficient hepatocytes, which prevents the establishment of the canalicular domain itself. The trafficking defects in turn could be caused by defects in the organization of the subluminal actin cytoskeleton since the authors also observed reduced Radixin staining at the canalicular domain. Radixin is a linker protein that connects the actin cytoskeleton with the luminal membrane. Subluminal actin is indeed crucial for the retention of membrane proteins at this pole (454). The bile duct phenotype resembles that of murine models of Alagille syndrome, which is due to altered Notch signaling $(144,383)$. Although no direct link between Notch and LKB1 has been reported to date, the LKB1 substrate Par1 has been shown to function upstream of Notch in developmental processes in Drosophila and Xenopus $(30,348)$.

The hepatic polarity phenotype of LKB1-KO mice is consistent with the effect Arias and colleagues observed when they expressed a dominant negative (DN) form of LKB1 in primary hepatic sandwich cultures (134). DN-LKB1 inhibited the formation of an extensive branched bile canalicular network that developed over 6 days in the cultures while LKB1 activators accelerated bile canalicular-network formation. The authors identified AMPK as the LKB1 substrate responsible for polarization. They found AMPK levels and activity to go up with polarity development, and reported that DN-AMPK inhibits polarization similarly to DN-LKB1 expression. Importantly, the AMPK activators AICAR and 2-DG overcame the inhibitory effect of DN-LKB1, suggesting that both kinases operate in a linear pathway. DNAMPK not only prevented the establishment of hepatic polarity but also disrupted already established bile canaliculi-networks in that in vitro system. This is in contrast to LKB1knockout in the adult mouse liver, which caused no apparent polarity disruption (404). The discrepancy might be due to redundancy in AMPK activating kinases in the adult liver that would be prevented from operating in the dominant-negative approach. One likely mechanism for AMPK function is to promote tight junction assembly $(508,509)$, possibly through the phosphorylation of myosin regulatory light chain, which occurs downstream of AMPK activation in the kidney-derived epithelial culture model MDCK (57). Indeed, activators of LKB1 and AMPK all prevented the disruption of tight junctions that were induced by $\mathrm{Ca}^{2+}$ withdrawal in the heptocyte sandwich model. The recent identification of 28 novel AMPK substrates in an unbiased screen in nonpolarized kidney epithelial cells (HEK293) suggests that AMPK participates in many more cellular processes than previously thought (19). One substrate potentially relevant for hepatocyte polarization is the Rab11 effector Rab11-FIP1 that participates with Rab11 in the plasma membrane recycling system (166). Rab11a is a crucial regulator of lumen formation in WIFB cells by promoting protein traffic to the luminal pole.

Is there a role for the LKB1 substrate Par1b in hepatic polarization as suggested by the Par1b-induced hepatic polarity phenotype in kidney-derived MDCK cells? Our data indicate 
that similar to DN-AMPK in primary hepatocytes, DN-Par1b expression in WIFB cells inhibits the formation of bile canalicular-like lumina (81). Similar to AMPK activity in primary hepatocytes, we find Parlb activity to be increased during WIFB cell polarization (our unpublished results). There is some evidence that AMPK-related kinases might have overlapping substrate specificity (212). For instance, the rho-GTPase adaptor and actinfilament regulating protein IRSp53/BAIAP2 that we identified as a Par1b substrate involved in hepatic-type polarization of MDCK-Par1b cells (82) was subsequently also identified as AMPK substrate (19). Moreover, Par1b and AMPK phoshorylate IRSp53 at the same site. Similarly, we have identified several of the published AMPK substrates as Parlb substrates in an unbiased substrate screen in MDCK cells (our unpublished data). Thus, it is possible that both kinases operate at least in part redundantly downstream of LKB1 in hepatocyte polarization. Depletion, rather than dominant-negative approaches will be necessary to assess their relative contributions.

\section{Bile acid-induced signaling pathway(s) for polarity}

The first observation that bile acids promote polarization of hepatic cells was made accidentally by $\mathrm{Ng}$ et al. (335). The authors cultured nonpolarized hepatic Fao cells and a derivative line in the presence of various bile acids with the intention to select for spontaneously polarized clones that, they reasoned, would present higher resistance to the cytotoxic effects of bile acids due to their ability to metabolize and secrete the products into the bile canaliculus. Unexpectedly, rather than selecting for polarized cells, they found the primary bile acid chenodeoxycholic acid to potently induce polarity in Fao clones. The polarized clones exhibited bile canalicular structures that were positive for the apical proteins APN, BSEP, Mrp2, and were sealed by tight junctions. The bile canalicular-like structures were capable of metabolizing and secreting carboxyfluorescin diacetate dye.

Bile acid synthesis, turnover, and secretion are sparse in the fetal liver, but rapidly increase postnatally (272), (271), concomitant with hepatocyte polarization and development of a branched canalicular network. That led Arias and coworkers to assess the effect of taurocholic acid, the major primary bile acid, on the development of polarity in their primary hepatocyte sandwich culture model (135). They observed an acceleration of the polarization process similarly to that seen upon experimental AMPK activation. By employing specific inhibitors of known taurocholate signaling pathways, the authors pinpointed the effect to a stimulation of c-AMP production by unknown G protein-coupled receptors. They subsequently determined that activation of the exchange protein directly activated by c-Amp (Epac) rather than PKA was important for polarization downstream of c-AMP. Further downstream in the signaling cascade Epac activated the Ras-like small GTPase Rap1 that is involved in many cellular events, including proliferation, junction formation, and polarity. Expression of a Rap1Gap that maintains Rap1 in the GDP bound, inactive form prevented the taurocholate and Epac-induced acceleration of polarization. Similarly, pharmacological inhibition of the Rap1 effector MEK blocked the taurocholate-polarity signaling cascade. Excitingly, the authors linked the taurocholic acid effects to activation of LKB1/AMPK downstream of MEK. How MEK activates LKB1 in this system remains to be established. In some cell types, ERK and p90 ribosomal S6 kinase have been implicated in LKB1 activation $(117,126,388)$. While this is the first bile acid-induced signaling pathway that governs hepatocyte polarization, taurocholic acid has likely additional, AMPK-independent effects on polarity since it could partially overcome the detrimental effect of DN-AMPK expression on bile canalicular formation.

As summarized in Figure 5, all of the signaling pathways discussed above converge on the establishment of adherens and tight junctions and on the development of the luminal/apical domain. As hallmarks of the epithelial phenotype, these features essentially served as 
readouts for hepatocyte polarity. Further mechanistic insight is required to determine the common and divergent molecular targets these signaling pathways regulate.

\section{The Role of Cell Adhesion in Hepatocyte Polarity}

The ECM is a complex macromolecular structural network that surrounds stromal cells and underlies the majority of endothelial and epithelial cells. It is a mechanical scaffold for adhesion and migration and provides signaling platforms by sequestering or releasing cytokines and by anchoring processing enzymes. Importantly, the direct interaction of ECM molecules with cell surface receptors, notably the integrins, leads to their activation, which triggers intracellular signaling effects (outside-in signaling). ECM receptors are connected to a variety of cytoplasmic plaque proteins that serve as signaling hubs and connect the ECM receptors to the cellular cytoskeleton. Conversely, intracellular signaling events can modulate the interaction of integrins with the ECM (inside-out signaling), which results in complex feedback signaling cascades [for review, see references $(45,334)]$.

The final step of hepatocyte differentiation that takes place 7 days after birth in rodents is critically dependent on signaling of ECM proteins via integrins (219). In addition to induction of a set of genes relating to adult liver function and down regulation of growthrelated genes, terminal hepatocyte differentiation also involves the reorganization of hepatocytes from ascinar structures into one-cell-thick liver plates, that is, a transition from columnar to hepatic polarity. The role of ECM signaling in the hepatocyte differentiation process has also been appreciated in the longstanding efforts toward the development of a bioartificial liver that have led to constant improvements in culture conditions to maintain highly differentiated and polarized hepatocytes in either monolayers or spheroids for weeks $(33,332)$. These studies established that it is the chemical and physical properties of the surrounding ECM that largely define the hepatic differentiation status. Thus, when plated on a matrix of either collagen or matrigel, hepatocytes rapidly dedifferentiate. The degree of polarity loss is inversely correlated with the density of the matrix and the extent of cell spreading. Even dedifferentiated monolayers can be "rescued"; however, when overlaid with a gelling matrix at the free cell surface (111). The nature of the ECM gel appears to be unimportant; even agarose has been reported to be efficient (111) and recently synthetic matrices containing galactose ligands that mediate cell adhesion via the ASOR have been employed (75). These data suggest that the overlay may simply provide a suitable scaffold that favors accumulation of ECM molecules secreted by the hepatocytes themselves that may sequester other factors (e.g., growth factors). Indeed, cultured hepatocytes in collagen sandwiches secrete their own matrix proteins including laminin, collagen, and fibronectin (119). Thus, being surrounded by hepatocyte-derived ECM molecules on both noncontacting surfaces appears to be crucial for polarization in vitro. This is also the situation for hepatocytes in vivo as they are surrounded in the space of Disse by a lowdensity ECM that is of basement membrane-like composition [reviewed in reference (294)]. Notably, however, unlike all other epithelia heptocytes in vivo are not attached to a bona fide basal lamina $(193,294)$. The basal lamina (also referred to as basement membrane) is a tough, two-dimensional, flexible sheet of matrix molecules secreted by epithelial cells and the underlying connective tissue. It is organized into sheets primarily by laminin and fibrous collagen IV networks that are connected with each other via nidogen and the proteoglycan perlecan. The absence of laminin and nidogen in the ECM-surrounding mature hepatocytes accounts for the lack of an obstructive basement membrane in the space of Disse, a feature that appears to be important for the intimate contact between hepatocytes and the fenestrated endothelium for the exchange of macromolecules [discussed in reference (295)]. The deposition of a basement membrane in the hepatic sinusoids that transforms the space of Disse into a densely fibrous interstitium is a hallmark of liver cirrhosis, and is associated with impaired hepatic function $(292,295,398)$ (see also Section "Liver fibrosis and 
cirrhosis"). Interestingly, a comparison of the ECM compositions of embryonic, adult and regenerating livers revealed that, while absent from mature liver parenchyma, laminin was present around hepatocytes of embryonic and in regenerating livers $(17,296,489)$ hinting at a crucial role for laminin in the differentiation and repolarization process [discussed in reference (295)].

Is the unique ECM distribution around hepatocytes responsible for the distinct hepatocytespecific lumen polarity? Evidence for a correlation between ECM deposition and establishment of the epithelial luminal domain came first from work with the columnar MDCK cells. When plated on a substrate, in the absence of all other cues, single MDCK cells establish their luminal domain at the free, nonsubstrate-contacting surface (465). The ECM molecules MDCK cells secrete become trapped and can assemble into a basal lamina only at the substrate-contacting surface (386). It was proposed that localized ECM signaling constitutes the polarization cue to establish the luminal surface away from the basal lamina $(380,474)$. Furthermore, when plated on collagen I and subsequently overlaid with additional collagen at the apex, MDCK cells rapidly remove their apical surface. MDCK sandwich cultures subsequently reorganize into two columnar cell layers that form an enclosed lumen between them, away from the surrounding ECM (168,399). From those observations, it became apparent that the presence of ECM is not compatible with the establishment or maintenance of a luminal domain. Thus, for hepatocytes in vivo, the ECMfilled space of Disse prevents the establishment of a luminal pole at either of the sinusoids, leaving as the only option the surface between neighboring cells. Interestingly, MDCKParlb cells, which organize with hepatic lumen polarity when plated on plastic, have reduced collagen-IV and laminin staining at the substrate contacting surface and at the same time display ECM molecules at their apex, mimicking the low-density, symmetric ECM distribution of hepatocytes in vivo [(82) and Lazaro-Dieguez, Cohen, Fernandez, van Ijzendoorn and Müsch, in preparation]. Supplementing the basal ECM of MDCK-Par1b cells with collagen IV reverted lumen polarity back to a columnar phenotype (LazaroDieguez, Cohen, Fernandez, van Ijzendoorn and Müsch, in preparation). Thus, we propose that a steep ECM gradient along the apical-basolateral polarity axis favors columnar lumen position while a low-density symmetric ECM distribution (as in the hepatocyte collagen sandwich configuration and MDCK cells upon Parlb overexpression) promotes the hepatic polarity phenotype (Fig. 6A).

\section{The role of Intercellular Junctions in Hepatic Polarity}

In polarized epithelia, the contacting membranes form intercellular junctions that are comprised of tight junction, anchoring junctions and gap junctions. Tight junctions provide a barrier and a fence within the membrane by regulating paracellular permeability and diffusion of membrane proteins between the apical and basolateral domains, thus maintaining cell surface polarity and enforcing vectorial transport of macromolecules across epithelial cells. Anchoring junctions, which include adherens junctions and desmosomes couple cytoskeletal elements to the plasma membrane, providing mechanical integrity to tissues, while gap junctions allow for cell-cell communication by allowing the passage of small molecular weight solutes (up to $1 \mathrm{kD}$ ) directly between neighboring cells. Recent evidence indicates that intercellular junctions participate in signal transduction pathways that regulate gene expression, differentiation, proliferation, and morphogenesis. The formation, detailed composition and complex functions of these junctional complexes have been extensively reviewed elsewhere [for instance, see references $(29,59,153,158,174$, 191, 406) for the most recent updates]. Here, we will summarize findings that specifically relate to their role in the development of hepatic polarity. 
E-cadherin is considered a key determinant and trigger for epithelial differentiation and polarization (434). As a $\mathrm{Ca}^{2+}$-dependent homophilic cell-cell adhesion molecule, E-cadherin provides the platform for the assembly of adherens junctions, a protein complex that links cell-cell contacts to the actin cytoskeleton; the circumferential actin belt that pulls neighbors together via their adherens junctions is responsible for the tight apposition of epithelial cells. Like the cytoplasmic plaques assembled on integrins, E-cadherin mediated junctions also serve as signaling platforms and can mediate outside-in signaling. Thus, MDCK cells cultured in the absence of $\mathrm{Ca}^{2+}$ do not polarize, even when plated at confluency (150). Addition of $\mathrm{Ca}^{2+}$ in millimolar concentrations to those cultures is sufficient to trigger the polarization program that is initiated by homophilic E-cadherin interactions $(69,467)$.

Notably, E-cadherin-based adherens junctions organize the tight junctions and the establishment of luminal and basolateral surfaces in this and other epithelial model systems $(163,202,480)$. Loss of cadherin-based adhesions, on the other hand, is a hallmark of carcinogenesis and correlates with tumor progression. In many epithelial-derived tumors, including hepatocarcinoma, E-cadherin expression is downregulated, leading to loss of cell adhesions, increased proliferation, and tumor invasiveness $(13,262,434,456)$. Not surprisingly, E-cadherin knockout mice are embryonic lethal, failing to develop past the trophoectoderm, 32-cell stage $(255,346)$. In the embryonic mouse liver, E-cadherin expression is induced at embryonic day 12.5 in hepatoblasts (338), which correlates with the onset of differentiation into hepatic and biliary epithelial cells. The precise role of Ecadherin for hepatic polarity is being elucidated in cell culture models, and has so far yielded some surprising results. Unexpectedly, a HepG2 cell line that failed to target Ecadherin and $\beta$-catenin to the cell surface still established functional tight junctions, bile canaliculi-like luminal domains (albeit with delayed kinetics), and developed basolateral polarity, suggesting that E-cadherin contributes, but is not absolutely essential for the establishment of hepatic polarity. Curiously, E-cadherin inactivation altered the biosynthetic targeting of the apical protein DPPIV from a transcytotic to a direct route (441). As indirect apical protein targeting is a hallmark of the hepatic polarity phenotype, it will be important to elucidate how E-cadherin and/or $\beta$-catenin regulate this process. Konopka et al. found instead that increased E-cadherin levels disrupted hepatic polarity in HepG2 cells (241). The authors depleted HepG2 cells of the membrane protein junctional adhesion molecule-A (JAM-A), a cell-adhesion protein of the IgG superfamily that has been found at primordial cell-cell contact sites and at tight junctions and has been implicated in tight junction formation. JAM-A depletion resulted in the loss of bile canalicular-like luminal domains and in the organization of the tight junctions in a chickenwire arrangement, consistent with columnar polarity. The authors went on to show that this polarity change was largely due to an increase in E-cadherin expression in JAM-A depleted cells. Braiterman et al. reported a similar disruption of hepatic polarity in JAM-A depleted WIFB cells, but they did not observe changes in E-cadherin levels (48). Substitution of endogenous E-cadherin in MDCK cells for an adhesion-defective mutant that lacked the extracellular cell-cell contact-forming domain and thus was defective in outside-in signaling, but still capable of protein interactions via their cytoplasmic domain (453), promoted a transient polarization of MDCK cells with hepatic polarity (85).

Collectively, these data suggest a model in which the nature or extent of E-cadherinmediated adhesion signaling determines whether tight junctions assemble with either parallel or vertical orientation to the ECM contacting surface; tight junction position then in turn dictates lumen position. Thus, E-cadherin mediated cell-cell adhesion might contribute to the decision to polarize with hepatic or columnar polarity (Fig. 6B). The composition of the tight junction protein complex itself might also be important for the orientation of the tight junction belt. Thus, siRNA-mediated depletion of the integral tight junction protein Claudin-2 from WIFB cells resulted in a "chickenwire" tight junction organization (418). It should be added that gap junctions, although not directly implicated in epithelial polarity, 
might also contribute to tight junction development $(237,238)$. In hepatocytes, gap junctions occupy a particularly large membrane surface area, as much as $3 \%$ of the total membrane. Their presumed primary function is to aid the synchronized periodic contractions of the bile canaliculi to stimulate bile flow. There is accumulating evidence that gap junction membrane proteins, particularly connexin Cx32 in hepatocytes, colocalize, and physically interact with tight junction proteins, namely the transmembrane proteins Occludin and Claudin-1 (237). It has been proposed that this interaction might contribute to the clustering of tight junction proteins as a prerequisite for tight junction assembly. However, no solid evidence for such a scenario has been presented so far.

\section{Epithelial Polarity Complexes}

In addition to cell-cell interaction proteins, an evolutionary highly conserved physically and functionally interconnected network of polarity determinants has been described, which stakes out the future apical, lateral and junctional domains of differentiating columnar epithelial cells. It is the subject of several extensive recent reviews $(302,309,421,478)$ and will, therefore, only be briefly mentioned here. Three major protein complexes with distinct membrane domain localization have been characterized. The apically localized CrumbsPatj-PALS complex provides apical membrane identity. It is linked, via PALs, to the apicaljunctional Par3-Par6-aPKC complex that promotes the establishment of tight junctions and contributes to apical surface formation, in part by activating Crumbs. The lateral Lgl-DlgScribble complex defines basolateral domain identity. The mutually exclusive localization of the three complexes is at least in part accomplished by inhibitory phosphorylation. Thus, aPKC phosphorylation of $\mathrm{Lgl}$ removes it from the apical surface and junctional region, while Par3 phosphorylation by Par1, the latter being present at the lateral domain, removes Par3 from the basolateral surface.

In the adult liver, immunohistochemical analysis has determined that aPKC iota and zeta and Par3 are colocalized with tight junction markers, specifically ZO1, Occludin and Claudin- 3 at the boundary between bile canaliculi and sinusoidal membranes, suggesting that they function in apical junctional complexes as in other epithelial cells (433). The basolateral polarity determinants Scribble and Lgl-2 have been localized to the sinusoidal domains in WIFB cells and Scribble has been shown to mediate similar protein-protein interactions in WIFB and MDCK cells (215). The available data, therefore, suggest that the polarity complexes that determine epithelial surface domains in columnar epithelia also operate in hepatocytes, although whether and how they contribute to the hepatic-specific polarity phenotype remains to be elucidated.

\section{Polarized Vesicular Protein Trafficking in Hepatic Cells}

To establish and maintain polarized surface domains and to mediate polarized protein secretion, epithelial cells have evolved strategies to target newly synthesized proteins to either the luminal/apical or basolateral domains in the biosynthetic pathway and to recycle endocytosed proteins faithfully back to their membrane domain of origin. Some membrane proteins are targeted from the basolateral to the apical surface, in a pathway termed transcytosis to deliver ligands from the blood to the epithelial lumen. Polarized protein trafficking is based on address signals in the targeted proteins themselves and on the cellular machinery that recognizes and interprets them. Although not as strictly polarized as proteins, lipids also show domain-selective enrichment and hence polarized intracellular traffic and membrane retention. Thus, sphingolipids, although contributing less than 5\% to the cellular lipid pool, are highly enriched in the outer leaflet of the apical domain. Sorting of some apical proteins has been linked to the formation of lipid microdomains that are formed by 
clusters of sphingolipids and cholesterol at the trans-Golgi network (TGN), in recycling endosomes and the plasma membrane.

The study of the polarized trafficking machinery in epithelial cells began in the 1970s with the introduction of the canine kidney-derived MDCK model (70, 317). MDCK cells have remained the primary workhorse for the ongoing refinement of old and the establishment of novel techniques and approaches to polarized protein targeting that have subsequently been adapted to other epithelial lines of columnar polarity, most prominently the human intestinal CaCo- 2 cells, the Fisher rat thyroid (FRT) cells and retinal pigment epithelial cells. The study of polarized trafficking in hepatic cells, however, has lagged behind. This is, in part, due to the fact that few model cell lines exist for the study of hepatic polarity and that these cell lines are generally less amenable to experimental manipulation and require different approaches than those developed for MDCK cells. It has nevertheless become clear that hepatocytes differ from all other nonstratified epithelial cells in several key aspects of protein trafficking: (i) they lack a mechanism for polarized exocytosis of secretory proteins to the luminal surface. (ii) They further distinguish themselves by targeting all apical singlespanning and GPI-anchored membrane proteins studied to date via a detour to the basolateral surface prior to their arrival at the luminal pole. (iii) Interference with protein trafficking to the luminal pole in hepatic cells frequently prevents the formation of a luminal domain altogether, which is not the case in other epithelial models. In the following chapters, we will review our current knowledge of the exocytic and endocytic trafficking pathways in hepatic cells in comparison to that in nonhepatic epithelial cells.

\section{Tools and approaches}

\section{Protein targeting in vivo analyzed upon subcellular fractionation of the} perfused liver-Hepatic protein trafficking was first studied on the isolated, perfused rat liver that was subjected to cell fractionation (24). The authors combined an in vivo pulsechase protocol with cell fractionation that allowed them to establish the targeting itinerary of newly synthesized membrane proteins. Their protocol still represents the gold standard for the analysis of protein trafficking in hepatocytes. It is in fact the only in vivo approach to protein trafficking for any mammalian epithelium.

When injected into the tail vein, ${ }^{35} \mathrm{~S}$-methionine first reaches the liver and is mostly incorporated into newly synthesized hepatocyte proteins. When followed by the injection of cold methionine the investigator can set a metabolic pulse and analyze the fate of the newly synthesized protein pool at different chase times. For each chase point, rat livers were homogenized and the plasma membrane sheets separated from other intracellular compartments by a series of differential centrifugation steps followed by a single floatation through a one-step sucrose gradient. Sonication of the isolated plasma membrane sheets then resulted in the formation of vesicles derived from either the luminal or the basolateral domains. The two resultant vesicle populations were separated by equilibrium sucrose gradient centrifugation. The Hubbard group later combined the in vivo pulse-chase approach with an immuno-depletion/adsorption scheme to demonstrate that newly synthesized DPPIV was present in $\mathrm{pIgA}$-containing vesicles, indicating that both proteins shared the same transcytotic carriers (20). In vivo pulse-chase experiments have also been performed to analyze polarized secretion of albumin and the shedding of transcytosed pIgR into either the bile or the blood (253).

\section{Quantitative analysis of protein arrival at distinct cell surface domains in cultured epithelial cells-The culture of polarized columnar epithelial cells on} permeable filter substrates allows for their domain-specific manipulation $(379,412)$ (Fig. 7 , left panel). To study the kinetics and polarity of the arrival of newly synthesized proteins at 
either the apical or basolateral surface domain, polarized epithelial cultures that express recombinant apical and basolateral model proteins, are subjected to a metabolic pulse with ${ }^{35} \mathrm{~S}$-methionine/cysteine. The labeled protein fraction is subsequently chased through the secretory pathway in the presence of an excess of cold amino acids. At different chase points, the apical and basolateral surface domains of the filter cultures are selectively labeled with a succidimidoester of biotin that becomes covalently linked to primary and secondary amino groups in the extracellular domains of membrane proteins. Tight junctions prevent the paracellular leakage of the small molecule from the apical into the basolateral filter chamber and vice versa ensuring domain-specific surface labeling (see Fig. 7). Upon cell lysis, and immunoisolation of the cargo proteins, their respective apical and basolateral surface populations are reisolated on immobilized streptavidin that interacts with the biotin on the labeled surface pool $(270,389)$. In a variation of this assay, polarized protein secretion into the apical and basolateral milieu can be assessed by collecting the medium in the apical and basolateral filter chambers at different chase times and by subsequently analyzing their radioactive protein content by polyacrylamide gel electrophoresis. Routinely used in columnar epithelial cell cultures, this assay is not applicable to polarized hepatic cell cultures as their luminal domains are not experimentally accessible (see Fig. 7, right panel). Hence a similar quantitative analysis of membrane protein targeting has not been performed in hepatic cell lines, although a semiquantitative assay has been developed that employs a morphological "pulse-chase" analysis where changes in relative fluorescence intensities of a membrane protein at the apical or basolateral PM at different times upon inhibition of protein synthesis was plotted (372). However, the polarity of secretion has been determined in WIFB cultures grown on coverslips utilizing a variation of the MDCK targeting assay. After the medium, representing the basolateral secreted population, was collected, the luminal domain of WIFB cells was opened up by inducing the disruption of the adhesion and tight junctions through $\mathrm{Ca}^{2+}$ withdrawal. Proteins secreted into the luminal space could then be collected (27). The accuracy of the measurement was critically dependent on the high polarity index ( $>95 \%$ ) of the WIFB cultures, and could not be conducted in HepG2 cells (with only $20-40 \%$ of the cells polarized).

Analysis of protein exit from the TGN-Metabolic labeling techniques combined with subcellular fractionation of perfused livers have also been utilized to immunoisolate postGolgi transport carriers en route to the sinusoidal membrane. These studies identified distinct transport carriers enriched in membrane and soluble proteins (392) and distinct albumin and heparan sulfate proteoglycan containing vesicles (336), respectively. While providing valuable in vivo insight into cargo segregation, these approaches are too cumbersome for mechanistic studies, which instead have been developed in cell lines. Pulse labeled apical and basolateral cargo proteins reversibly accumulate in the TGN at $20^{\circ} \mathrm{C}$ in most if not all cell lines, including WIFB cells (159). Although the reason for that phenomenon has remained obscure, it has been exploited as a tool to stage membrane and secretory cargo at the site of apical-basolateral protein sorting in MDCK cells prior to their synchronized exit from the Golgi toward the plasma membrane. The in vitro reconstitution of the release of TGN-derived vesicles from isolated Golgi membrane fractions or from semi-intact MDCK cells has not only established that apical and basolateral proteins exit the TGN in distinct transport carriers in these cells but has also allowed the identification of machinery that mediates the distinct TGN-derived trafficking pathways $(330,331,410,449,473)$. Although principally applicable to hepatic cells, these biochemical assays have not been utilized to study protein sorting in hepatic cell lines. They have more recently been replaced in MDCK cells by live cell imaging based pulse-chase assays that allow the analysis of protein sorting and exit from the TGN in intact cells $(225,242)$. In those assays, a pulse of fluorescently labeled apical and/or basolateral cargo is set by microinjecting the encoding cDNA(s) into the nucleus of glass- or filter-grown MDCK cells, 
which results in their expression and appearance in the endoplasmic reticulum 1 to $2 \mathrm{~h}$ postinjection. In the presence of cyclohexamide, which prevents further protein synthesis, the cargo pool is chased to the TGN at $20^{\circ} \mathrm{C}$ where exit from the TGN can be studied upon release of the temperature block. cDNAs, recombinant proteins or antibodies expected to interfere with protein exit can be microinjected into the same cells and their effects on protein exit and/or sorting be tested. Fast dual color high-resolution imaging has allowed the observation of distinct apical and basolateral transport carriers exiting the TGN in MDCK cells $(225,387)$, while imaging at lower spatial and time resolution has been employed to resolve the kinetics of TGN-to-surface transport $(95,242,329)$ (see Fig. 8). Similar assays have still to be reported for hepatic cells. One technical caveat is that WIFB cells are very sensitive to microinjection and easily lose polarity, that is, their morphologically defined luminal domain disappears when touched by a microinjection needle.

Analysis of polarized endocytic and transcytotic pathways-Upon endocytosis proteins either recycle to their originating membrane domain, are sent to lysosomes for degradation or undergo transcytosis to the opposite membrane domain. To analyze their fate fluorescent or radiolabeled ligands that have been bound to their cell surface receptors at $4^{\circ} \mathrm{C}$, are allowed to be internalized at $37^{\circ} \mathrm{C}$. Subsequently, any ligand remaining at the original surface is stripped from its receptor by an acid wash. During the subsequent chase in the presence of excess unlabeled ligand in the apical and basolateral medium, respectively, the fluorescent or radiolabeled ligand pool that reappears in either apical or basolateral medium is collected and quantified. In addition, the cell-associated acid precipitable, that is, protein bound, fluorescence, or radioactivity is counted. The total amount recovered in all three fractions allows one to calculate how much of the ligand has been degraded $(351,479)$. A similar experimental approach has been taken to follow membrane proteins by labeling their domain-specific surface pool with antibodies against their ectodomains, which in turn can be detected with a labeled secondary antibody after the chase (Fig. 9A). As explained for the secretory pathway, however, this approach is not feasible in hepatic cells, where the apical domain is sequestered from the medium. Only qualitative, or at best semiquantitative observations have been made in hepatic cells. Notably, antibody uptake experiments have revealed that single-spanning membrane proteins undergo transcytosis from the basolateral to the apical domain $(199,204,372,454)$ (Fig. 9B). It should be noted, however, that quantitative assays to measure basolateral recycling and internalization have been developed for use in WIFB cells (372). For a review on techniques in the study of protein trafficking, see reference (203).

From the above, it is apparent that new efforts are required to establish and adapt modern technologies to allow the research of protein transport in hepatocytes catch up with that in columnar epithelial cells.

\section{Trafficking routes}

Trafficking routes in the biosynthetic pathway-Work over the last decade has dramatically expanded our picture of protein trafficking pathways in epithelial cells (Fig. 10A,B). Since the 1980s, epithelial cells were known to operate three distinct routes for the biosynthetic targeting of apical and basolateral proteins: a direct pathway from the TGN to the basolateral domain, a direct pathway from the TGN to the apical domain, and an "indirect" pathway for apical proteins that takes them from the TGN first to the basolateral domain, from where they then reach the apical domain via transcytosis $(379,412)$. Different epithelial cells utilize the direct and transcytotic apical pathways to different extents. While MDCK cells target all apical proteins directly, intestinal $\mathrm{CaCo} 2$ cells employ direct targeting for some and transcytotic targeting for other proteins. These premises were established from measurements of surface arrival of newly synthesized proteins as described above. The 
elegant pulse chase experiments conducted by A. Hubbard's group in the liver had further revealed that hepatocytes target sinusoidal proteins directly, while all bile canalicular membrane proteins the authors investigated, where targeted via transcytosis (24). The hepatic HepG2 and WIFB cell lines were later found to mimic the hepatocyte targeting pattern, although as explained above, a quantitative appreciation of the extent of direct versus transcytotic trafficking for a given apical membrane protein was not possible in those culture models $(199,413)$. In some instances, the same protein (e.g., DPPIV and GFP-GPI) was shown to be targeted directly in MDCK and indirectly in WIFB cells, indicating that the two epithelial cell types interpret the apical sorting information differently $(24,67,189,199$, $280,352,454)$. In addition to membrane protein targeting, secretion in hepatocytes is predominantly directed into the sinusoidal space. In contrast to MDCK or $\mathrm{CaCo} 2$ cells, no endogenous or recombinant proteins are known to be secreted with apical polarity in hepatocytes $(26,27)$. It should be noted that while albumin is found in the bile canaliculi, this population represents a small fraction compared to the amount secreted into the sinusoidal space $(27,253,391)$. Similar to the situation for membrane proteins, the difference between hepatocytes and the simple epithelial cells studied appears to be the interpretation of sorting signals by the secretory machinery. Thus, while clusterin, known as gp80 in MDCK cells is secreted apically in these cells (455) and in $\mathrm{CaCo} 2$ cells (10), the hepatocyte clusterin serum SP-40,40 is secreted basolaterally (211). Likewise, hepatitis surface antigen (HBsAg) is released in particles associated with host-derived lipids from the basolateral domain in hepatocytes (445), but when transfected into MDCK cells, it is secreted apically (151). In addition, an engineered soluble form of the membrane proteins DPPIV is secreted apically in MDCK cells (485) but into the sinusoidal space in hepatocytes (27).

Thus, it was concluded that hepatic cells do not utilize a direct pathway between the TGN and the bile canalicular domain to target luminal proteins. Then, in 2000, Kipp and Arias challenged that paradigm when they revisited the original pulse-chase studies in the liver, this time analyzing a different repertoire of apical proteins (230). Remarkably, the authors could distinguish two classes of apical proteins: cCAM105, which contained a singletransmembrane domain, was targeted by transcytosis and the polytopic membrane proteins and ATP-binding cassette (ABC) transporters MDR1, MPR2, and BSEP/SPGS were targeted from the TGN directly to the apical domain, that is, without first appearing at the basolateral surface. Thus, hepatocytes operate at least two apical targeting routes: for polytopic and for GPI-anchored and single-spanning membrane proteins, respectively.

More recently, assays designed to detect the meeting of newly synthesized proteins with endosomal compartments and mostly performed in MDCK cells, have revealed that different endosomal compartments are obligate transit points for some apical (p75 neurotrophin receptor, influenza HA, and GPI-anchored proteins) and basolateral (e.g., TfR, pIgR, VSVG, and E-cadherin) proteins en route to the apical and basolateral plasma membrane domains [reviewed in references $(152,486)]$. These findings imply the presence of even more pathways to either domain, which could provide the cells with the ability to selectively regulate the targeting of individual groups of membrane proteins. They also suggest that endosomal compartments may increase sorting fidelity or, in case of the common recycling endosome (CRE) where apical and basolateral proteins mix (see below), serve as an alternative sorting stations to the TGN. For a detailed list of all known proteins that take the individual pathways, the reader is referred to Figs. 6.2-6.4 in reference (49). These figures also list all components of the machinery that are known for each pathway.

Trafficking routes in the recycling and transcytotic pathways-Since half of the proteins of a typical plasma membrane are endocytosed every hour, protein sorting in the endosomal system is as, if not more important than sorting in the biosynthetic pathway for the maintenance of cell surface polarity (425). In the liver in particular, an estimated $8 \%$ of 
the hepatocyte basolateral surface area is internalized per minute per cell (87). From studies of fluid phase transcytosis, it has been calculated that approximately 600 to 850 vesicles fuse with the bile canalicular membrane every minute. To maintain membrane identity and polarity in the face of such membrane flux, a precise regulation of the endocytic pathways is imperative.

Quantitative three-dimensional (3D) microscopy in hepatocytes has revealed a tubulovesicular endocytic reticulum that squeezes between organelles and stretches from the basolateral to the apical pole. Although it makes up only $2 \%$ of cell volume, its surface area equals twice that of the canalicular membrane (290). Whether trafficking within that network occurs via maturation, by vesicle budding and fusion, or a combination of both processes is still not understood. However, kinetic, immunological, and topographic analysis allows for the elucidation of distinct steps and itineraries (Fig. 11). Proteins endocytosed from either domain are first found in spatially and biochemically distinct basolateral or apical early endosomes (BEEs and AEEs) $(39,405)$, where plasma membrane proteins are segregated from soluble proteins that are targeted to the lysosome for degradation [reviewed in reference (301)]. Interestingly, apical proteins that are sorted into distinct apical transport carriers at the TGN of MDCK cells, are endocytosed via distinct clathrin-dependent and independent mechanisms from the basolateral domain of hepatic cells during their transcytotic targeting (2) (Fig. 11). From the AEE and BEE, proteins may rapidly recycle to their originating membrane domain without intermediate. For instance, a fraction of basolaterally internalized TfR takes that route. The majority of TfR, however, is targeted from the BEE to the CRE from where it is recycled back to the basolateral surface [reviewed in reference (301)]. The CRE is a tubular organelle with distinguishable subdomains that receives endocytic cargo from both surfaces and represents a major sorting station for apical and basolateral -directed cargo $(342,405,443,476)$. The CRE has recently also been identified as an intermediate between the TGN and the cell surface for multiple basolateral, but so far for only one (artificial) apical protein (7). It is likely, therefore, that the CRE does not replace the TGN as the main sorting site that specifies domain-specific surface arrival of apical and basolateral proteins upon their synthesis, but has a sorting function mainly in the endocytic pathways.

From the CRE, proteins internalized from the basolateral domain are either redirected there without further intermediate or, when designated for basolateral-to-apical transcytosis, are targeted to the apical domain via an apical recycling endosome (ARE) $(9,21,147)$. While well established in MDCK cells, in hepatocytes the identity and nomenclature of apical/ basolateral sorting endosomes and endosomes that specifically carry apically directed cargo is still controversial.

Hoekstra and colleagues as well as Landmann's group refer to an apically localized, tubular endosome that contains apical and basolateral cargo and thus would be the hepatic equivalent of the CRE as SAC $(188,290,370)$. The Hoeckstra group also characterized the $\mathrm{SAC}$ as a central compartment for the apical/basolateral sorting of sphingolipids. As mentioned above, spingolipids display a polarized distribution in epithelial cells. Thus, glycosylceramide (GlcCer) is enriched at the apical domain while sphingomyelin (SM) is concentrated at the basolateral domain. In addition to their function as signaling molecules, GlcCer together with cholesterol participates in apical protein sorting, as we will discuss below, and is essential for basolateral-to-apical transcytosis in hepatic cells (339). Utilizing fluorescent acyl chain-labeled lipid analogues, Hoeckstra and colleagues initially determined that newly synthesized NBD-GlcCer and NBD-SM are sorted at the TGN in HepG2 cells (504). When added to the basal domain, however, both fluorescent lipids first undergo basolateral-to-apical transcytosis, are re-endocytosed and subsequently sorted in the SAC 
from where NBD-GlcCer recycles apically while NBD-SM undergoes transcytosis back to the basolateral domain $(461,463)$.

Work from the Hubbard group on the other hand, had defined the SAC as a crescent-shaped organelle that is localized adjacent to the apical domain and functions more distal in the transcytotic pathway. It contains only apical proteins as well as endolyn-78, a lysosomal protein that appears to reach its destination via the SAC $(20,199)$. According to the former view, the ARE is a subdomain of the SAC that contains sorted apically destined proteins and is characterized by the presence of Rab11, Rab25, and Rab3 (188).

Recently, the ARE has been identified as an intermediate in TGN-to-apical surface targeting of two apical proteins in MDCK cells (88), and of BSEP in rat heptocytes (230) indicating that the direct route from the TGN to the luminal pole also involves passage through the ARE, at least for some apical proteins. Thus, the CRE/SAC and ARE model for hepatocytes would match the scenario described for MDCK cells (Fig. 11, model 1). The alternative model proposes instead that the SAC is a unique compartment distinct from both the CRE and the ARE and a unidirectional weigh station for apical proteins en route from the basolateral to the apical domain. According to the latter model, the pathways of apically endocytosed proteins and of proteins targeted from the TGN to the apical domain via apical endosomes does not intersect with that of proteins that reach the apical domain via transcytosis from the basolateral domain [see Fig. 4 in reference (49)] (Fig. 11, model 2).

On the other hand, there is an agreement that all transcytotic markers reach the apical domain via a common pathway. Thus, DPPIV and pIgR in WIFB cells (20) and B10 and pIgR in primary hepatocytes (180), are internalized at the basolateral membrane via different mechanisms, yet are transported in common transport carriers in the transcytotic pathway after being segregated from basolateral proteins in sorting endosomes.

Regardless of its role in the exocytic pathway, the ARE has also been implicated as a holding cell for bile canalicular proteins that are internalized and re-inserted into the luminal membrane in a signal-dependent and dynamic manner (see below) (471). Indeed, defects in ARE-to-bile canalicular surface targeting usually result in the loss of a morphologically distinguishable luminal pole in hepatic cells, presumably because much of the luminally directed membrane traffic depends on that transport leg.

\section{Sorting signals and their recognition}

The address signals for their destination are encoded in the structure of membrane and secretory proteins. To consider a moiety a bona fide sorting motif its deletion/mutagenesis must result in missorting of the carrier protein and it must be sufficient to confer targeting information when transplanted onto a reporter protein that lacks inherent polarity.

Membrane proteins can contain multiple sorting signals, even to different destinations, but one always prevails. Basolateral sorting signals are usually dominant over apical ones, and in many proteins, inactivation of basolateral sorting information unmasks a subordinate apical signal.

Basolateral signals that have been delineated in single-spanning membrane proteins are often comprised of minimal amino acid motifs in the cytoplasmic domain. They can be (i) a short degenerate sequence based around a tyrosine residue or a dileucine motif that is colinear with endocytic determinants; (ii) tyrosine-based, di- or mono leucine motifs that do not function as endocytic signals, (iii) or unique signals that do not conform with any consensus sequence [for a detailed list, see references $(65,109)]$. Some proteins have bipartite sorting motifs, in the case of the low-density lipoprotein receptor (LDLR) or aquaporin 4 , a tyrosine-based motif and a cluster of acid residues $(286,299)$. There is little 
known about the 3D structure of those signals, although a type 1 beta turn may be a conserved feature for at least some of them $(206,326)$. It is believed that the cytoplasmic basolateral sorting motifs are recognized by cytosolic adaptor protein complexes that couple the recruitment of basolateral cargo to the generation of coated transport vesicles [reviewed in references $(40,41)]$. The tyrosine and dileucine-based signals are recognized by the heterotetrameric clathrin adaptors AP-1, AP-2 [reviewed in references (345)] (178), and tyrosine-based signals also by the nonclathrin adaptor AP-4 (409). Adaptor protein complexes are composed of two large, a medium, and a small subunit. Biochemical and structural studies have determined that the tyrosine motif engages the medium $\mu$ subunit of the adaptor complexes $(345,349)$ while the interaction mode for dileucine motif signals is still under debate. The $\mu$-chain is apparently able to bind a variety of basolateral signals. Gravotta et al. recently demonstrated an interaction of the AP1- $\mu$ chain with the noncanonical signals of TfR and LDLR by yeast-two-hybrid analysis (156).

Some cytoplasmic signals serve to anchor proteins at the basolateral (or apical) domains and thus promote their domain-selective retention. Among them are binding domains, usually at the very C-terminus, for PDZ proteins, which are named after their three founding members (PSD-95, Disc Large, and ZO-1). As scaffolding proteins, PDZ proteins often contain multiple of the 80 to 100 amino acid long PDZ modules to organize protein complexes. In hepatocytes, the scavenger receptor-B1 and the organic anion transporter protein-1 (OATP-1) are retained by the multi-PDZ protein PDZK1 at the sinusoidal membrane (76, $233,477)$. More rigorous approaches are necessary to determine whether PDZ motifs also serve as targeting signals.

Apical signals are mostly present in the luminal or transmembrane domains of singlespanning membrane proteins, although cytoplasmic signals have also been reported [for a detailed list, see reference (486)]. Apical signals often represent posttranslational modifications as is the case for the first rigorously identified apical targeting signal, the glycolipid GPI $(54,269)$. The GPI anchor becomes covalently attached to the C-terminus of proteins in the endoplasmic reticulum and mediates their membrane anchorage. Thus, GPIanchored proteins contain neither a transmembrane nor a cytoplasmic domain. A second group of signals comprises $\mathrm{N}$-glycans and O-glycans that are added to the luminal domain as proteins traverse from the endoplasmic reticulum to the TGN. Treatment of cells with the GlcNAc analogue tunicamycin that inhibits the first step in N-glycosylation, and the removal of $\mathrm{N}$ - or O-glycosylation sites by mutagensis have all been shown to lead to the mislocalization of some apical membrane as well as secretory proteins in MDCK cells [reviewed in reference (486)]. Among them, the bile salt export pump BSEP requires two Nlinked glycans to maintain efficient localization at the apical domain in MDCK cells (322). Unlike basolateral signals, the apical transmembrane and luminal signals cannot engage the cytoplasmic vesicle generating machinery that is characteristic of most intracellular trafficking events. In fact, none of the known coat or adaptor complexes has been linked to the release of apical transport carriers from the TGN to the cell surface, perhaps indicating that the generation of apical carriers is mediated by an unconventional mechanism.

Regardless of their nature, what luminal and transmembrane domain sorting signals appear to have in common is their ability to cluster apical cargo. The GPI anchor and the transmembrane domain of some apical proteins such as that of influenza HA confer affinity for microdomains of glycosphingolipids and cholesterol (lipid rafts) that are assembled at the Golgi complex and that are also present at the plasma membrane and on recycling endosomes $(411,464)$. Raft assembly presumably results from the ability of glycospingolipids to readily self-associate and tightly pack into membranes. Cholesterol has been proposed to stabilize the boundaries between microdomains. Depletion of cholesterol results indeed in missorting of GPI-anchored proteins and influenza HA in MDCK cells $(224,512)$. The tight packing of the sphingolipid-containing domains makes them relatively 
insoluble to certain nonionic detergents (such as Triton X-100 or Lubrol WX) and allows their isolation as insoluble domains. Association with detergent resistant lipid domains is indeed the operational way to determine protein association with such lipid rafts.

Sugar moieties are thought to mediate apical protein clustering via lectins. Galectins have recently emerged as candidates in this process. Depletion of Galectin-4 impaired apical trafficking of raft-associated proteins in polarized intestinal HT-29 cells $(99,424)$, while Galectin-3 is essential for raft-independent apical trafficking in MDCK cells $(98,100)$. Since galectins are excreted from cells in a mechanism that bypasses the secretory pathway and have only been found in the apical endosomal membrane system, presumably after endocytosis from the extracellular milieu, they are more likely to mediate protein clustering and sorting in the lumen of endosomal sorting stations than in the TGN $(192,394)$. Much needs to be learned about what makes apical protein clusters specific and how they are translated into apical sorting platforms. Lipid raft association and glycosylation by itself does not necessarily correlate with apical membrane targeting, as basolateral proteins can also partition into lipid rafts and are glycosylated to the same extent as apical proteins. In FRT cells, raft-associated GPI-anchored proteins are targeted basolaterally (511) and some raft-associated GPI-anchored proteins are targeted basolaterally in MDCK cells [discussed in reference (353)]. Some of the targeting differences might be due to differences in the nature of the GPI-attachment signal and the GPI moiety (31). However, other evidence suggests that additional clustering mechanisms are necessary to convert lipid rafts into apical sorting domains [discussed in reference (378)]. Several TGN-proteins have been specifically implicated in apical raft formation: (i) VIP17/MAL-1 (myelin and lymphocyte protein) is present in lipid microdomains, and interacts with GPI-anchored proteins (73, 367). Spontaneously forming clusters of MAL-1 have been shown to concentrate markers of sphingolipid rafts in COS-7 cells (287). Importantly, MAL-1 depletion in MDCK cells affected the polarity of raft-associated influenza HA $(73,367)$ while its over-expression in the kidney of transgenic mice amplified the apical surface area (368). Interestingly, MAL-1 is absent in WIFB cells, which target apical proteins to the basolateral domain from the TGN. Strikingly, upon exogenous MAL-1 expression in these cells, a GPI-anchored reporter and several apical proteins with single transmembrane domain were targeted from the TGN to the apical pole (372). MAL-1 might thus have a critical role in clustering raft-associated proteins into membrane domains that will yield apical TGN-derived transport carriers. (ii) FAPP2 (PI(4)P adaptor protein) is a second candidate. Its depletion interfered with TGNderived apical protein transport in MDCK cells. FAPP2 binds Glc-Cers, the apically enriched lipid that is synthesized at the cytoplasmic leaflet of the Golgi and might contribute to the formation of apical-destined protein-lipid clusters (468). In addition, annexins, notably annexin 2 and 13b, have been shown to interact with lipid rafts and to participate in apically directed transport of channel proteins and influenza HA, respectively $(124,148$, $248,457)$. Recently, annexin $13 \mathrm{~b}$ has been proposed to also participate in the apical trafficking of nonraft proteins (14). Whether MAL-1, FAPP2 and annex-ins complement each other in the same apical pathways or function in parallel pathways, remains to be established.

Vectorial transport to the apical domain critically involves microtubules, and some evidence suggests that microtubule-motors actively participate in the generation of apical TGNderived transport carriers [reviewed in reference (328)]. Microtubules associate with TGN membranes via microtubule-anchoring proteins such as the CLIP-associating proteins (CLASPs) (114), and it is, therefore, feasible that TGN-associated microtubule-motors walking on TGN-associated microtubules could generate the amorphously shaped tubular structures enriched in apical cargo that are seen released from the Golgi in live imaging experiments (242). Dynein and the conventional kinesins KIF5B and KIF5C have been shown to determine the polarity of different apical proteins in MDCK cells $(15,210,430)$. 
Kinesin function-blocking antibodies blocked the exit of an apical reporter protein, NTRp75, from the TGN in MDCK cells (242) and microtubule-disruption led to missorting of apical proteins in MDCK cells (243). These functions are not readily explained with just motorizing the movement of vesicles along microtubule highways, since in this case, microtubule motors would be expected to determine the kinetics of protein delivery but not their generation or polarized targeting (see also below).

\section{Targeting machinery}

As mentioned above, basolateral protein targeting from the TGN and also from the CRE appears to involve the formation of coated vesicles that are assembled via adaptor proteins, which recognize the basolateral cytoplasmic signals. Clathrin-coated buds had been observed at the TGN and at recycling endosomes in both nonpolarized and polarized epithelial cells $(137,260,377)$. Both organelles also contain the clathrin adaptor AP-1, but only recently has an involvement of AP-1 and clathrin in basolateral sorting been established. Rodriguez-Boulan and colleagues demonstrated in an elegant set of experiments that knock-down of the clathrin heavy chain in MDCK cells caused loss of basolateral polarity due to transport and sorting defects both in the biosynthetic and recycling pathways (95). They also clarified the role of AP-1 in basolateral targeting. This adaptor complex exists in two isoforms, a ubiquitous (AP-1A) and an epithelial-specific one, (AP-1B) that only differ in the sequence of their $\mu$ chains, which are involved in cargo recognition (129). Folsch et al. first reported an essential role for AP-1B in the targeting of a subset of basolateral proteins (128). Gravotta et al. have now resolved that AP-1B operates at the CRE, both in the biosynthetic and recycling routes $(64,157)$ while AP-1A mediates basolateral vesicle formation at the TGN (156). From double knockdown experiments in MDCK cells, the authors determined that AP-1B can largely compensate for the lack of AP-1A at the TGN, whereas AP-1A was unable to correct the missorting of basolateral proteins in the recycling pathway caused by AP-1B deficiency. Basolateral proteins targeted from the TGN of AP-1A-deficient cells passed through the CRE on the way to the basolateral domain to a greater extent than in wild-type cells. That let the authors suggest that AP-1A promotes a direct TGN-to-surface pathway, while AP-1B participation at the TGN (even under normal circumstances), promotes the indirect route. Significantly, hepatocytes and WIFB cells lack AP-1B but utilize the CRE as apical/basolateral sorting station. It is apparent that they must have evolved distinct machinery to mediate basolateral protein sorting, at least in the recycling pathway.

The vesicle-generating machinery in the apical pathways remains obscure, but microtubules likely play a role. Microtubules and microtubule motors have not only been implicated in TGN-derived apical carrier formation as mentioned above, but also in the apically directed transport out of the CRE, that is, in the basolateral-to-apical transcytotic pathway $(51,195)$, [reviewed in reference (8)].

The Golgi apparatus, endosomes, and the plasma membrane are all linked to an actin cytoskeleton. Thus, both the generation and fission of transport carriers from a donor organelle and their docking at the acceptor membrane likely involves a remodeling of the local actin cytoskeleton [reviewed in references $(8,105,138)$ ]. Several actin-regulating proteins (such as Cdc42, LIMK, and Cofilin) $(244,329,387)$ and several motors of the myosin family (MyoI, MyoII, MyoVI, and MyoVb) (5, 16, 71, 88, 167, 330, 470) have been implicated in post-Golgi trafficking.

Live imaging experiments have further revealed that transport carriers are linked to microtubules for long-distance transport when they are released from the TGN or from endosomal compartments $(365,416)$. In WIFB cells, different microtubule populations have been identified for different trafficking routes: stable microtubules for the TGN- to surface 
transport of basolateral proteins and dynamic, short-lived microtubules for protein secretion and in the basolateral-to-apical transcytotic pathway (366). In HepG2 cells, on the other hand, microtubules were dispensable for sphingolipid transport in the transcytotic route, and only required for the direct targeting of fluorescent sphingolipid analogues from the TGN to the apical pole (506). Whether the differences are due to cell-specific roles for microtubules or due to different transport carriers for sphingolipids and apical transcytotic proteins remains to be determined. In the transcytotic pathway, vesicular carriers are also propelled by the assembly and disassembly of short actin filaments, which are under the control of the formin INF2 and the GTPase Cdc42 (285). The actin comet tails have been proposed to shuttle MAL2 in tubulovesicular carriers between the subapical zone and more peripheral endosomes. MAL2, a transmembrane protein with similarities to MAL1 discussed above, encounters internalized transcytotic cargo after internalization and ferries it to subapical endosomes. In the absence of MAL2 transcytotic cargo fails to reach the apical domain but instead accumulates in sorting endosomes $(93,94)$.

The coordination of cytosolic coat assembly, recruitment of actin-regulating proteins, of actin- and microtubule-based motors and of the vesicle docking machinery is under the control of a family of small GTPases, the Rab proteins [for review, see reference (198)]. More than 60 members are known in humans. They are localized to distinct intracellular membranes and regulate virtually all intracellular transport events, with multiple Rab proteins cooperating in each of the transport steps. Rab GTPases function as molecular switches that alternate between two conformational states: the GTP-bound "ON" state, in which they are recognized by multiple effector proteins, and the GDP-bound inactive form that terminates effector functions.

Employing a combination of proteomics, immunofluorescence analysis, and in vitro microtubule motility assays with isolated early and late rat liver endosomes, Wolkoff and colleagues have characterized the role of several Rab proteins in the regulation of microtubule plus- and minus-end directed endosome motility in hepatic cells. They determined that Rab1a promotes minus-end directed motility of early endosomes by recruiting the minus-end directed kinesin KIFC1 (327), while Rab4 activates KIFC2, which engages in a tug of war with the plus-end directed Kinesin 1 to induce fission of early endosomes, a process associated with protein sorting in the endocytic pathway (18).

Only few Rab proteins with a specific role in apical/basolateral protein trafficking have been described so far. The best characterized ones are Rab8 and Rab10, which control TGN-tobasolateral surface traffic, most likely between the TGN and the CRE $(181,190,396)$, and Rab25 and Rab11a, which operate at the ARE (470, 479). It should be noted, however, that Rab8-knockout mice showed missorting of apical peptidases and transporters in the small intestine, suggesting that Rab8 has additional roles in apical targeting at least in same cell types (390). Interestingly, hepatocytes feature Rab3D on pIgA-containing transcytotic vesicles. Rab3D is thought to specifically mediate regulated secretory and exocytic events, which raises the question whether even constitutively secretory cells regulate distinct secretory pathways such as basolateral-to-apcal transcytosis $(253,254)$.

The targeting of transport carriers to the right acceptor membrane is regulated on multiple levels. That includes the action of tethering factors and docking complexes (55), of which the exocyst, an 8 subunit protein complex involved in the fusion of basolateral vesicles with the plasma membrane, is the best characterized (273). Ultimate fusion specificity, however, is thought to be provided by SNARE proteins on the vesicle and the acceptor membrane, respectively (417). The vesicle SNARE (v-SNARE) and the SNARE on the target membrane (t-SNARE) need to match like a key its lock to execute membrane fusion (304). Proteins of the SNARE family are tail-anchored membrane proteins that upon pairing of a v- 
SNARE with its cognate t-SNARE on opposing membranes assemble into trans-v/t-SNARE complexes. On the structural level, the SNARE complexes are four-helix bundles, in which three of the helices are contributed by two t-SNARE proteins and one helix by the v-SNARE protein (354). Those "SNAREpins" pull the opposing membranes together to allow the lipid bilayer merger. In vitro studies have established that SNAREs comprise the minimal membrane fusion machinery (482). Cultured epithelial cells and epithelial tissues express four plasma membrane SNAREs: Syntaxin 2, 3, 4, and Snap23 (136, 266, 276, 279). In all epithelial cells analyzed to date, including hepatic cells, the SNARE Syntaxin 3 is polarized to the apical domain. Disruption of Syntaxin 3 function using antibodies, overexpression or by ablating its apical targeting signal, inhibited all apically directed traffic in MDCK and intestinal $\mathrm{CaCo} 2$ cells $(52,249,277,403,439)$. The available data suggest that Syntaxin 3 together with the SNARE protein SNAP23 form the functional t-SNARE for apical fusion events. Two distinct v-SNAREs have been identified that can fuse with the Syntaxin3/ Snap23 t-SNARE complex. They are VAMP7 (also termed Ti-VAMP, because of its resistance to tetanus toxin, which targets other SNARE proteins) and VAMP8 $(139,249)$. In $\mathrm{CaCo} 2$ and FRT cells, RNA interference studies determined that VAMP7/Ti-VAMP mediates the fusion of apical transport carriers in the direct pathway while VAMP8 is the vSNARE in the transcytotic pathway (364). Immuno-EM and immunofluorescence studies in hepatocytes have suggested VAMP3/cellubrevin to function in fusion events of pIgAcontaining carriers along the transcytotic route prior to fusion with the apical domain (62). VAMP3/cellubrevin has been identified as the only v-SNARE in the basolateral pathway so far $(125,201)$. The basolateral t-SNARE has been proposed to be comprised of Syntaxin 4 and Snap23 based on the fact that Syntaxin 4 is the only syntaxin with a strictly basolateral localization in several epithelial cell types, including MDCK cells and hepatic cells (136, 276). The experimental evidence, however, is circumstantial, based on an efficient and specific coprecipitation of recombinant Cellubrevin with Syntaxin 4 (125). Recently, Reales et el. showed that disruption of the basolateral targeting signal of Syntaxin 4 inhibited the overall development of epithelial polarity in MDCK cells but no specific effect on basolateral vesicle fusion was reported (373). Recombinant Syntaxin 2 has a nonpolarized distribution in MDCK cells; but endogenous Syntaxin 2 is enriched at the bile canalicular domain in hepatocytes. While the significance for these differences remains unclear, no involvement for Syntaxin 2 in vesicle fusion with either membrane domain has been reported to date; instead, Syntaxin 2 has been implicated in the abscission step after cytokinesis (278).

\section{The formation and maintenance of the hepatic canalicular pole-a central role for the ARE?}

The journey of apical proteins does not end when they reach the bile canalicular domain. The hepatic luminal surface area would double every 15 to $20 \mathrm{~min}$ if vesicle targeting to the canalicular pole would not be compensated by endocytosis (87). Bile canalicular proteins that are removed from the membrane are either sent to late endosomes and lysosomes for degradation, or maintained in intracellular compartments. The bile acid ABC transporters in particular, which have a half-life of approximately 5 days cycle many times between the plasma membrane and intracellular compartments during their life time in a regulated manner (471). The intrahepatic reservoir for ABC transporters is at least sixfold greater than the content of those proteins at the canalicular membrane. It is mobilized to cope with increased demand on bile acid secretion by two major physiological stimuli: the bile acids that circulate in the enterohepatic circuit and by post-prandially secreted peptide hormones that increase cAMP production in hepatocytes (471). Treatment of rats with taurocholate or cAMP can increase the amounts of their canalicular MDR1, MPR2 and BSEP abundance by approximately threefold $(142,231)$. This effect occurs independently of novel protein synthesis, highlighting the importance of these dynamic intracellular apical storage 
compartments. The available data suggest that taurocholate and cAMP activate distinct signaling pathways to mobilize ABC transporters to the cell surface (320). Whether they activate distinct populations or the same pools by distinct routes is currently not clear. Administration of cAMP results in a PKA-dependent stimulation of PI3K activity and PI3K inhibitors blocked the cAMP effect, but not the taurocholate stimulated incorporation of BSEP into the canalicular membrane in WIFB cells (320). As mentioned above, recent evidence by the Arias group has suggested that taurocholic acid activates a cAMP dependent, but PI3K independent pathway that results in the activation of AMPK, which is crucial for bile canaliculi formation and maintenance (see Section "Bile acid-induced signaling path-way(s) for polarity") and might operate by regulating luminal-directed protein targeting (135). The actin cytoskeleton that is prominent around the bile canalicular lumen appears to have critical roles in the cycling of ABC transporters. Disruption of actin filaments with Cytochalesin D or Latrunculin A inhibited the cAMP-mediated increase in bile acid secretion in vivo (320) and Radixin knockout mice showed impaired apical trafficking of MRP2 and the disappearance of other canalicular ABC transporters from the canalicular membrane (229). Radixin crosslinks the actin cytoskeleton to the underlying luminal membrane. Experiments in BSEP-YFP expressing WIFB cells indicate that actin filament disruption inhibits cycling of the protein (470). Actin-filament disruption also affected the distribution of single-spanning membrane proteins in WIFB cells. Upon Latrunculin A treatment they were not retained at the canalicular-like domain and were mistargeted to the basolateral surface (454).

Immunofluorescence studies with YFP-tagged BSEP and MDR1 in WIFB cells localized the intracellular transporters to endosomal compartment(s) adjacent to the micrtotubule organizing center and to vesicular structures. Colocalization studies revealed a high degree of colocalization of BSEP-YFP with the ARE marker Rab11a, suggesting that the ARE serves as the main dynamic storage compartment for the intracellular transporters (470). Although it is still controversial whether the ARE is also an obligate transit point for apical proteins that are delivered in the transcytotic route and it is unclear at present to which extent the ARE participates in direct protein targeting from the Golgi, it is clear nevertheless that this compartment occupies a central role in luminal surface identity. It is not surprising, therefore, that inhibition of Rab11a function by expressing a DN form of the GTPase, or inhibiting one of its effectors Myosin $\mathrm{Vb}$, not only blocked ARE-to-luminal surface targeting of individual proteins, but in a more profound manner, prevented the establishment of a canalicular pole altogether (470). We expect that as more details of this transport step are elucidated, the signaling roles of bile acids, OSM, and of polarity determinants such as Par1b, LKB1, and AMPK will become associated with the ARE and apical transport. Interestingly, Par1b-overexpression in MDCK cells did not only promote hepatic lumen organization but also a switch from direct to indirect apical protein targeting (84). Thus, Parlb substrate(s) are also expected to operate at the TGN.

\section{So how is hepatocyte protein trafficking different?}

The tremendous amount of proteins that hepatocytes secrete into the sinusoidal space might have made a protein targeting system that emphasizes basolaterally directed traffic from the TGN an evolutionary favorable solution. A basolateral detour for apical membrane proteins might be detrimental mainly for the vectorial transport of bile acids in the enterohepatic circuit and perhaps that is why ABC transporters evolved a direct route from the TGN to the apical pole.

Does all direct apical targeting occur via the same mechanism or do different $A B C$ transporters employ different signals and distinct routes?-Data obtained in different experimental systems suggest the latter. (i) The kinetics of TGN-to-surface 
transport between BSEP and MDR1 in vivo differ vastly and BSEP but not MDR1 has been observed in the ARE (230). (ii) In HepG2 cells, MDR1, but not MPR2 targeting was dependent on a Golgi PKA RIIa anchoring protein and on ceramide (492). Identification of the individual targeting signals and their recognition machinery in combination with high resolution live imaging will be required to solve this important question.

\section{Does the hepatic TGN possess sorting ability for different classes of apical} and basolateral proteins?-This is another open question, although some evidence for multiple distinct sorting and clustering mechanisms has been obtained. In HepG2 cells, Hoeckstra and colleagues reported that the directly targeted polytopic membrane proteins MDR1-GFP and ATP7B cluster into cholesterol-based lipid rafts that were Lubrol WX resistant but soluble in Triton X-100, while GPI-GFP, an indirectly targeted apical protein, was present in Tx100 resistant but Lubrol extractable lipid rafts at the Golgi. A third, indirectly targeted apical protein, DPPIV showed no raft association, consistent with their clustering behavior in other epithelial cell types (413). While these biochemical features do not prove functional sorting platforms, they nevertheless suggest the presence of distinct lipid microdomains in the hepatocye TGN capable of sorting of different protein classes. A more direct evidence for TGN-based sorting comes from Tuma and colleagues who showed that MAL-2 depletion (a protein previously only implicated in the transcytotic pathway) has distinct effects on basolateral surface delivery of pIgR (a basolateral protein) and DPPIV (an apical protein) from the Golgi in WIFB cells, suggesting that they are mediated by different machineries (204). Earlier work by Saucan and Palade showed that basolaterally secreted proteins in hepatocytes in vivo are delivered to the basolateral surface in different vesicles than newly synthesized basolateral recycling receptors or pIgA-R (391).

\section{Do apical and basolateral proteins exit the TGN in common or separate} transport carriers and what is their nature?-Despite evidence for protein sorting in the TGN, it remains unknown whether apical proteins are targeted to the basolateral domain in cognate apical carriers separate from basolateral vesicles, whether apical carriers piggyback onto basolateral ones for transport or vice versa, or whether in a third possible scenario, apical and basolateral proteins reach the basolateral domain in common transport carriers (Fig. 10B). Any common carriers would likely travel directly from the TGN to the basolateral domain, bypassing the CRE that serves as apical/basolateral sorting station in the recycling/transcytotic pathway. This scenario would be due to the lack of a functional TGN sorting mechanism for either apical or basolateral proteins, resulting in the generation of carriers that may either share features with basolateral vesicles generated in other epithelial cells or have unique characteristics. If instead apical and basolateral proteins are packaged into different transport carriers, it can be expected that basolateral proteins are transported, as in MDCK cells, via AP1A/clathrin-coated vesicles, while the apical carriers may differ from those in MDCK cells by their targeting directionality, perhaps due to the attachment of different microtubule motors. Because Syntaxin 3 is delivered to the apical domain via transcytosis, the SNARE protein is also present at the basolateral membrane in heptocytes (although at much lower levels than at the apical pole) and could thus mediate apical vesicle fusion at both plasma membrane domains (136). High-resolution live cell imaging, and interference with machinery known to specifically mediate apical and basolateral targeting in MDCK cells, will be required to elucidate the TGN-derived pathways in hepatic cells.

\section{What makes the sorting endosome the dominant sorting station in}

hepatocytes?-For single-spanning membrane proteins, the CRE rather than the TGN is the apical/basolateral sorting station in hepatocytes. It has long been believed that both organelles employ the same protein sorting mechanisms and machinery since they share many features believed to be central to sorting, notably the presence of lipid microdomains, 
the microtubule dependence of apically directed transport that occurs in tubular structures from both organelles, and the generation of clathrin-coated vesicles that had been postulated to mediate basolaterally directed transport. However, recently mechanistic differences have become apparent in MDCK cells. While basolateral vesicles at the TGN are generated utilizing the AP-1A adaptor complex, those vesicles are formed by AP-1B at the CRE (156). So, it is conceivable that the hepatocyte CRE differs functionally from the TGN in either apical/basolateral protein segregation, and/or in linking apical sorting platforms to the generation of apically directed carriers. Thus, while MAL-1 can drive apical targeting from the TGN, it is dispensable for apical sorting in the CRE of hepatic cells. Unraveling the differences in the protein sorting machinery at both locales promises to yield key insights into the different epithelial targeting strategies that are employed by MDCK cells and hepatocytes, respectively.

\section{Hepatic Polarity in Disease}

The concept of hepatocyte polarity extends onto the mechanisms that underlie many pathological states of the liver. Frequently, in liver disease the proper polarized state of hepatic cells is compromised, as we have already mentioned briefly for HCC. In this section, we will look more closely at this and several other diseases whose mechanisms are tied with hepatic polarity and its defects.

\section{Cholestasis}

Cholestasis is a disease where the normal secretion and flow of bile from the hepatocytes to the biliary tree and ultimately to the digestive organs is altered, resulting in accumulation of excess bile components in the liver and the ensuing damage this inflicts on the hepatic tissue. Cholestatic disorders may arise from toxin or genetic mutation-induced (and thus mainly hereditary) failure of hepatocytes to transport and secrete the different components of bile to the canalicular space, or, alternatively, from a physical obstruction of bile flow presenting outside of the hepatic tissue, such as in the cases of bile duct stricture or gallstones in humans. Depending on the root site of the pathogenesis, the types of cholestatic disease are defined as intrahepatic or extrahepatic, accordingly.

Generally in cholestasis, the backup of bile salts in the bile canaliculi or the bile ductules, and the resulting increased biliary pressure cause altered hepatocyte morphology and the disruption of polarity at the apical pole. Studies of cholestatic rat liver models as well as in vitro hepatocyte cultures have elucidated that common morphological features of cholestasis include diminished contractility of the canaliculi, canalicular dilation, disorganized pericanalicular actin-myosin network, reduced microvilli, loss of gap junctions, and disorganized tight junctions that result in increased paracellular permeability $(102,213,223$, $360,369,451)$. Thus, as bile cannot be cleared from hepatocytes in the forward direction, the canaliculi dilate and stiffen, eliminating canalicular contractions that normally promote forward bile clearance, while the tight junctions open to an extent, creating an osmotic retrogradient for the flow of bile from the hepatocytes to the sinusoidal blood to relieve the former of the toxic bile salt accumulation.

In intrahepatic cholestasis, the issue of altered bile flow stems from the failure of hepatocytes to efficiently secrete bile acids to the canalicular space, leading to their accumulation inside the hepatocytes themselves. Such incapacity comes from improper localization and intracellular trafficking of the $\mathrm{ABC}$ transporters, which as discussed above, are mobilized from apical endosomal populations to the bile canalicular domain. Mutations in ABCB11 (encoding BSEP) and ABCC2 (encoding MRP2) that result in their absence from the canalicular membrane have been associated with such defects as progressive familial intrahepatic cholestasis and conjugated hyperbilirubinemia in Dubin-Johnson 
syndrome $(229,250,356,428))$. In response, conjugated bile acid transporters such as MRP3 and MRP4 become expressed at the basolateral surface to secrete the bile acids and anionic bilirubin conjugates into the plasma so as to relieve the producing hepatocyte from bile toxicity (469). The concept of regulation of organic transporters in response to cholestatic conditions is in fact a prevalent one. Canalicular bile acid transporter BSEP was successfully upregulated at the canaliculi in hypo-osmotic rat hepatocytes following stimulation with taurocholate, a bile salt that acts on the components of PI3-K signaling cascade (namely, mitogen-activated protein kinase and extracellular signal-regulated kinase) (176). PI3-K signaling is also responsible for the taurocholate-induced up-regulation of other canalicular and basolateral export pumps (319). We will come back to this phenomenon again in Section "Hepatocellular carcinoma."

In most cases of intra- and extrahepatic cholestasis, altered hepatocyte protein trafficking is apparent. Hepatocytes from cholestatic livers accumulate apical proteins in special intracellular vacuoles $(223,298,450)$, similar to those observed in intestinal microvilliinclusion disease (6) or in nonpolarized cultured MDCK cells (466). It has been proposed that hepatic vacuolar apical compartments serve to regurgitate bile contents into the sinusoidal space to relieve the fluid and pressure build up in the cholestatic liver. However, their mode of generation, the itineraries, and destinations of their contents are not known. Cholestasis induced by bile duct ligation (a model for mechanically induced biliary obstruction) led to the acute accumulation of vesicles under the canalicular membrane that rapidly disappeared after the release of the block. Secretion of $\mathrm{pIgA}$ into the bile canaliculi was reversibly inhibited (427). PIgA accumulated in Rab3D and Rab11 positive endosomes, suggesting blockage at a preapical transport step (253). In addition, several studies of experimental cholestasis reported the basolateral mislocalization of canalicular membrane proteins, both a multitopic membrane protein (132) that is directly targeted from the Golgi, and of single-spanning membrane proteins that traffic via transcytosis from the basolateral surface $(252,427)$. Together, these findings suggest that cholestasis leads to the inhibition of protein trafficking specifically to the apical pole, both in the direct and transcytotic pathways. By contrast, no defects in basolateral endocytosis or basolateral protein polarity were observed (427) and the kinetics of basolateral-directed exocytosis of secretory and membrane proteins appeared unaltered (253). Thus, altered apical membrane properties and apical cytoskeletal organization might result in trafficking defects that could either further exasperate defects in bile acid secretion into the biliary tree or, alternatively serve to relieve the backup of bile acids in the bile canaliculi by secreting them into the sinusoidal space.

\section{Liver fibrosis and cirrhosis}

Liver fibrosis is the hepatic tissue's response to chronic liver injury, manifested through excess matrix deposition in the space of Disse between hepatocytes and sinusoidal endothelium, thus reducing the basolateral access of hepatocytes to the sinusoidal blood flow. The deposition of ECM results in distortion and scarification of the hepatic parenchyma. As fibrosis induces progressively increasing damage to the hepatocytes, the liver in turn attempts to repair its parenchyma through regeneration. Fibrotic ECM depositions, however, collapse and enclose the newly formed hepatocytes into nodules of regenerating cells. The excess scar tissue and highly apparent nodules constitute liver cirrhosis, an end-stage liver disease that results in liver failure and requires transplantation.

Fibrosis and cirrhosis arise from some form of chronic metabolic liver injury, with preexisting genetic conditions or pathogenic events, such as Wilson disease, Hepatitis B and $\mathrm{C}$, alcoholic liver disease, and nonalcoholic steatohepatitis, forming the basis for inflammatory damage and repair cycles that lead to the progressive scarification of the liver. In addition, the fibrosing or cirrhotic liver may give rise to further complications, such as HCC. 
From the mechanistic point of view of polarity and organization, fibrosis may be thought of as a misadaptation of an otherwise natural repair mechanism that serves to organize a regenerating liver. There are several steps in the changing ECM environment during fibrosis that need to be considered. First, there is a general substitution of the collagens of the space of Disse, from the normally predominant type IV to more fibril-forming types I and III (232, 408). The changing collagen composition engages in a feedback loop with fibrogenic stellate cells where (i) activity of GTP-binding proteins increases due to ECM stimulation of stellate cells, causing them to contract and migrate (500), (77), and (ii) stellate cells deposit new ECM at sites of migration throughout the space of Disse (209, 344). In addition, matrix metalloproteases become activated as a result of increased matrix formation, yet their activation leads to release of growth factors normally bound within the matrix, which contribute to further growth and further fibril deposition $(32,431,432)$. Thus, although ECM signaling is required for differentiation and organization of regenerating hepatic plates, excessive integrin receptor signaling, and matrix stiffness destroy the functional organization of hepatic units in the case of fibrosis $(145,371,487)$. Collagen-I deposition is a feature of fibroblastic cells, and a-smooth muscle actin-positive myofibroblasts derived from activated hepatic stellate cells through transdifferentiation have been considered the major source of matrix deposition $(133,447)$. Recently, however, the field has been imbued with the concept that epithelial to mesenchymal transition (EMT) of hepatocytes and biliary epithelial cells contribute to the rapid mobilization of large numbers of fibrogenic cells after injury. EMT constitutes the loss of key epithelial characteristics, including apical/basolateral polarity, cell-cell adhesion, and epithelial-specific organization of the actin, intermediate, and microtubule cytoskeletons and promotes a motile and invasive phenotype. Hepatocyte lineage-tracing experiments in experimental mouse models of liver fibrosis have led different authors to opposite conclusions and the issue remains controversial $(437,507)$. However, recent questions about the specificity of a single fibroblastic marker utilized in most studies, the generally poorly defined criteria for EMT and difficulties to specify the source of any extracellular protein such as collagen in vivo, have cast serious doubt on the studies that forwarded the concept that EMT contributes to ECM deposition in hepatic fibrosis [discussed in references $(362,488)$ ]. It nevertheless remains appreciated that injuryactivated EMT does occur in chronic fibrogenic disorders. Rather than leading to myofibrobasts and ECM deposition, however, this genetic reprogramming into a less adhesive, migratory phenotype might enable injured hepatocytes to escape "hostile" sites of injury toward a more hospitable microenvironment where they have a chance of resettling if they reprogram or otherwise eventually undergo apoptosis. Either fate is better than that of necrosis at the site of injury [hypothesis from reference (362)]. Thus, EMT might be a mechanism of limiting rather than propagating fibrogenesis.

\section{Hepatitis}

Viral hepatitis, frequently referred to simply as hepatitis, is an infection of the liver by one of the seven known human hepatitis viruses, with hepatitis B and hepatitis C (HBV and $\mathrm{HCV}$, respectively) presenting the greatest health concern due to their ability to persist in the infected tissue and cause chronic hepatitis (333). HCV specifically presents the greatest medical challenge, due to the lack of available vaccines or post-exposure prophylaxis, the relatively low 50\% cure rate of the most prevalent $\mathrm{HCV}$ genotype variant even with the best available treatments, and the fact that acute stages of HCV infection are usually asymptomatic and clinically undetectable $(288,289,490)$. HCV infection manifests in continuous inflammation of the liver and often precipitates in fibrosis, cirrhosis and, eventually, HCC (407).

Hepatitis virus infection occurs in several steps that encompass virus particle capture via extracellular receptors, and a crucial binding step to a membrane protein on the basolateral 
surface of the hepatocyte. Studies in HepG2 cells have shown that ASOR plays the role in viral capture and uptake in HBV infection (452). In the case of HCV infection, the virus binds tight junction proteins, and then undergoes clathrin-mediated endocytosis and fusion with the early endosomes $(91,308)$. Hepatitis virus infection thus relies on the polarized distribution of membrane proteins in the hepatocyte, and in the case of HCV, actually requires binding to a polarity-determining protein complex. Most epithelia-infecting viruses that utilize the tight junction complexes for entry invade from the lumen that is in contact with the body's exterior and hence have direct access to the tight junctions (165). In HCV infection, however, the situation is more complicated, as the virus enters from the circulating blood and encounters the sinusoidal and lateral membranes where cell-cell adhesion junctions preclude direct virus access to tight junction molecules (91).

Initial enrichment of the HCV particles in the liver may occur via the interaction of the positively charged N-terminus of HCV envelope glycoprotein E2 with heparan sulfate proteoglycan, lectins, and LDLR expressed on the basolateral domains of hepatocytes and on the surface of the sinusoidal endothelium $(1,22,281)$. Following this initial capture, four additional factors are required for the binding and endocytosis of the virus particles. These factors are tetraspanin CD81, scavenger receptor class B type I, and tight junction complex proteins Claudin 1 and Occludin (58). The latter two have been shown to be essential for conferring viral entry in human (Claudin 1), and nonhuman (Occludin) cells, confirming the tight junction complex to be crucial for $\mathrm{HCV}$ infection $(91,118,363)$. Coexpression of CD81, SR-BI, Occludin, and Claudin-1 rendered nonliver cells permissive for HCV entry, demonstrating that these four proteins constitute the minimal viral receptor machinery (106). HCV binding to Claudin-1 and Occludin is mediated by the small population of these tight junction proteins that is present on the basolateral surfaces of hepatocytes (376). Thus, initial infection is essentially opportunistic; it occurs via minimally mislocalized proteins on the hepatocyte basolateral domain. Presumably, the preceding loose electrostatic interactions with hepatic and sinusoidal surface moieties are necessary to capture and/or enrich the virus for subsequent uptake via the tight junction protein-containing receptor complex.

Biochemical and live imaging experiments have shown that CD81 and Claudin-1 are associated with each other, that they are coendocytosed in vesicles that fuse with Rab5 positive early endosomes and that their endocytosis is enhanced by HCV $(121,172,173)$. However, the precise roles of the individual receptor proteins for virus endocytosis and/or intracellular postendocytic events are currently not understood. Interestingly, once HCV infection is initiated, an increase in the basolateral distribution of Claudin-1 is observed suggesting a positive feedback loop that allows more viruses to be taken up (376). The increasing uptake of virus at the basolateral surface is further aided by the export of newly synthesized viral particles to the basolateral domain of the infected hepatocyte. Studies with polarized HepG2 cells of HBV and HAV infection and export suggest that the viruses may take advantage of the hepatocytes' post-Golgi vectorial transport system, which delivers most of the newly synthesized membrane proteins and specific sphingolipids, such as SM, to the basolateral domain of the cell, although data from animal models and human clinical studies shows antigens to both viruses to be detectable in bile over the course of infection as well $(35,186,361,397,414)$.

Several signaling molecules have been linked to Claudin-1 mislocalizion in hepatic cells and their regulation has been shown or predicted to increase or decrease susceptibility to $\mathrm{HCV}$ infection. Thus, increased activity of PKA, a cytoskeletal remodeling regulator, has been associated with Claudin-1 mislocalization in HepG2 cells (307). Studies have also linked VEGF-induced reduction in polarity of HepG2 and WIFB cells to mislocalized Occludin and increased HCV susceptibility $(172,306)$. On the other hand, treatment with either Oncostatin M or PKA inhibitors promoted Claudin-1 association to tight junctions in HepG2 
cells (307). PKA inhibitor treatment was also able to reduce HCV entry into Huh7 cells (120).

\section{Hepatocellular carcinoma}

HCC is the primary cancer of the liver's parenchyma and is the most common form of hepatic cancer. It usually results from chronic liver injury from preexisting pathological states such as chronic hepatitis or alcohol-induced cirrhosis. Although HCC presents dramatically altered hepatic morphology and abrogated function, it is most remarkable that the onset of such catastrophic condition bears close similarity to certain morphological and polarity-affecting events that take place in the developing and the regenerating liver.

Chemically induced carcinogenesis of rat hepatic tissue has been extensively utilized as a model to study the emergence of HCC and its progression from hyperplastic nodules to fullblown cancer. Following HCC induction with 2-acetyl-aminofluorene, Ogawa and colleagues have established that the initially transformed cells form acinar structures that are made up of multiple hepatocytes surrounding an irregular and dilated central lumen (Fig. 2). Such structures are indeed observed during normal development of embryonic hepatocytes, during regeneration, and, to a very small extent even in healthy adult tissue. The hyperplastic acini, however, are significantly more irregular and exhibit more distended lumen, and enlarged intercellular space between acinar hepatocytes than those observed in regeneration and development $(239,343)$. Further dissection of the HCC morphology demonstrated defects in the distribution of canalicular proteins even in preneoplastic hepatocytes. Thus, canalicular proteins such as alkaline phosphatase and ATPase are mislocalized and may be found spread across the entire surface membrane (220), (221). In fully neoplastic lesions, canalicular antigens are often no longer detectable at the canalicular membrane, indicating further abrogation in their delivery to the apical plasma membrane and/or downregulation of their expression (400). By contrast, basolateral domain identities appear preserved in $\mathrm{HCC}$ based on the localization of their specific antigens. In addition to the loss of bile canaliculi function, fully transformed hepatocytes exhibit changes in microfilament- and microtubule-organization, cell junctions are compromised or lost to varying degrees, which altogether results in a change from an epithelial to a migratory, mesenchymal-like morphology.

A frequent hallmark of the progression of EMT in HCC is the loss of the transcription factor HNF-4a. As discussed in Section "Signaling Molecules and Pathways for Hepatic Polarity," HNF-4a is required for the epithelial differentiation program starting around embryonic day 14 and onward, by inducing the expression of a number of junctional proteins including ECadherin, Claudin-1, and Eppk1, and down-regulation of HNF-4a in transformed hepatocytes results in diminished tight and gap junctions and ECM-adhesion proteins (28, 257, 258). Expression of exogenous HNF-4a in rat livers following adenoviral transduction attenuates dimethyl-nitrosamine-induced fibrosis by preventing collagen deposition, and most remarkably, decreases the carcinogen-induced EMT by upregulating junctional integrity and by reducing nuclear $\beta$-catenin signaling. As part of the same study, HNF-4atransduced HepG2 cells treated with TGF $\beta$, a mesenchymal inducer, have shown resistance to the transformation (337).

In addition to transcriptional loss of HNF-4a-dependent polarity proteins, aberrant activity of Rho-GTPases and loss of Phosphatase and tensin homolog (PTEN) has been implicated in HCC progression. While these proteins have been linked to a myriad of signaling pathways implicated in cancer, those also include crucial roles in epithelial polarity (146, 222). PTEN phosphatase antagonized PI3K signaling. As an epithelial polarity determinant, it is responsible for sequestering the phosphoinositides PIP2 and PIP3 to the apical and basolateral domains, respectively, which in turn is a prerequisite for the maintenance of the 
apical-basolateral surface identities (141,291). PTEN null mice show increased tumorigenic and adipogenic events, and develop fibrosis as in human nonalcoholic steatohepatitis, and eventually-HCC (481). RhoA, which plays a role in regulating actin microfilament network organization at cadherin-dependent cell-cell attachment sites and at focal adhesions (79), has been shown to be upregulated in fibrotic regions and HCC neoplasms in human specimens, associated with excessive matrix deposition, and epithelial-mesenchymal transition in intrahepatic metastasis $(393,475)$. Depletion of Cdc42, a regulator of apical surface formation and polarized protein targeting $(291,329)$ resulted in distended canaliculi, damaged hepatic and biliary tissues, and HCC in mouse livers (460). Overexpression of TIAM1 GTP-exchange factor that activates Rac1 and is required for junctional assembly (79) has been found in human HCC samples (103).

Of note, it is necessary to mention that in specific cases, hepatocellular carcinogenesis does not present a loss of what appears as normal hepatic polarity. Thus, the bile canaliculi, or the propensity of hepatocytes to polarize with canalicular lumina in vitro, may be retained in cells of HCC origin. Examples of this phenomenon come from histological data on human $\mathrm{HCC}$, as well from the different hepatic cell lines that were mentioned in earlier sections of this review, such as WIFB and HepG2, and Can10 cells (60, 113, 200, 226, 357). Moreover, certain pathways that promote hepatic polarization may incidentally be upregulated in hepatic carcinogenesis. An example of this is Galectin-1 (Gal-1), a $\beta$-galactosidase binding protein that interacts with different integrin family members and glycoproteins of the ECM (115). Gal-1 has been found to be overexpressed in HCC and at metastasizing HCC sites, and, it has been demonstrated that both the size and metastatic rate of mouse liver HCC increases after inoculation with HepG2 cells transfected with Gal-1 (116, 240, 419, 496). HepG2 cells grown in vitro, however, exhibit enhanced cell-ECM interactions, and an increase in the number of emerging bile canaliculi following addition of exogenous Gal-1 (116). Furthermore, canalicular localization of the transporters MDR1 and MRP2 was not perturbed in this case. One way in which Gal-1 is thought to act on the polarization process of canalicular proteins is by mediating integrin and PI3K signaling, which play a regulatory role in choleresis by promoting the transport and insertion of canalicular BSEP, MRP2, and MDR1 and 3, as well as basolateral Ntcp to their respective domains on hepatocytes (116, $176,245,318,319,483)$. This effect demonstrates once more, the parallel between aspects of normal hepatic growth and polarization and HCC.

In conclusion, some of the morphological changes associated with the development of HCC, notably the reorganization of hepatocytes into ascini during early stages and the loss of HFN4a expression closely resemble developmental events in the liver in reverse, a notion that has been invoked in other epithelial-derived malignancies as well. In fact, since cancer is primarily an epithelial disease, drawing connections between carcinogenic events and normal epithelial morphogenesis is a recurring concept in cancer biology (435).

\section{Wilson's disease}

Wilson's disease, also known as progressive hepatolenticular degeneration, is a genetic disorder of copper metabolism that is characterized by hepatic and neurological pathology. It is a rare recessive disease, with incidence of between 1 in 30,000 and 1 in 100,000 births, with a late onset, but it is fatal if left untreated (3). The pathology of Wilson's disease is caused by impaired clearance of copper from the body due to mutations in the coppertransporting ATPase ATP7B. The toxic accumulation of intracellular copper leads to chronic hepatitis, cirrhosis, and liver failure $(3,284)$. As we will see below, Wilson's disease is a protein trafficking disorder.

Copper, coming primarily from dietary sources, is normally absorbed in the gut, taken up by the liver and stored in the hepatocytes conjugated to the cuproproteins, such as the principle 
six copper atom-containing enzyme ceruloplasmin located in the TGN $(63,179,268,440)$. The internalization and processing of copper consists of several steps. The first one is its uptake by copper transporter 1 and divalent metal transporter 1 . The internalized copper is quickly bound by cofactors, most importantly a copper metallochaperone ATOX1, which assists in translocating it to the TGN (34). At the TGN, ATOX1 binds and transfers the metal to ATP7B-a copper transporting P-type ATPase, which translocates copper into the TGN lumen for its incorporation into cuproproteins, such as the aforementioned ceruloplasmin, which is then secreted into the blood $(34,472)$. In hepatocytes, ATP7B also mediates the excretion of excess ATP7B-chelated copper into the bile via TGN-derived transport carriers that are observed in the subapical domain and either fuse directly with the canalicular surface and release the metal into the bile canaliculi or serve as intermediates for apical copper excretion (247). To execute its dual function of TGN uptake and canalicular secretion of copper, ATP7B cycles between the TGN and the canalicular domain in a manner dependent on the TGN-copper-load. Under conditions of excess copper, ATP7B relocalizes from the TGN to subapical vesicles, from which the transporter might constitutively communicate with the luminal surface via endocytosis and recycling. In Wilson's disease, ATP7B mutations at either the N-terminus or C-terminus of the transporter result in two cell biologically distinguishable functional and trafficking defects, each resulting in impaired copper clearance $(47,228)$. Experimental observations in WIFB cells have shown that mutations in the C-terminal region of ATP7B render the transporter insensitive to copper loading levels at the TGN, cause decreased TGN retention, and failure of ATP7B retrograde transport from subapical vesicles to the TGN (47). In turn, mutations in the N-terminus result in the constitutive targeting of ATP7B from the TGN to the basolateral surface $(46,164)$. Although the precise mechanisms behind ATP7B mistargeting are unknown, it can be speculated that impaired recycling and TGN retention of the Cterminal mutant proteins results from defects in apical postendocytic sorting events at either the AEE, the ARE or even the SAC, preventing targeting of the transporter to the TGN or rapidly deliver defective ATP7B to lysosomes for degradation. N-terminal mutations, on the other hand, likely cause protein sorting defects at the TGN that divert ATP7B into basolaterally rather than apically destined transport carriers. It has not been resolved whether basolaterally targeted ATP7B can subsequently undergo transcytosis to the canalicular surface, but in any case, the mistargeted mutant ATP7B species are unable to clear the noncuproprotein-associated copper from the cell $(46,47)$.

\section{Familial hypercholesterolemia and low-density lipoprotein receptor}

Familial hypercholesterolemia $(\mathrm{FH})$ is a genetic disorder characterized by elevated plasma levels of LDL, which in turn results in cardiovascular disease and premature coronary atherosclerosis. In the vast majority of FH cases, the underlying cause of the disease is one of approximately 150 mutations in the gene encoding LDLR, which mediates LDL uptake from the sinusoidal plasma in the liver, and whose synthesis, processing, or transport are altered as a result of the mutation $(185,446)$.

Since LDLR is active at the basolateral surface of the hepatocytes, where it mediates endocytic uptake of LDL, the correct targeting of LDLR to the basolateral plasma membrane is both crucial and what is often disrupted in FH. Work from the Ira Mellman group has identified two tyrosine-dependent targeting signals in the LDLR cytoplasmic tail, which are required for the normal sorting of LDLR from the Golgi or the endosomes to the basolateral membrane. The two determinants, which lie proximally and distally to the plasma membrane, act independently to modulate both the basolateral delivery (via either signal) and endocytosis (via the proximal signal) (299). Moreover, the group identified a cluster of acidic residues flanking both signals, and, specifically for the distal signal, a glycine residue, that was required for efficient basolateral localization of the receptor (300). 
It has been speculated that such structures, with an acidic residue stretch downstream of a tyrosine signal, bear similarity to those of other receptors, such as pIg-R, and may be important for their initial or ultimate basolateral targeting $(11,66,300)$.

The mechanistic evidence for an FH mutation directly responsible for missorting of LDLR and leading to abnormal LDL metabolism was shown by Koivisto et al. for (FH)-Turku LDLR allele, prevalent in Finnish population (236). The allele presents an aspartic acid substitution for the glycine residue flanking the tyrosine signal of the distal targeting determinant of LDLR. Koivisto et al. demonstrated that such single amino-acid substitution of the glycine residue is sufficient to cause missorting of LDLR to the apical domain of MDCK and WIFB cells, and to cause defective LDL clearance in mouse livers transduced with the FH-Turku allele (235). The decreased presence at the basolateral surface and the transcytotic delivery to the apical surface seen with the FH-Turku LDLR indicate that the missorting occurs due to the absence of a strong basolateral retention signal structure. It has been speculated that the signal structures containing a negatively charged amino acid cluster with varying degree of reliance on proximally located tyrosine show similarity between LDLR and other receptors, such as pIg-R, which normally undergoes transcytosis $(12,300$, 325). The FH-Turku mutation may therefore point out the signaling itinerary differences that may be important for regulating basolateral retention versus transcytosis of surface proteins in hepatocytes.

\section{Conclusions and Future Directions}

Many of the important insights into hepatocyte polarity from the last decade such as the discovery of a direct apical targeting pathway or the identification of LKB1 and AMPKrelated kinases as key polarity determinants have been made utilizing "old" and longestablished methodology. Meanwhile, polarity research in nonliver epithelia has benefited tremendously from the adaptation of new technologies, particularly in the area of light microscopy and the development of new fluorophores and fluorescent proteins. Live-cell imaging has made Drosophila and C. elegans, which have long been used as genetically tractable in vivo models for epithelial polarity research, amenable for cell-biological studies. Fast, high resolution, and recently even superresolution microscopy, as well as correlative light- and electron microscopy applied to cultured epithelial cells have revolutionized the field of polarized protein trafficking. The routine application of RNAi techniques in epithelial cultures has made loss-of-function analysis easy and the gold standard for the characterization of a proteins function. All these techniques and technologies have yet to be exploited to their full potential in hepatic polarity research. Their implementation will help answer many of the open questions in the field that we have mentioned throughout the text. In addition, novel concepts and strategies that are specifically aimed at tackling questions of hepatic polarity should be developed and embraced. Some of the emerging ideas are mentioned here:

I. Hepatocyte proliferation after partial hepatectomy results in a discontinuous, less extensive canaliculi network, in multicell thick plates and later in acinar structures before the normal biliary architecture is reestablished $(175,433,448)$. There is still surprisingly little known about how these morphogenetic rearrangements come about and how the liver maintains a reasonably functional integrity during the regeneration process. One important question is how hepatocytes divide and how they prevent the mixing of blood and bile during the period of extensive cell divisions. In fixed cell sections of dividing hepatocytes, the cleavage furrow is rarely seen cutting through a bile canalicular domain $(25,422)$. This is in sharp contrast to the well-established mode of cell divisions in columnar epithelial cells, where the cleavage furrow always halves the apical domain to yield two equal daughters (374). Does the alignment of the cytokinesis axis in hepatocytes lead to 
asymmetric divisions or to a random distribution of luminal surfaces in these multipolar cells? Do hepatocytes seal off the part of their canalicular network that intersects the plane of the division furrow by forming tight junctions between the cells that face a mitotic cell as proposed by Hughes and colleagues (422)? To unequivocally answer these and other questions regarding the mechanisms of reorganizing and maintaining polarity, hepatic cells must be analyzed in their entire three-dimensionality and morphological processes need to be followed over time, which means four-dimensional liver imaging approaches are required. This should be an attainable goal given the recent advances in three areas of tool and technology development: (i) an ever expanding list of bright and photostable cDNA-encoded fluorescent probes is becoming available for live cell imaging, particularly in the less cytotoxic red and infrared spectrum (426). (ii) Tail-vein injections of recombinant adenoviruses have proven an efficient and relatively selective method to transiently express exogenous proteins or shRNA constructs in hepatocytes (183). In addition, naked DNA can be efficiently delivered to hepatocytes by rapid injection of a large volume into the tail vain of rodents $(10 \%$ of the animals weight is injected in 5-7s). It targets mostly hepatocytes, has low toxicity (only $\sim 2 \%$ hepatic cell death), and acceptable efficiency ( $\sim 50 \%$ of hepatocytes contain siRNA $5 \mathrm{~min}$ following injection and average target gene inhibition is 40-60\%) (264). Neither approach requires specialized equipment or surgical expertise. Tail vein injection under nonhydrodynamic conditions coupled with immediate electroporation of liver lobes results in even more effective and exquisitely specific gene delivery $(207,350)$. These methods allow fast and inexpensive expression of fluorescently-labeled marker proteins for live cell imaging and at the same time can also deliver cDNAs to manipulate the polarization process that will be followed. (iii) The greatest challenge will be to establish in situ imaging protocols that yield sufficient subcellular resolution and can be performed over several hours. High-resolution live imaging of exposed liver lobes in anesthetized mice has been pioneered to track malaria parasites as they cross from the sinusoidal lumen into the liver parenchyma and as they are released from hepatocytes into the bloodstream $(130,131,442)$. In those experiments, conventional confocal and spinning disc confocal microscopy have been employed and imaging sessions for up to $2 \mathrm{~h}$ were reported to follow the highly motile fluorescent Plasmodium parasite within a depth of $80 \mu \mathrm{m}$ into the tissue.

Comparable resolution at lower imaging frequency, but longer imaging times will be desirable to follow morphological events such as mitosis and cytokinesis. Multiphoton microscopy, which offers the advantage of deep tissue penetration with minimal cell damage, should also be evaluated for such studies.

II. Vertebrate models, particularly zebrafish (Danio rerio) that are faster and easier to manipulate than mice are beginning to be explored for the study of hepatic polarity development during embryogensis. Analysis of liver morphogenesis in mice is focused mostly on liver regeneration and maintenance of liver function since it is inherently difficult to study and manipulate embryogenesis in utero. There is significant overlap in the pathways and genes that control liver development, regeneration, recovery from injury, and cancer development (78). Thus, complementary approaches in the adult mouse liver and the study of hepatogenesis in Zebrafish will be the most effective way to elucidate major hepatic polarity pathways. The ability to conduct forward genetic screens combined with live realtime imaging of developmental processes in transparent fish embryos that develop outside of the mother makes the zebrafish a powerful model to study morphogenetic events in vivo. Transgenes are also easily expressed in a tissuedependent fashion and hepatocyte-specific and endoderm-specific promotors have 
been characterized. Although classical reverse-genetic approaches whereby a specific gene is inactivated and the resulting phenotype analyzed, are limited and transient gene knock downs with antisense morpholinos are restricted to early embryonic events, recent novel technologies such as TILLING and zinc finger nucleases promise to facilitate targeted gene mutation in zebrafish $(107,127,323)$. Basic transcription factors and signaling pathways in early development that drive hepatic lineage and suppress pancreas formation are well conserved between zebrafish and mice. Histologically, hepatocytes are identifiable $36 \mathrm{hpf}$ (hours postfertilization), the extrahepatic billiary duct by $52 \mathrm{hpf}$ and endothelial-lined sinusoids at $3 \mathrm{dpf}$. Bile production, serum protein secretion, glycogen storage, and other liver functions are fully operational and can be measured by day 5 [reviewed in reference (78)]. There is also evidence that liver regeneration and hepatocarcinogenesis are similar to mammals $(251,384)$. Regarding liver morphology, the basic arrangement of bile canaliculi drained by a hierarchy of ducts is identical in mammals and in fish. There are, however, also differences: the fish liver lacks portal triads but is composed of hepatocyte plates that are lined by sinusoids and biliary ductules. Thus, while in mammals the major intralobular biliary structure is the canaliculus, only 4 to 9 fish hepatocytes line a canaliculus that merges into preductal passageways. The hepatocytes are joined to a preductular epithelial cell analogous to the Canal of Hering at the junction site between canaliculus and ductile $(169,171,385)$. These differences notwithstanding, all distinct liver epithelial cell types and phenotypes are present in the fish.

Morphological studies are still in their infancy, but have already revealed important insights, such as a role for endothelial cells in hepatocyte apical surface development (385), or for tight junction proteins in the development of the biliary network (74) and thus validated the zebrafish as a promising model for polarity studies in the liver.

III. It has recently been appreciated that cell shape and the mechanical properties of the cellular environment can induce cell fate decisions leading to differentiation. In particular, mechanical forces such as shear stresses and tensile loads, as well as the rigidity and topography of the ECM have been shown to induce significant changes in the morphology and fate of stem cells (89). This phenomenon appears to be distinct from conventional ECM-mediated signaling, but rather involves yet unknown mechanotransduction signaling cascades, that may well merge with ECM signaling pathways on the same cytokeletal targets. Several lines of evidence indicate that mechanosignaling might be important for the differentiation of hepatocytes, including their polarization. Reid and colleagues cultured human hepatic stem/progenitor cells in hyaluronic acid-based hydrogels of similar chemical composition but different stiffness and observed differences in their gene expression profiles related to their differentiation state (283). In addition, they reported an example of protein regulation on the translational level that was dependent on the mechanical properties of the cell environment. Laurent et al. measured the expression of differentiation markers and transcription factors, namely, of HNF-4a in several established human hepatic cell lines and found that it correlated with a spherical cell shape that could be induced either in 3D-matrix culture or simply by pharmacological disruption of the actin cytoskeleton (256). Most importantly for the field of polarity, Cassio and co-workers induced permanent polarity in a subset of nonpolarized Fao cells simply by growing the cell lines as spheroids, that is, in the absence of an exogenously provided ECM, in conditions that favor intense cell-cell contacts and tight packing of the cells (357). It is likely that the cell shape induced by these culture conditions triggered permanent cell fate changes that caused the polarized clones to subsequently 
maintain polarity even under conventional culture conditions over many passages. Thus, the emerging area of mechanosignal transduction is likely to impact hepatic polarity studies.

IV. The two LKB1-activated kinases AMPK and Par1b have been suggested to play key roles in the development of hepatic polarity $(81,134)$. Both kinases have few known substrates in epithelial cells. Therefore, unbiased AMPK and Parlb substrate screens in hepatic cells seem to be warranted. K. Shokat's group has devised a chemical genetics approach in which the ATP-binding pocket of a kinase is altered to accommodate bulky ATP analogues that when offered as phosphate donor in complex mixtures can only be utilized by the engineered kinase to selectively phosphorylate its substrates. The ATP analogues contain a chemical affinity tag that is transferred onto the substrates and allows their isolation and the identification of the phosphorylation sites by LC-MS/MS analysis (36). This approach has recently yielded 28 previously unidentified AMPK substrates in HEK293 cells (19) and should be repeated in a polarized hepatic cell line and/or primary hepatocytes. In a similar screen, we have identified more than 60 putative novel Par1b substrates in MDCK cells that we are currently validating and plan to evaluate for their role in the hepatic polarity phenotype in these cells (Fernandez, Callaway, Angeletti, Müsch, manuscript in preparation). We expect that these substrate data will provide the starting point for a concerted effort by many laboratories to delineate essential polarity pathways as they relate to cytoskeletal organization or protein trafficking in hepatic cells.

\section{Acknowledgments}

We acknowledge the input and suggestions of the anonymous reviewers. We thank our team members David Cohen, Dawn Fernandez, Jeanette Nachbar, and Francisco Lazaro-Dieguez for the many discussions on the topic of hepatic polarity, for letting us mention yet unpublished data from our lab and last not least for their comments on the manuscript. We are grateful to E. Rodriguez-Boulan and D. Gravotta for providing us with their manuscript on AP-1A function at the TGN prior to publication and to L. Homolya and I. Arias for communicating unpublished data. This work was supported by NIH/NIDDK R01KD064842-07 to A. Müsch.

\section{References}

1. Agnello V, Abel G, Elfahal M, Knight GB, Zhang QX. Hepatitis C virus and other flaviviridae viruses enter cells via low density lipoprotein receptor. Proc Natl Acad Sci U S A. 1999; 96:1276612771. [PubMed: 10535997]

2. Ait-Slimane T, Galmes R, Trugnan G, Maurice M. Basolateral internalization of GPI-anchored proteins occurs via a clathrin-independent flotillin-dependent pathway in polarized hepatic cells. Mol Biol Cell. 2009; 20:3792-3800. [PubMed: 19605558]

3. Ala A, Walker AP, Ashkan K, Dooley JS, Schilsky ML. Wilson's disease. Lancet. 2007; 369:397408. [PubMed: 17276780]

4. Alessi DR, Sakamoto K, Bayascas JR. LKB1-dependent signaling pathways. Annu Rev Biochem. 2006; 75:137-163. [PubMed: 16756488]

5. Almeida CG, Yamada A, Tenza D, Louvard D, Raposo G, Coudrier E. Myosin 1b promotes the formation of post-Golgi carriers by regulating actin assembly and membrane remodelling at the trans-Golgi network. Nat Cell Biol. 2011; 13:779-789. [PubMed: 21666684]

6. Ameen NA, Salas PJ. Microvillus inclusion disease: A genetic defect affecting apical membrane protein traffic in intestinal epithelium. Traffic. 2000; 1:76-83. [PubMed: 11208062]

7. Ang AL, Taguchi T, Francis S, Folsch H, Murrells LJ, Pypaert M, Warren G, Mellman I. Recycling endosomes can serve as intermediates during transport from the Golgi to the plasma membrane of MDCK cells. J Cell Biol. 2004; 167:531-543. [PubMed: 15534004]

8. Apodaca G. Endocytic traffic in polarized epithelial cells: Role of the actin and microtubule cytoskeleton. Traffic. 2001; 2:149-159. [PubMed: 11260520] 
9. Apodaca G, Katz LA, Mostov KE. Receptor-mediated transcytosis of IgA in MDCK cells is via apical recycling endosomes. J Cell Biol. 1994; 125:67-86. [PubMed: 8138576]

10. Appel D, Koch-Brandt C. Sorting of a secretory protein (gp80) to the apical surface of Caco-2 cells. J Cell Sci. 1994; 107(Pt 2):553-559. [PubMed: 8207078]

11. Aroeti B, Kosen PA, Kuntz ID, Cohen FE, Mostov KE. Mutational and secondary structural analysis of the basolateral sorting signal of the polymeric immunoglobulin receptor. J Cell Biol. 1993; 123:1149-1160. [PubMed: 8245123]

12. Aroeti B, Okhrimenko H, Reich V, Orzech E. Polarized trafficking of plasma membrane proteins: Emerging roles for coats, SNAREs, GTPases and their link to the cytoskeleton. Biochim Biophys Acta. 1998; 1376:57-90. [PubMed: 9666078]

13. Arzumanyan A, Friedman T, Kotei E, Ng IO, Lian Z, Feitelson MA. Epigenetic repression of Ecadherin expression by hepatitis B virus $x$ antigen in liver cancer. Oncogene. 2011; 231:563-572. [PubMed: 21706058]

14. Astanina K, Delebinski CI, Delacour D, Jacob R. Annexin XIIIb guides raft-dependent and independent apical traffic in MDCK cells. Eur J Cell Biol. 2010; 89:799-806. [PubMed: 20708818]

15. Astanina K, Jacob R. KIF5C, a kinesin motor involved in apical trafficking of MDCK cells. Cell Mol Life Sci. 2010; 67:1331-1342. [PubMed: 20094756]

16. Au JS, Puri C, Ihrke G, Kendrick-Jones J, Buss F. Myosin VI is required for sorting of AP-1Bdependent cargo to the basolateral domain in polarized MDCK cells. J Cell Biol. 2007; 177:103114. [PubMed: 17403927]

17. Baloch Z, Klapper J, Buchanan L, Schwartz M, Amenta PS. Ontogenesis of the murine hepatic extracellular matrix: An immunohistochemical study. Differentiation. 1992; 51:209-218. [PubMed: 1459362]

18. Bananis E, Murray JW, Stockert RJ, Satir P, Wolkoff AW. Regulation of early endocytic vesicle motility and fission in a reconstituted system. J Cell Sci. 2003; 116:2749-2761. [PubMed: 12759371]

19. Banko MR, Allen JJ, Schaffer BE, Wilker EW, Tsou P, White JL, Villen J, Wang B, Kim SR, Sakamoto K, Gygi SP, Cantley LC, Yaffe MB, Shokat KM, Brunet A. Chemical genetic screen for AMPKalpha2 substrates uncovers a network of proteins involved in mitosis. Mol Cell. 2011; 44:878-892. [PubMed: 22137581]

20. Barr VA, Scott LJ, Hubbard AL. Immunoadsorption of hepatic vesicles carrying newly synthesized dipeptidyl peptidase IV and polymeric IgA receptor. J Biol Chem. 1995; 270:27834-27844. [PubMed: 7499255]

21. Barroso M, Sztul ES. Basolateral to apical transcytosis in polarized cells is indirect and involves BFA and trimeric $G$ protein sensitive passage through the apical endosome. J Cell Biol. 1994; 124:83-100. [PubMed: 7905002]

22. Barth H, Schafer C, Adah MI, Zhang F, Linhardt RJ, Toyoda H, Kinoshita-Toyoda A, Toida T, Van Kuppevelt TH, Depla E, Von Weiz-sacker F, Blum HE, Baumert TF. Cellular binding of hepatitis $\mathrm{C}$ virus envelope glycoprotein $\mathrm{E} 2$ requires cell surface heparan sulfate. J Biol Chem. 2003; 278:41003-41012. [PubMed: 12867431]

23. Bartles JR, Braiterman LT, Hubbard AL. Endogenous and exogenous domain markers of the rat hepatocyte plasma membrane. J Cell Biol. 1985; 100:1126-1138. [PubMed: 2984213]

24. Bartles JR, Feracci HM, Stieger B, Hubbard AL. Biogenesis of the rat hepatocyte plasma membrane in vivo: Comparison of the pathways taken by apical and basolateral proteins using subcellular fractionation. J Cell Biol. 1987; 105:1241-1251. [PubMed: 3654750]

25. Bartles JR, Hubbard AL. Preservation of hepatocyte plasma membrane domains during cell division in situ in regenerating rat liver. Dev Biol. 1986; 118:286-295. [PubMed: 3533679]

26. Bartles JR, Hubbard AL. Plasma membrane protein sorting in epithelial cells: Do secretory pathways hold the key? Trends Biochem Sci. 1988; 13:181-184. [PubMed: 3255200]

27. Bastaki M, Braiterman LT, Johns DC, Chen YH, Hubbard AL. Absence of direct delivery for single transmembrane apical proteins or their "Secretory" forms in polarized hepatic cells. Mol Biol Cell. 2002; 13:225-237. [PubMed: 11809835] 
28. Battle MA, Konopka G, Parviz F, Gaggl AL, Yang C, Sladek FM, Duncan SA. Hepatocyte nuclear factor 4alpha orchestrates expression of cell adhesion proteins during the epithelial transformation of the developing liver. Proc Natl Acad Sci U S A. 2006; 103:8419-8424. [PubMed: 16714383]

29. Baum B, Georgiou M. Dynamics of adherens junctions in epithelial establishment, maintenance, and remodeling. J Cell Biol. 2011; 192:907-917. [PubMed: 21422226]

30. Bayraktar J, Zygmunt D, Carthew RW. Par-1 kinase establishes cell polarity and functions in Notch signaling in the Drosophila embryo. J Cell Sci. 2006; 119:711-721. [PubMed: 16449319]

31. Benting J, Rietveld A, Ansorge I, Simons K. Acyl and alkyl chain length of GPI-anchors is critical for raft association in vitro. FEBS Lett. 1999; 462:47-50. [PubMed: 10580089]

32. Benyon RC, Iredale JP, Goddard S, Winwood PJ, Arthur MJ. Expression of tissue inhibitor of metalloproteinases 1 and 2 is increased in fibrotic human liver. Gastroenterology. 1996; 110:821831. [PubMed: 8608892]

33. Berthiaume F, Moghe PV, Toner M, Yarmush ML. Effect of extracellular matrix topology on cell structure, function, and physiological responsiveness: Hepatocytes cultured in a sandwich configuration. FASEB J. 1996; 10:1471-1484. [PubMed: 8940293]

34. Bertinato J, L'Abbe MR. Maintaining copper homeostasis: Regulation of copper-trafficking proteins in response to copper deficiency or overload. J Nutr Biochem. 2004; 15:316-322. [PubMed: 15157936]

35. Bhat P, Snooks MJ, Anderson DA. Hepatocytes traffic and export hepatitis B virus basolaterally by polarity-dependent mechanisms. J Virol. 2011; 85:12474-12481. [PubMed: 21937643]

36. Blethrow JD, Glavy JS, Morgan DO, Shokat KM. Covalent capture of kinase-specific phosphopeptides reveals Cdk1-cyclin B substrates. Proc Natl Acad Sci U S A. 2008; 105:14421447. [PubMed: 18234856]

37. Block GD, Locker J, Bowen WC, Petersen BE, Katyal S, Strom SC, Riley T, Howard TA, Michalopoulos GK. Population expansion, clonal growth, and specific differentiation patterns in primary cultures of hep-atocytes induced by HGF/SF, EGF and TGF alpha in a chemically defined (HGM) medium. J Cell Biol. 1996; 132:1133-1149. [PubMed: 8601590]

38. Boehlke C, Kotsis F, Patel V, Braeg S, Voelker H, Bredt S, Beyer T, Janusch H, Hamann C, Godel M, Muller K, Herbst M, Hornung M, Doerken M, Kottgen M, Nitschke R, Igarashi P, Walz G, Kuehn EW. Primary cilia regulate mTORC1 activity and cell size through Lkb1. Nat Cell Biol. 2010; 12:1115-1122. [PubMed: 20972424]

39. Bomsel M, Parton R, Kuznetsov SA, Schroer TA, Gruenberg J. Microtubule- and motor-dependent fusion in vitro between apical and basolateral endocytic vesicles from MDCK cells. Cell. 1990; 62:719-731. [PubMed: 2143699]

40. Bonifacino JS, Glick BS. The mechanisms of vesicle budding and fusion. Cell. 2004; 116:153166. [PubMed: 14744428]

41. Bonifacino JS, Lippincott-Schwartz J. Coat proteins: Shaping membrane transport. Nat Rev Mol Cell Biol. 2003; 4:409-414. [PubMed: 12728274]

42. Bort R, Martinez-Barbera JP, Beddington RS, Zaret KS. Hex homeobox gene-dependent tissue positioning is required for organogenesis of the ventral pancreas. Development. 2004; 131:797806. [PubMed: 14736744]

43. Bossard P, Zaret KS. GATA transcription factors as potentiators of gut endoderm differentiation. Development. 1998; 125:4909-4917. [PubMed: 9811575]

44. Bossard P, Zaret KS. Repressive and restrictive mesodermal interactions with gut endoderm: Possible relation to Meckel's Diverticulum. Development. 2000; 127:4915-4923. [PubMed: 11044405]

45. Boudreau NJ, Jones PL. Extracellular matrix and integrin signalling: The shape of things to come. Biochem J. 1999; 339(Pt 3):481-488. [PubMed: 10215583]

46. Braiterman L, Nyasae L, Guo Y, Bustos R, Lutsenko S, Hubbard A. Apical targeting and Golgi retention signals reside within a 9-amino acid sequence in the copper-ATPase, ATP7B. Am J Physiol Gastrointest Liver Physiol. 2009; 296:G433-G444. [PubMed: 19033537]

47. Braiterman L, Nyasae L, Leves F, Hubbard AL. Critical roles for the $\mathrm{COOH}$ terminus of the $\mathrm{Cu}-$ ATPase ATP7B in protein stability, trans-Golgi network retention, copper sensing, and retrograde trafficking. Am J Physiol Gastrointest Liver Physiol. 2011; 301:G69-G81. [PubMed: 21454443] 
48. Braiterman LT, Heffernan S, Nyasae L, Johns D, See AP, Yutzy R, McNickle A, Herman M, Sharma A, Naik UP, Hubbard AL. JAM-A is both essential and inhibitory to development of hepatic polarity in WIF-B cells. Am J Physiol Gastrointest Liver Physiol. 2008; 294:G576-G588. [PubMed: 18096610]

49. Braiterman, LT.; Hubbard, AH. Hepatocyte surface polarity: Its dynamic maintenance and establishment. In: Arias, IM.; Alter, HJ.; Boyer, JL.; Cohen, DE.; Fausto, N.; Shafritz, DA.; Wolkoff, AW., editors. The Liver, Biology and Pathobiology. 5. Chistester, West Sussex, UK: Wiley-Blackwell; 2009. p. 73-105.

50. Bravo P, Bender V, Cassio D. Efficient in vitro vectorial transport of a fluorescent conjugated bile acid analogue by polarized hepatic hybrid WIF-B and WIF-B9 cells. Hepatology. 1998; 27:576583. [PubMed: 9462660]

51. Breitfeld PP, McKinnon WC, Mostov KE. Effect of nocodazole on vesicular traffic to the apical and basolateral surfaces of polarized MDCK cells. J Cell Biol. 1990; 111:2365-2373. [PubMed: 2277063]

52. Breuza L, Fransen J, Le Bivic A. Transport and function of syntaxin 3 in human epithelial intestinal cells. Am J Physiol Cell Physiol. 2000; 279:C1239-C1248. [PubMed: 11003604]

53. Brooling JT, Campbell JS, Mitchell C, Yeoh GC, Fausto N. Differential regulation of rodent hepatocyte and oval cell proliferation by interferon gamma. Hepatology. 2005; 41:906-915. [PubMed: 15799032]

54. Brown DA, Crise B, Rose JK. Mechanism of membrane anchoring affects polarized expression of two proteins in MDCK cells. Science. 1989; 245:1499-1501. [PubMed: 2571189]

55. Brown FC, Pfeffer SR. An update on transport vesicle tethering. Mol Membr Biol. 2010; 27:457461. [PubMed: 21067454]

56. Bryant DM, Mostov KE. From cells to organs: Building polarized tissue. Nat Rev Mol Cell Biol. 2008; 9:887-901. [PubMed: 18946477]

57. Bultot L, Horman S, Neumann D, Walsh MP, Hue L, Rider MH. Myosin light chains are not a physiological substrate of AMPK in the control of cell structure changes. FEBS Lett. 2009; 583:25-28. [PubMed: 19061891]

58. Burlone ME, Budkowska A. Hepatitis C virus cell entry: Role of lipoproteins and cellular receptors. J Gen Virol. 2009; 90:1055-1070. [PubMed: 19264629]

59. Burra S, Jiang JX. Regulation of cellular function by connexin hemichannels. Int J Biochem Mol Biol. 2011; 2:119-128. [PubMed: 21968837]

60. Caballero T, Aneiros J, Lopez-Caballero J, Gomez-Morales M, Nogales F. Fibrolamellar hepatocellular carcinoma. An immunohistochemical and ultrastructural study. Histopathology. 1985; 9:445-456. [PubMed: 2408985]

61. Calmont A, Wandzioch E, Tremblay KD, Minowada G, Kaestner KH, Martin GR, Zaret KS. An FGF response pathway that mediates hepatic gene induction in embryonic endoderm cells. Dev Cell. 2006; 11:339-348. [PubMed: 16950125]

62. Calvo M, Pol A, Lu A, Ortega D, Pons M, Blasi J, Enrich C. Cellubrevin is present in the basolateral endocytic compartment of hepatocytes and follows the transcytotic pathway after IgA internalization. J Biol Chem. 2000; 275:7910-7917. [PubMed: 10713107]

63. Camakaris J, Voskoboinik I, Mercer JF. Molecular mechanisms of copper homeostasis. Biochem Biophys Res Commun. 1999; 261:225-232. [PubMed: 10425169]

64. Cancino J, Torrealba C, Soza A, Yuseff MI, Gravotta D, Henklein P, Rodriguez-Boulan E, Gonzalez A. Antibody to AP1B adaptor blocks biosynthetic and recycling routes of basolateral proteins at recycling endosomes. Mol Biol Cell. 2007; 18:4872-4884. [PubMed: 17881725]

65. Carmosino M, Valenti G, Caplan M, Svelto M. Polarized traffic towards the cell surface: How to find the route. Biol Cell. 2010; 102:75-91. [PubMed: 19909237]

66. Casanova JE, Apodaca G, Mostov KE. An autonomous signal for basolateral sorting in the cytoplasmic domain of the polymeric immunoglobulin receptor. Cell. 1991; 66:65-75. [PubMed: 2070419]

67. Casanova JE, Mishumi Y, Ikehara Y, Hubbard AL, Mostov KE. Direct apical sorting of rat liver dipeptidylpeptidase IV expressed in Madin-Darby canine kidney cells. J Biol Chem. 1991; 266:24428-24432. [PubMed: 1684792] 
68. Cassio D, Hamon-Benais C, Guerin M, Lecoq O. Hybrid cell lines constitute a potential reservoir of polarized cells: Isolation and study of highly differentiated hepatoma-derived hybrid cells able to form functional bile canaliculi in vitro. J Cell Biol. 1991; 115:1397-1408. [PubMed: 1955480]

69. Cereijido M, Gonzalez-Mariscal L, Contreras RG, Gallardo JM, Garcia-Villegas R, Valdes J. The making of a tight junction. J Cell Sci Suppl. 1993; 17:127-132. [PubMed: 8144687]

70. Cereijido M, Robbins ES, Dolan WJ, Rotunno CA, Sabatini DD. Polarized monolayers formed by epithelial cells on a permeable and translucent support. J Cell Biol. 1978; 77:853-880. [PubMed: 567227]

71. Chan W, Calderon G, Swift AL, Moseley J, Li S, Hosoya H, Arias IM, Ortiz DF. Myosin II regulatory light chain is required for trafficking of bile salt export protein to the apical membrane in Madin-Darby canine kidney cells. J Biol Chem. 2005; 280:23741-23747. [PubMed: 15826951]

72. Chaumontet C, Mazzoleni G, Decaens C, Bex V, Cassio D, Martel P. The polarized hepatic human/rat hybrid WIF 12-1 and WIF-B cells communicate efficiently in vitro via connexin 32constituted gap junctions. Hepatology. 1998; 28:164-172. [PubMed: 9657109]

73. Cheong KH, Zacchetti D, Schneeberger EE, Simons K. VIP17/MAL, a lipid raft-associated protein, is involved in apical transport in MDCK cells. Proc Natl Acad Sci U S A. 1999; 96:62416248. [PubMed: 10339572]

74. Cheung ID, Bagnat M, Ma TP, Datta A, Evason K, Moore JC, Lawson ND, Mostov KE, Moens CB, Stainier DY. Regulation of intrahepatic biliary duct morphogenesis by Claudin 15-like b. Dev Biol. 2012; 361:68-78. [PubMed: 22020048]

75. Cho CS, Seo SJ, Park IK, Kim SH, Kim TH, Hoshiba T, Harada I, Akaike T. Galactose-carrying polymers as extracellular matrices for liver tissue engineering. Biomaterials. 2006; 27:576-585. [PubMed: 16084586]

76. Choi JH, Murray JW, Wolkoff AW. PDZK1 binding and serine phosphorylation regulate subcellular trafficking of organic anion transport protein 1a1. Am J Physiol Gastrointest Liver Physiol. 2011; 300:G384-G393. [PubMed: 21183661]

77. Choi SS, Sicklick JK, Ma Q, Yang L, Huang J, Qi Y, Chen W, Li YX, Goldschmidt-Clermont PJ, Diehl AM. Sustained activation of Rac1 in hepatic stellate cells promotes liver injury and fibrosis in mice. Hepatology. 2006; 44:1267-1277. [PubMed: 17058265]

78. Chu J, Sadler KC. New school in liver development: Lessons from zebrafish. Hepatology. 2009; 50:1656-1663. [PubMed: 19693947]

79. Citi S, Spadaro D, Schneider Y, Stutz J, Pulimeno P. Regulation of small GTPases at epithelial cell-cell junctions. Mol Membr Biol. 2011; 28:427-444. [PubMed: 21781017]

80. Clotman F, Jacquemin P, Plumb-Rudewiez N, Pierreux CE, Van der Smissen P, Dietz HC, Courtoy PJ, Rousseau GG, Lemaigre FP. Control of liver cell fate decision by a gradient of TGF beta signaling modulated by Onecut transcription factors. Genes Dev. 2005; 19:1849-1854. [PubMed: 16103213]

81. Cohen D, Brennwald PJ, Rodriguez-Boulan E, Musch A. Mammalian PAR-1 determines epithelial lumen polarity by organizing the microtubule cytoskeleton. J Cell Biol. 2004; 164:717-727. [PubMed: 14981097]

82. Cohen D, Fernandez D, Lazaro-Dieguez F, Musch A. The serine/threonine kinase Par1b regulates epithelial lumen polarity via IRSp53-mediated cell-ECM signaling. J Cell Biol. 2011; 192:525540. [PubMed: 21282462]

83. Cohen D, Musch A. Apical surface formation in MDCK cells: Regulation by the serine/threonine kinase EMK1. Methods. 2003; 30:269-276. [PubMed: 12798141]

84. Cohen D, Rodriguez-Boulan E, Musch A. Par-1 promotes a hepatic mode of apical protein trafficking in MDCK cells. Proc Natl Acad Sci U S A. 2004; 101:13792-13797. [PubMed: 15365179]

85. Cohen D, Tian Y, Musch A. Par1b promotes hepatic-type lumen polarity in Madin Darby canine kidney cells via myosin II- and E-cadherin-dependent signaling. Mol Biol Cell. 2007; 18:22032215. [PubMed: 17409351]

86. Cox DN, Lu B, Sun TQ, Williams LT, Jan YN. Drosophila par-1 is required for oocyte differentiation and microtubule organization. Curr Biol. 2001; 11:75-87. [PubMed: 11231123] 
87. Crawford JM. Role of vesicle-mediated transport pathways in hepatocellular bile secretion. Semin Liver Dis. 1996; 16:169-189. [PubMed: 8781022]

88. Cresawn KO, Potter BA, Oztan A, Guerriero CJ, Ihrke G, Golden-ring JR, Apodaca G, Weisz OA. Differential involvement of endocytic compartments in the biosynthetic traffic of apical proteins. Embo J. 2007; 26:3737-3748. [PubMed: 17673908]

89. Dado D, Sagi M, Levenberg S, Zemel A. Mechanical control of stem cell differentiation. Regen Med. 2012; 7:101-116. [PubMed: 22168501]

90. Darlington GJ, Kelly JH, Buffone GJ. Growth and hepatospecific gene expression of human hepatoma cells in a defined medium. In Vitro Cell Dev Biol. 1987; 23:349-354. [PubMed: 3034851]

91. Davis, C.; Harris, HJ.; McKeating, JA.; Alan, SLY. Current Topics in Membranes. Academic Press; Waltham, MA: 2010. Chapter 12 - The involvement of tight junction protein claudin-1 in hepatitis C virus entry; p. 273-292.

92. De Bartolo L, Morelli S, Lopez LC, Giorno L, Campana C, Salerno S, Rende M, Favia P, Detomaso L, Gristina R, d'Agostino R, Drioli E. Biotransformation and liver-specific functions of human hepatocytes in culture on RGD-immobilized plasma-processed membranes. Biomaterials. 2005; 26:4432-4441. [PubMed: 15701372]

93. de Marco MC, Martin-Belmonte F, Kremer L, Albar JP, Correas I, Vaerman JP, Marazuela M, Byrne JA, Alonso MA. MAL2, a novel raft protein of the MAL family, is an essential component of the machinery for transcytosis in hepatoma HepG2 cells. J Cell Biol. 2002; 159:37-44. [PubMed: 12370246]

94. de Marco MC, Puertollano R, Martinez-Menarguez JA, Alonso MA. Dynamics of MAL2 during glycosylphosphatidylinositol-anchored protein transcytotic transport to the apical surface of hepatoma HepG2 cells. Traffic. 2006; 7:61-73. [PubMed: 16445687]

95. Deborde S, Perret E, Gravotta D, Deora A, Salvarezza S, Schreiner R, Rodriguez-Boulan E. Clathrin is a key regulator of basolateral polarity. Nature. 2008; 452:719-723. [PubMed: 18401403]

96. Decaens C, Durand M, Grosse B, Cassio D. Which in vitro models could be best used to study hepatocyte polarity? Biol Cell. 2008; 100:387-398. [PubMed: 18549352]

97. Decaens C, Rodriguez P, Bouchaud C, Cassio D. Establishment of hepatic cell polarity in the rat hepatoma-human fibroblast hybrid WIF-B9. A biphasic phenomenon going from a simple epithelial polarized phenotype to an hepatic polarized one. J Cell Sci. 1996; 109(Pt 6):1623-1635. [PubMed: 8799849]

98. Delacour D, Cramm-Behrens CI, Drobecq H, Le Bivic A, Naim HY, Jacob R. Requirement for galectin-3 in apical protein sorting. Curr Biol. 2006; 16:408-414. [PubMed: 16488876]

99. Delacour D, Gouyer V, Zanetta JP, Drobecq H, Leteurtre E, Grard G, Moreau-Hannedouche O, Maes E, Pons A, Andre S, Le Bivic A, Gabius HJ, Manninen A, Simons K, Huet G. Galectin-4 and sulfatides in apical membrane trafficking in enterocyte-like cells. J Cell Biol. 2005; 169:491501. [PubMed: 15883199]

100. Delacour D, Greb C, Koch A, Salomonsson E, Leffler H, Le Bivic A, Jacob R. Apical sorting by galectin-3-dependent glycoprotein clustering. Traffic. 2007; 8:379-388. [PubMed: 17319896]

101. Deschatrette J, Weiss MC. Characterization of differentiated and dedifferentiated clones from a rat hepatoma. Biochimie. 1974; 56:1603-1611. [PubMed: 4157008]

102. Desmet VJ. Current problems in diagnosis of biliary disease and cholestasis. Semin Liver Dis. 1986; 6:233-245. [PubMed: 3535088]

103. Ding Y, Chen B, Wang S, Zhao L, Chen J, Chen L, Luo R. Overexpression of Tiam1 in hepatocellular carcinomas predicts poor prognosis of HCC patients. Int J Cancer. 2009; 124:653658. [PubMed: 18972435]

104. Doerflinger H, Benton R, Shulman JM, St Johnston D. The role of PAR-1 in regulating the polarised microtubule cytoskeleton in the Drosophila follicular epithelium. Development. 2003; 130:3965-3975. [PubMed: 12874119]

105. Doherty GJ, McMahon HT. Mechanisms of endocytosis. Annu Rev Biochem. 2009; 78:857-902. [PubMed: 19317650] 
106. Dorner M, Horwitz JA, Robbins JB, Barry WT, Feng Q, Mu K, Jones CT, Schoggins JW, Catanese MT, Burton DR, Law M, Rice CM, Ploss A. A genetically humanized mouse model for hepatitis C virus infection. Nature. 2011; 474:208-211. [PubMed: 21654804]

107. Doyon Y, McCammon JM, Miller JC, Faraji F, Ngo C, Katibah GE, Amora R, Hocking TD, Zhang L, Rebar EJ, Gregory PD, Urnov FD, Amacher SL. Heritable targeted gene disruption in zebrafish using designed zinc-finger nucleases. Nat Biotechnol. 2008; 26:702-708. [PubMed: 18500334]

108. Du Y, Han R, Ng S, Ni J, Sun W, Wohland T, Ong SH, Kuleshova L, Yu H. Identification and characterization of a novel prespheroid 3-dimensional hepatocyte monolayer on galactosylated substratum. Tissue Eng. 2007; 13:1455-1468. [PubMed: 17518743]

109. Duffield A, Caplan MJ, Muth TR. Protein trafficking in polarized cells. Int Rev Cell Mol Biol. 2008; 270:145-179. [PubMed: 19081536]

110. Duncan SA. Mechanisms controlling early development of the liver. Mech Dev. 2003; 120:1933. [PubMed: 12490293]

111. Dunn JC, Tompkins RG, Yarmush ML. Long-term in vitro function of adult hepatocytes in a collagen sandwich configuration. Biotechnol Prog. 1991; 7:237-245. [PubMed: 1367596]

112. Dunn JC, Yarmush ML, Koebe HG, Tompkins RG. Hepatocyte function and extracellular matrix geometry: Long-term culture in a sandwich configuration. FASEB J. 1989; 3:174-177. [PubMed: 2914628]

113. Edmondson HA, Steiner PE. Primary carcinoma of the liver: A study of 100 cases among 48,900 necropsies. Cancer. 1954; 7:462-503. [PubMed: 13160935]

114. Efimov A, Kharitonov A, Efimova N, Loncarek J, Miller PM, Andreyeva N, Gleeson P, Galjart N, Maia AR, McLeod IX, Yates JR III, Maiato H, Khodjakov A, Akhmanova A, Kaverina I. Asymmetric CLASP-dependent nucleation of noncentrosomal microtubules at the trans-Golgi network. Dev Cell. 2007; 12:917-930. [PubMed: 17543864]

115. Elola MT, Chiesa ME, Alberti AF, Mordoh J, Fink NE. Galectin-1 receptors in different cell types. J Biomed Sci. 2005; 12:13-29. [PubMed: 15864736]

116. Espelt MV, Croci DO, Bacigalupo ML, Carabias P, Manzi M, Elola MT, Munoz MC, Dominici FP, Wolfenstein-Todel C, Rabinovich GA, Troncoso MF. Novel roles of galectin-1 in hepatocellular carcinoma cell adhesion, polarization, and in vivo tumor growth. Hepatology. 2011; 53:2097-2106. [PubMed: 21391228]

117. Esteve-Puig R, Canals F, Colome N, Merlino G, Recio JA. Uncoupling of the LKB1-AMPKalpha energy sensor pathway by growth factors and oncogenic BRAF. PLoS One. 2009; 4:e4771. [PubMed: 19274086]

118. Evans MJ, von Hahn T, Tscherne DM, Syder AJ, Panis M, Wolk B, Hatziioannou T, McKeating JA, Bieniasz PD, Rice CM. Claudin-1 is a hepatitis $C$ virus co-receptor required for a late step in entry. Nature. 2007; 446:801-805. [PubMed: 17325668]

119. Ezzell RM, Toner M, Hendricks K, Dunn JC, Tompkins RG, Yarmush ML. Effect of collagen gel configuration on the cytoskeleton in cultured rat hepatocytes. Exp Cell Res. 1993; 208:442-452. [PubMed: 8375473]

120. Farquhar MJ, Harris HJ, Diskar M, Jones S, Mee CJ, Nielsen SU, Brimacombe CL, Molina S, Toms GL, Maurel P, Howl J, Herberg FW, van Ijzendoorn SC, Balfe P, McKeating JA. Protein kinase A-dependent step(s) in hepatitis C virus entry and infectivity. J Virol. 2008; 82:87978811. [PubMed: 18579596]

121. Farquhar MJ, Hu K, Harris HJ, Davis C, Brimacombe CL, Fletcher SJ, Baumert TF, Rappoport JZ, Balfe P, McKeating JA. Hepatitis C virus induces CD81 and claudin-1 endocytosis. J Virol. 2012; 86:4305-4316. [PubMed: 22318146]

122. Fausto N, Campbell JS, Riehle KJ. Liver regeneration. Hepatology. 2006; 43:S45-S53. [PubMed: 16447274]

123. Feracci H, Connolly TP, Margolis RN, Hubbard AL. The establishment of hepatocyte cell surface polarity during fetal liver development. Dev Biol. 1987; 123:73-84. [PubMed: 3305113]

124. Fiedler K, Lafont F, Parton RG, Simons K. Annexin XIIIb: A novel epithelial specific annexin is implicated in vesicular traffic to the apical plasma membrane. J Cell Biol. 1995; 128:1043-1053. [PubMed: 7896870] 
125. Fields IC, Shteyn E, Pypaert M, Proux-Gillardeaux V, Kang RS, Galli T, Folsch H. v-SNARE cellubrevin is required for basolateral sorting of AP-1B-dependent cargo in polarized epithelial cells. J Cell Biol. 2007; 177:477-488. [PubMed: 17485489]

126. Fogarty S, Hardie DG. C-terminal phosphorylation of LKB1 is not required for regulation of AMP-activated protein kinase, BRSK1, BRSK2, or cell cycle arrest. J Biol Chem. 2009; 284:7784. [PubMed: 18854318]

127. Foley JE, Yeh JR, Maeder ML, Reyon D, Sander JD, Peterson RT, Joung JK. Rapid mutation of endogenous zebrafish genes using zinc finger nucleases made by Oligomerized Pool ENgineering (OPEN). PLoS One. 2009; 4:e4348. [PubMed: 19198653]

128. Folsch H, Ohno H, Bonifacino JS, Mellman I. A novel clathrin adaptor complex mediates basolateral targeting in polarized epithelial cells. Cell. 1999; 99:189-198. [PubMed: 10535737]

129. Folsch H, Pypaert M, Schu P, Mellman I. Distribution and function of AP-1 clathrin adaptor complexes in polarized epithelial cells. J Cell Biol. 2001; 152:595-606. [PubMed: 11157985]

130. Frevert U, Engelmann S, Zougbede S, Stange J, Ng B, Matuschewski K, Liebes L, Yee H. Intravital observation of plasmodium berghei sporo-zoite infection of the liver. PLoS Biol. 2005; 3:e192. [PubMed: 15901208]

131. Frevert U, Moreno A, Calvo-Calle JM, Klotz C, Nardin E. Imaging effector functions of human cytotoxic CD4+ T cells specific for Plasmodium falciparum circumsporozoite protein. Int $\mathbf{J}$ Parasitol. 2009; 39:119-132. [PubMed: 18723023]

132. Fricker G, Landmann L, Meier PJ. Extrahepatic obstructive cholestasis reverses the bile salt secretory polarity of rat hepatocytes. J Clin Invest. 1989; 84:876-885. [PubMed: 2760217]

133. Friedman SL. Mechanisms of disease: Mechanisms of hepatic fibrosis and therapeutic implications. Nat Clin Pract Gastroenterol Hepatol. 2004; 1:98-105. [PubMed: 16265071]

134. Fu D, Wakabayashi Y, Ido Y, Lippincott-Schwartz J, Arias IM. Regulation of bile canalicular network formation and maintenance by AMP-activated protein kinase and LKB1. J Cell Sci. 2010; 123:3294-3302. [PubMed: 20826460]

135. Fu D, Wakabayashi Y, Lippincott-Schwartz J, Arias IM. Bile acid stimulates hepatocyte polarization through a cAMP-Epac-MEK-LKB1-AMPK pathway. Proc Natl Acad Sci U S A. 2011; 108:1403-1408. [PubMed: 21220320]

136. Fujita H, Tuma PL, Finnegan CM, Locco L, Hubbard AL. Endogenous syntaxins 2, 3 and 4 exhibit distinct but overlapping patterns of expression at the hepatocyte plasma membrane. Biochem J. 1998; 329(Pt 3):527-538. [PubMed: 9445379]

137. Futter CE, Gibson A, Allchin EH, Maxwell S, Ruddock LJ, Odorizzi G, Domingo D, Trowbridge IS, Hopkins CR. In polarized MDCK cells basolateral vesicles arise from clathrin-gammaadaptin-coated domains on endosomal tubules. J Cell Biol. 1998; 141:611-623. [PubMed: 9566963]

138. Galletta BJ, Cooper JA. Actin and endocytosis: Mechanisms and phylogeny. Curr Opin Cell Biol. 2009; 21:20-27. [PubMed: 19186047]

139. Galli T, Zahraoui A, Vaidyanathan VV, Raposo G, Tian JM, Karin M, Niemann H, Louvard D. A novel tetanus neurotoxin-insensitive vesicle-associated membrane protein in SNARE complexes of the apical plasma membrane of epithelial cells. Mol Biol Cell. 1998; 9:1437-1448. [PubMed: 9614185]

140. Gartner, LP.; Hiatt, JL. Color Textbook of Histology. 2. Philadelphia: W.B. Saunders; 2001. p. 416-434.

141. Gassama-Diagne A, Yu W, ter Beest M, Martin-Belmonte F, Kierbel A, Engel J, Mostov K. Phosphatidylinositol-3,4,5-trisphosphate regulates the formation of the basolateral plasma membrane in epithelial cells. Nat Cell Biol. 2006; 8:963-970. [PubMed: 16921364]

142. Gatmaitan ZC, Nies AT, Arias IM. Regulation and translocation of ATP-dependent apical membrane proteins in rat liver. Am J Physiol. 1997; 272:G1041-G1049. [PubMed: 9176212]

143. Gautam A, Ng OC, Strazzabosco M, Boyer JL. Quantitative assessment of canalicular bile formation in isolated hepatocyte couplets using microscopic optical planimetry. J Clin Invest. 1989; 83:565-573. [PubMed: 2913052] 
144. Geisler F, Nagl F, Mazur PK, Lee M, Zimber-Strobl U, Strobl LJ, Radtke F, Schmid RM, Siveke JT. Liver-specific inactivation of Notch2, but not Notch1, compromises intrahepatic bile duct development in mice. Hepatology. 2008; 48:607-616. [PubMed: 18666240]

145. Georges PC, Hui JJ, Gombos Z, McCormick ME, Wang AY, Uemura M, Mick R, Janmey PA, Furth EE, Wells RG. Increased stiffness of the rat liver precedes matrix deposition: Implications for fibrosis. Am J Physiol Gastrointest Liver Physiol. 2007; 293:G1147-G1154. [PubMed: 17932231]

146. Georgescu MM. PTEN tumor suppressor network in PI3K-Akt pathway control. Genes Cancer. 2010; 1:1170-1177. [PubMed: 21779440]

147. Gibson A, Futter CE, Maxwell S, Allchin EH, Shipman M, Kraehen-buhl JP, Domingo D, Odorizzi G, Trowbridge IS, Hopkins CR. Sorting mechanisms regulating membrane protein traffic in the apical transcytotic pathway of polarized MDCK cells. J Cell Biol. 1998; 143:81-94. [PubMed: 9763422]

148. Girard C, Tinel N, Terrenoire C, Romey G, Lazdunski M, Borsotto M. p11, an annexin II subunit, an auxiliary protein associated with the background K+ channel, TASK-1. EMBO J. 2002; 21:4439-4448. [PubMed: 12198146]

149. Godlewski G, Gaubert-Cristol R, Rouy S, Prudhomme M. Liver development in the rat during the embryonic period (Carnegie stages 15-23). Acta Anat (Basel). 1997; 160:172-178. [PubMed: 9718390]

150. Gonzalez-Mariscal L, Chavez de Ramirez B, Cereijido M. Tight junction formation in cultured epithelial cells (MDCK). J Membr Biol. 1985; 86:113-125. [PubMed: 4032460]

151. Gonzalez A, Nicovani S, Juica F. Apical secretion of hepatitis B surface antigen from transfected Madin-Darby canine kidney cells. J Biol Chem. 1993; 268:6662-6667. [PubMed: 8454638]

152. Gonzalez A, Rodriguez-Boulan E. Clathrin and AP1B: Key roles in basolateral trafficking through trans-endosomal routes. FEBS Lett. 2009; 583:3784-3795. [PubMed: 19854182]

153. Goodenough DA, Paul DL. Gap junctions. Cold Spring Harb Perspect Biol. 2009; 1:a002576. [PubMed: 20066080]

154. Graf J, Boyer JL. The use of isolated rat hepatocyte couplets in hepatobiliary physiology. J Hepatol. 1990; 10:387-394. [PubMed: 2195112]

155. Graf J, Gautam A, Boyer JL. Isolated rat hepatocyte couplets: A primary secretory unit for electrophysiologic studies of bile secretory function. Proc Natl Acad Sci U S A. 1984; 81:65166520. [PubMed: 6149546]

156. Gravotta D, Carvajal-Gonzalez JM, Mattera R, Deborde S, Banfelder JR, Bonifacino JS, Rodriguez-Boulan E. Novel role of the clathrin adaptor AP-1A in basolateral polarity. Dev Cell. 2012; 22(4):811-823. [PubMed: 22516199]

157. Gravotta D, Deora A, Perret E, Oyanadel C, Soza A, Schreiner R, Gonzalez A, Rodriguez-Boulan E. AP1B sorts basolateral proteins in recycling and biosynthetic routes of MDCK cells. Proc Natl Acad Sci U S A. 2007; 104:1564-1569. [PubMed: 17244703]

158. Green KJ, Getsios S, Troyanovsky S, Godsel LM. Intercellular junction assembly, dynamics, and homeostasis. Cold Spring Harb Perspect Biol. 2010; 2:a000125. [PubMed: 20182611]

159. Griffiths G, Fuller SD, Back R, Hollinshead M, Pfeiffer S, Simons K. The dynamic nature of the Golgi complex. J Cell Biol. 1989; 108:277-297. [PubMed: 2537312]

160. Gripon P, Rumin S, Urban S, Le Seyec J, Glaise D, Cannie I, Guyomard C, Lucas J, Trepo C, Guguen-Guillouzo C. Infection of a human hepatoma cell line by hepatitis B virus. Proc Natl Acad Sci U S A. 2002; 99:15655-15660. [PubMed: 12432097]

161. Gualdi R, Bossard P, Zheng M, Hamada Y, Coleman JR, Zaret KS. Hepatic specification of the gut endoderm in vitro: Cell signaling and transcriptional control. Genes Dev. 1996; 10:16701682. [PubMed: 8682297]

162. Guillouzo A, Corlu A, Aninat C, Glaise D, Morel F, Guguen-Guillouzo C. The human hepatoma HepaRG cells: A highly differentiated model for studies of liver metabolism and toxicity of xenobiotics. Chem Biol Interact. 2007; 168:66-73. [PubMed: 17241619]

163. Gumbiner B, Stevenson B, Grimaldi A. The role of the cell adhesion molecule uvomorulin in the formation and maintenance of the epithelial junctional complex. J Cell Biol. 1988; 107:15751587. [PubMed: 3049625] 
164. Guo Y, Nyasae L, Braiterman LT, Hubbard AL. NH2-terminal signals in ATP7B Cu-ATPase mediate its $\mathrm{Cu}$-dependent anterograde traffic in polarized hepatic cells. Am J Physiol Gastrointest Liver Physiol. 2005; 289:G904-G916. [PubMed: 15994426]

165. Guttman JA, Finlay BB. Tight junctions as targets of infectious agents. Biochim Biophys Acta. 2009; 1788:832-841. [PubMed: 19059200]

166. Hales CM, Griner R, Hobdy-Henderson KC, Dorn MC, Hardy D, Kumar R, Navarre J, Chan EK, Lapierre LA, Goldenring JR. Identification and characterization of a family of Rab11-interacting proteins. J Biol Chem. 2001; 276:39067-39075. [PubMed: 11495908]

167. Hales CM, Vaerman JP, Goldenring JR. Rab11 family interacting protein 2 associates with Myosin Vb and regulates plasma membrane recycling. J Biol Chem. 2002; 277:50415-50421. [PubMed: 12393859]

168. Hall HG, Farson DA, Bissell MJ. Lumen formation by epithelial cell lines in response to collagen overlay: A morphogenetic model in culture. Proc Natl Acad Sci U S A. 1982; 79:4672-4676. [PubMed: 6956885]

169. Hampton JA, Lantz RC, Goldblatt PJ, Lauren DJ, Hinton DE. Functional units in rainbow trout (Salmo gairdneri, Richardson) liver: II. The biliary system. Anat Rec. 1988; 221:619-634. [PubMed: 2970812]

170. Hardie DG. AMP-activated protein kinase: An energy sensor that regulates all aspects of cell function. Genes Dev. 2011; 25:1895-1908. [PubMed: 21937710]

171. Hardman RC, Volz DC, Kullman SW, Hinton DE. An in vivo look at vertebrate liver architecture: Three-dimensional reconstructions from medaka (Oryzias latipes). Anat Rec (Hoboken). 2007; 290:770-782. [PubMed: 17516461]

172. Harris HJ, Davis C, Mullins JG, Hu K, Goodall M, Farquhar MJ, Mee CJ, McCaffrey K, Young $\mathrm{S}$, Drummer H, Balfe P, McKeating JA. Claudin association with CD81 defines hepatitis C virus entry. J Biol Chem. 2010; 285:21092-21102. [PubMed: 20375010]

173. Harris HJ, Farquhar MJ, Mee CJ, Davis C, Reynolds GM, Jennings A, Hu K, Yuan F, Deng H, Hubscher SG, Han JH, Balfe P, McKeating JA. CD81 and claudin 1 coreceptor association: Role in hepatitis C virus entry. J Virol. 2008; 82:5007-5020. [PubMed: 18337570]

174. Harris TJ, Tepass U. Adherens junctions: From molecules to morphogenesis. Nat Rev Mol Cell Biol. 2010; 11:502-514. [PubMed: 20571587]

175. Hata S, Namae M, Nishina H. Liver development and regeneration: From laboratory study to clinical therapy. Dev Growth Differ. 2007; 49:163-170. [PubMed: 17335437]

176. Haussinger D, Kurz AK, Wettstein M, Graf D, Vom Dahl S, Schliess F. Involvement of integrins and Src in tauroursodeoxycholate-induced and swelling-induced choleresis. Gastroenterology. 2003; 124:1476-1487. [PubMed: 12730886]

177. Hayhurst GP, Strick-Marchand H, Mulet C, Richard AF, Morosan S, Kremsdorf D, Weiss MC. Morphogenetic competence of HNF4 alpha-deficient mouse hepatic cells. J Hepatol. 2008; 49:384-395. [PubMed: 18617288]

178. Heilker R, Manning-Krieg U, Zuber JF, Spiess M. In vitro binding of clathrin adaptors to sorting signals correlates with endocytosis and basolateral sorting. Embo J. 1996; 15:2893-2899. [PubMed: 8654387]

179. Hellman NE, Gitlin JD. Ceruloplasmin metabolism and function. Annu Rev Nutr. 2002; 22:439458. [PubMed: 12055353]

180. Hemery I, Durand-Schneider AM, Feldmann G, Vaerman JP, Maurice M. The transcytotic pathway of an apical plasma membrane protein (B10) in hepatocytes is similar to that of IgA and occurs via a tubular pericentriolar compartment. J Cell Sci. 1996; 109(Pt 6):1215-1227. [PubMed: 8799812]

181. Henry L, Sheff DR. Rab8 regulates basolateral secretory, but not recycling, traffic at the recycling endosome. Mol Biol Cell. 2008; 19:2059-2068. [PubMed: 18287531]

182. Herrema H, Czajkowska D, Theard D, van der Wouden JM, Kalicharan D, Zolghadr B, Hoekstra D, van Ijzendoorn SC. Rho kinase, myosin-II, and p42/44 MAPK control extracellular matrixmediated apical bile canalicular lumen morphogenesis in HepG2 cells. Mol Biol Cell. 2006; 17:3291-3303. [PubMed: 16687572] 
183. Herrmann J, Abriss B, van de Leur E, Weiskirchen S, Gressner AM, Weiskirchen R. Comparative analysis of adenoviral transgene delivery via tail or portal vein into rat liver. Arch Virol. 2004; 149:1611-1617. [PubMed: 15290384]

184. Hirano T, Nakajima K, Hibi M. Signaling mechanisms through gp130: A model of the cytokine system. Cytokine Growth Factor Rev. 1997; 8:241-252. [PubMed: 9620640]

185. Hobbs HH, Brown MS, Goldstein JL. Molecular genetics of the LDL receptor gene in familial hypercholesterolemia. Hum Mutat. 1992; 1:445-466. [PubMed: 1301956]

186. Hoefs JC, Renner IG, Askhcavai M, Redeker AG. Hepatitis B surface antigen in pancreatic and biliary secretions. Gastroenterology. 1980; 79:191-194. [PubMed: 7399225]

187. Hoehme S, Brulport M, Bauer A, Bedawy E, Schormann W, Hermes M, Puppe V, Gebhardt R, Zellmer S, Schwarz M, Bockamp E, Timmel T, Hengstler JG, Drasdo D. Prediction and validation of cell alignment along microvessels as order principle to restore tissue architecture in liver regeneration. Proc Natl Acad Sci U S A. 2010; 107:10371-10376. [PubMed: 20484673]

188. Hoekstra D, Tyteca D, van ISC. The subapical compartment: A traffic center in membrane polarity development. J Cell Sci. 2004; 117:2183-2192. [PubMed: 15126620]

189. Hua W, Sheff D, Toomre D, Mellman I. Vectorial insertion of apical and basolateral membrane proteins in polarized epithelial cells revealed by quantitative 3D live cell imaging. J Cell Biol. 2006; 172:1035-1044. [PubMed: 16567501]

190. Huber LA, Pimplikar S, Parton RG, Virta H, Zerial M, Simons K. Rab8, a small GTPase involved in vesicular traffic between the TGN and the basolateral plasma membrane. J Cell Biol. 1993; 123:35-45. [PubMed: 8408203]

191. Huber O. Structure and function of desmosomal proteins and their role in development and disease. Cell Mol Life Sci. 2003; 60:1872-1890. [PubMed: 14523549]

192. Hughes RC. Galectins in kidney development. Glycoconj J. 2004; 19:621-629. [PubMed: 14758088]

193. Hughes RC, Stamatoglou SC. Adhesive interactions and the metabolic activity of hepatocytes. J Cell Sci Suppl. 1987; 8:273-291. [PubMed: 3332663]

194. Hunter MP, Wilson CM, Jiang X, Cong R, Vasavada H, Kaestner KH, Bogue CW. The homeobox gene Hhex is essential for proper hepatoblast differentiation and bile duct morphogenesis. Dev Biol. 2007; 308:355-367. [PubMed: 17580084]

195. Hunziker W, Male P, Mellman I. Differential microtubule requirements for transcytosis in MDCK cells. EMBO J. 1990; 9:3515-3525. [PubMed: 2170116]

196. Hurd DD, Kemphues KJ. PAR-1 is required for morphogenesis of the Caenorhabditis elegans vulva. Dev Biol. 2003; 253:54-65. [PubMed: 12490197]

197. Hurley RL, Anderson KA, Franzone JM, Kemp BE, Means AR, Witters LA. The Ca2+/ calmodulin-dependent protein kinase kinases are AMP-activated protein kinase kinases. J Biol Chem. 2005; 280:29060-29066. [PubMed: 15980064]

198. Hutagalung AH, Novick PJ. Role of Rab GTPases in membrane traffic and cell physiology. Physiol Rev. 2011; 91:119-149. [PubMed: 21248164]

199. Ihrke G, Martin GV, Shanks MR, Schrader M, Schroer TA, Hubbard AL. Apical plasma membrane proteins and endolyn-78 travel through a subapical compartment in polarized WIF-B hepatocytes. J Cell Biol. 1998; 141:115-133. [PubMed: 9531552]

200. Ihrke G, Neufeld EB, Meads T, Shanks MR, Cassio D, Laurent M, Schroer TA, Pagano RE, Hubbard AL. WIF-B cells: An in vitro model for studies of hepatocyte polarity. J Cell Biol. 1993; 123:1761-1775. [PubMed: 7506266]

201. Ikonen E, Tagaya M, Ullrich O, Montecucco C, Simons K. Different requirements for NSF, SNAP, and Rab proteins in apical and basolateral transport in MDCK cells. Cell. 1995; 81:571580. [PubMed: 7758111]

202. Imhof BA, Vollmers HP, Goodman SL, Birchmeier W. Cell-cell interaction and polarity of epithelial cells: Specific perturbation using a monoclonal antibody. Cell. 1983; 35:667-675. [PubMed: 6652682]

203. In JG, Ihrke G, Tuma PL. Analysis of polarized membrane traffic in hepatocytes and hepatic cell lines. Curr Protoc Cell Biol. 2012; 15:15-17. 
204. In JG, Tuma PL. MAL2 selectively regulates polymeric IgA receptor delivery from the Golgi to the plasma membrane in WIF-B cells. Traffic. 2010; 11:1056-1066. [PubMed: 20444237]

205. Ito Y, Matsui T, Kamiya A, Kinoshita T, Miyajima A. Retroviral gene transfer of signaling molecules into murine fetal hepatocytes defines distinct roles for the STAT3 and ras pathways during hepatic development. Hepatology. 2000; 32:1370-1376. [PubMed: 11093744]

206. Iverson HA, Fox D III, Nadler LS, Klevit RE, Nathanson NM. Identification and structural determination of the $\mathrm{M}(3)$ muscarinic acetylcholine receptor basolateral sorting signal. J Biol Chem. 2005; 280:24568-24575. [PubMed: 15870063]

207. Jaichandran S, Yap ST, Khoo AB, Ho LP, Tien SL, Kon OL. In vivo liver electroporation: Optimization and demonstration of therapeutic efficacy. Hum Gene Ther. 2006; 17:362-375. [PubMed: 16544985]

208. Jansen M, Ten Klooster JP, Offerhaus GJ, Clevers H. LKB1 and AMPK family signaling: The intimate link between cell polarity and energy metabolism. Physiol Rev. 2009; 89:777-798. [PubMed: 19584313]

209. Jarnagin WR, Rockey DC, Koteliansky VE, Wang SS, Bissell DM. Expression of variant fibronectins in wound healing: Cellular source and biological activity of the EIIIA segment in rat hepatic fibrogenesis. J Cell Biol. 1994; 127:2037-2048. [PubMed: 7806580]

210. Jaulin F, Xue X, Rodriguez-Boulan E, Kreitzer G. Polarization-dependent selective transport to the apical membrane by KIF5B in MDCK cells. Dev Cell. 2007; 13:511-522. [PubMed: 17925227]

211. Jenne DE, Tschopp J. Clusterin: The intriguing guises of a widely expressed glycoprotein. Trends Biochem Sci. 1992; 17:154-159. [PubMed: 1585460]

212. Johnson C, Tinti M, Wood NT, Campbell DG, Toth R, Dubois F, Geraghty KM, Wong BH, Brown LJ, Tyler J, Gernez A, Chen S, Synowsky S, MacKintosh C. Visualization and biochemical analyses of the emerging mammalian 14-3-3-phosphoproteome. Mol Cell Proteomics. 2011; 10:M110.005751 1-15.

213. Jones AL, Hradek GT, Schmucker DL, Underdown BJ. The fate of polymeric and secretory immunoglobulin A after retrograde infusion into the common bile duct in rats. Hepatology. 1984; 4:1173-1183. [PubMed: 6500510]

214. Jung J, Zheng M, Goldfarb M, Zaret KS. Initiation of mammalian liver development from endoderm by fibroblast growth factors. Science. 1999; 284:1998-2003. [PubMed: 10373120]

215. Kallay LM, McNickle A, Brennwald PJ, Hubbard AL, Braiterman LT. Scribble associates with two polarity proteins, Lgl2 and Vang12, via distinct molecular domains. J Cell Biochem. 2006; 99:647-664. [PubMed: 16791850]

216. Kamiya A, Gonzalez FJ. TNF-alpha regulates mouse fetal hepatic maturation induced by oncostatin M and extracellular matrices. Hepatology. 2004; 40:527-536. [PubMed: 15349890]

217. Kamiya A, Inoue Y, Gonzalez FJ. Role of the hepatocyte nuclear factor 4alpha in control of the pregnane X receptor during fetal liver development. Hepatology. 2003; 37:1375-1384. [PubMed: 12774017]

218. Kamiya A, Kinoshita T, Miyajima A. Oncostatin M and hepatocyte growth factor induce hepatic maturation via distinct signaling pathways. FEBS Lett. 2001; 492:90-94. [PubMed: 11248243]

219. Kamiya A, Kojima N, Kinoshita T, Sakai Y, Miyaijma A. Maturation of fetal hepatocytes in vitro by extracellular matrices and oncostatin M: Induction of tryptophan oxygenase. Hepatology. 2002; 35:1351-1359. [PubMed: 12029620]

220. Karasaki S. Subcellular localization of surface adenosine triphosphatase activity in preneoplastic liver parenchyma. Cancer Res. 1972; 32:1703-1712. [PubMed: 4339748]

221. Karasaki S. Cell proliferation and subcellular localization of alkaline phosphatase activity in rat liver parenchyma during azo dye carcinogenesis. Cancer Res. 1975; 35:482-491. [PubMed: 803869]

222. Karlsson R, Pedersen ED, Wang Z, Brakebusch C. Rho GTPase function in tumorigenesis. Biochim Biophys Acta. 2009; 1796:91-98. [PubMed: 19327386]

223. Kawahara H, French SW. Role of cytoskeleton in canalicular contraction in cultured differentiated hepatocytes. Am J Pathol. 1990; 136:521-532. [PubMed: 1690509] 
224. Keller P, Simons K. Cholesterol is required for surface transport of influenza virus hemagglutinin. J Cell Biol. 1998; 140:1357-1367. [PubMed: 9508769]

225. Keller P, Toomre D, Diaz E, White J, Simons K. Multicolour imaging of post-Golgi sorting and trafficking in live cells. Nat Cell Biol. 2001; 3:140-149. [PubMed: 11175746]

226. Kelly JH, Darlington GJ. Modulation of the liver specific phenotype in the human hepatoblastoma line Hep G2. In Vitro Cell Dev Biol. 1989; 25:217-222. [PubMed: 2466032]

227. Kemphues KJ, Priess JR, Morton DG, Cheng NS. Identification of genes required for cytoplasmic localization in early C. elegans embryos. Cell. 1988; 52:311-320. [PubMed: 3345562]

228. Kenney SM, Cox DW. Sequence variation database for the Wilson disease copper transporter, ATP7B. Hum Mutat. 2007; 28:1171-1177. [PubMed: 17680703]

229. Kikuchi S, Hata M, Fukumoto K, Yamane Y, Matsui T, Tamura A, Yonemura S, Yamagishi H, Keppler D, Tsukita S. Radixin deficiency causes conjugated hyperbilirubinemia with loss of Mrp2 from bile canalicular membranes. Nat Genet. 2002; 31:320-325. [PubMed: 12068294]

230. Kipp H, Arias IM. Newly synthesized canalicular ABC transporters are directly targeted from the Golgi to the hepatocyte apical domain in rat liver. J Biol Chem. 2000; 275:15917-15925. [PubMed: 10748167]

231. Kipp H, Pichetshote N, Arias IM. Transporters on demand: Intrahepatic pools of canalicular ATP binding cassette transporters in rat liver. J Biol Chem. 2001; 276:7218-7224. [PubMed: 11113123]

232. Knittel T, Schuppan D, Meyer zum Buschenfelde KH, Ramadori G. Differential expression of collagen types I, III, and IV by fat-storing (Ito) cells in vitro. Gastroenterology. 1992; 102:17241735. [PubMed: 1373696]

233. Kocher O, Krieger M. Role of the adaptor protein PDZK1 in controlling the HDL receptor SR-BI. Curr Opin Lipidol. 2009; 20:236-241. [PubMed: 19421056]

234. Kodama Y, Hijikata M, Kageyama R, Shimotohno K, Chiba T. The role of notch signaling in the development of intrahepatic bile ducts. Gastroenterology. 2004; 127:1775-1786. [PubMed: 15578515]

235. Koivisto UM, Hubbard AL, Mellman I. A novel cellular phenotype for familial hypercholesterolemia due to a defect in polarized targeting of LDL receptor. Cell. 2001; 105:575-585. [PubMed: 11389828]

236. Koivisto UM, Viikari JS, Kontula K. Molecular characterization of minor gene rearrangements in Finnish patients with heterozygous familial hypercholesterolemia: Identification of two common missense mutations (Gly823-->Asp and Leu380-->His) and eight rare mutations of the LDL receptor gene. Am J Hum Genet. 1995; 57:789-797. [PubMed: 7573037]

237. Kojima T, Murata M, Go M, Spray DC, Sawada N. Connexins induce and maintain tight junctions in epithelial cells. J Membr Biol. 2007; 217:13-19. [PubMed: 17568974]

238. Kojima T, Yamamoto T, Murata M, Chiba H, Kokai Y, Sawada N. Regulation of the bloodbiliary barrier: Interaction between gap and tight junctions in hepatocytes. Med Electron Microsc. 2003; 36:157-164. [PubMed: 14505059]

239. Kondo Y, Nakajima T. Pseudoglandular hepatocellular carcinoma. A morphogenetic study. Cancer. 1987; 60:1032-1037. [PubMed: 2440554]

240. Kondoh N, Hada A, Ryo A, Shuda M, Arai M, Matsubara O, Kimura F, Wakatsuki T, Yamamoto M. Activation of Galectin-1 gene in human hepatocellular carcinoma involves methylationsensitive complex formations at the transcriptional upstream and downstream elements. Int $\mathbf{J}$ Oncol. 2003; 23:1575-1583. [PubMed: 14612929]

241. Konopka G, Tekiela J, Iverson M, Wells C, Duncan SA. Junctional adhesion molecule-A is critical for the formation of pseudocanaliculi and modulates E-cadherin expression in hepatic cells. J Biol Chem. 2007; 282:28137-28148. [PubMed: 17623668]

242. Kreitzer G, Marmorstein A, Okamoto P, Vallee R, Rodriguez-Boulan E. Kinesin and dynamin are required for post-Golgi transport of a plasma-membrane protein. Nat Cell Biol. 2000; 2:125-127. [PubMed: 10655593]

243. Kreitzer G, Schmoranzer J, Low SH, Li X, Gan Y, Weimbs T, Simon SM, Rodriguez-Boulan E. Three-dimensional analysis of post-Golgi carrier exocytosis in epithelial cells. Nat Cell Biol. 2003; 5:126-136. [PubMed: 12545172] 
244. Kroschewski R, Hall A, Mellman I. Cdc42 controls secretory and endocytic transport to the basolateral plasma membrane of MDCK cells. Nat Cell Biol. 1999; 1:8-13. [PubMed: 10559857]

245. Kurz AK, Graf D, Schmitt M, Vom Dahl S, Haussinger D. Tauroursodesoxycholate-induced choleresis involves $\mathrm{p} 38(\mathrm{MAPK})$ activation and translocation of the bile salt export pump in rats. Gastroenterology. 2001; 121:407-419. [PubMed: 11487550]

246. Kusakabe M, Nishida E. The polarity-inducing kinase Par-1 controls Xenopus gastrulation in cooperation with 14-3-3 and aPKC. Embo J. 2004; 23:4190-4201. [PubMed: 15343271]

247. La Fontaine S, Mercer JF. Trafficking of the copper-ATPases, ATP7A and ATP7B: Role in copper homeostasis. Arch Biochem Biophys. 2007; 463:149-167. [PubMed: 17531189]

248. Lafont F, Lecat S, Verkade P, Simons K. Annexin XIIIb associates with lipid microdomains to function in apical delivery. J Cell Biol. 1998; 142:1413-1427. [PubMed: 9744874]

249. Lafont F, Verkade P, Galli T, Wimmer C, Louvard D, Simons K. Raft association of SNAP receptors acting in apical trafficking in Madin-Darby canine kidney cells. Proc Natl Acad Sci U S A. 1999; 96:3734-3738. [PubMed: 10097106]

250. Lam P, Pearson CL, Soroka CJ, Xu S, Mennone A, Boyer JL. Levels of plasma membrane expression in progressive and benign mutations of the bile salt export pump (Bsep/Abcb11) correlate with severity of cholestatic diseases. Am J Physiol Cell Physiol. 2007; 293:C1709_ C1716. [PubMed: 17855769]

251. Lam SH, Wu YL, Vega VB, Miller LD, Spitsbergen J, Tong Y, Zhan H, Govindarajan KR, Lee S, Mathavan S, Murthy KR, Buhler DR, Liu ET, Gong Z. Conservation of gene expression signatures between zebrafish and human liver tumors and tumor progression. Nat Biotechnol. 2006; 24:73-75. [PubMed: 16327811]

252. Landmann L, Meier PJ, Bianchi L. Bile duct ligation-induced redistribution of canalicular antigen in rat hepatocyte plasma membranes demonstrated by immunogold quantitation. Histochemistry. 1990; 94:373-379. [PubMed: 2228735]

253. Larkin JM, Coleman H, Espinosa A, Levenson A, Park MS, Woo B, Zervoudakis A, Tinh V. Intracellular accumulation of pIgA-R and regulators of transcytotic trafficking in cholestatic rat hepatocytes. Hepatology. 2003; 38:1199-1209. [PubMed: 14578858]

254. Larkin JM, Woo B, Balan V, Marks DL, Oswald BJ, LaRusso NF, McNiven MA. Rab3D, a small GTP-binding protein implicated in regulated secretion, is associated with the transcytotic pathway in rat hepatocytes. Hepatology. 2000; 32:348-356. [PubMed: 10915742]

255. Larue L, Ohsugi M, Hirchenhain J, Kemler R. E-cadherin null mutant embryos fail to form a trophectoderm epithelium. Proc Natl Acad Sci U S A. 1994; 91:8263-8267. [PubMed: 8058792]

256. Laurent T, Murase D, Tsukioka S, Matsuura T, Nagamori S, Oda H. A novel human hepatoma cell line, FLC-4, exhibits highly enhanced liver differentiation functions through the 3dimensional cell shape. J Cell Physiol. 2011; 227:2898-2906. [PubMed: 21960466]

257. Lazarevich NL, Al'pern DV. Hepatocyte nuclear factor 4 (HNF4) in epithelial development and carcinogenesis. Mol Biol (Mosk). 2008; 42:786-797. [PubMed: 18988528]

258. Lazarevich NL, Cheremnova OA, Varga EV, Ovchinnikov DA, Kudrjavtseva EI, Morozova OV, Fleishman DI, Engelhardt NV, Duncan SA. Progression of HCC in mice is associated with a downregulation in the expression of hepatocyte nuclear factors. Hepatology. 2004; 39:10381047. [PubMed: 15057908]

259. Lazaro CA, Croager EJ, Mitchell C, Campbell JS, Yu C, Foraker J, Rhim JA, Yeoh GC, Fausto N. Establishment, characterization, and long-term maintenance of cultures of human fetal hepatocytes. Hepatology. 2003; 38:1095-1106. [PubMed: 14578848]

260. Le Borgne R, Griffiths G, Hoflack B. Mannose 6-phosphate receptors and ADP-ribosylation factors cooperate for high affinity interaction of the AP-1 Golgi assembly proteins with membranes. J Biol Chem. 1996; 271:2162-2170. [PubMed: 8567674]

261. LeCluyse EL, Audus KL, Hochman JH. Formation of extensive canalicular networks by rat hepatocytes cultured in collagen-sandwich configuration. Am J Physiol. 1994; 266:C1764C1774. [PubMed: 8023906]

262. Lee TK, Poon RT, Yuen AP, Ling MT, Kwok WK, Wang XH, Wong YC, Guan XY, Man K, Chau KL, Fan ST. Twist overexpression correlates with hepatocellular carcinoma metastasis 
through induction of epithelial-mesenchymal transition. Clin Cancer Res. 2006; 12:5369-5376. [PubMed: 17000670]

263. Lemaigre FP. Development of the biliary tract. Mech Dev. 2003; 120:81-87. [PubMed: 12490298]

264. Lewis DL, Wolff JA. Systemic siRNA delivery via hydrodynamic intravascular injection. Adv Drug Deliv Rev. 2007; 59:115-123. [PubMed: 17442446]

265. Li J, Ning G, Duncan SA. Mammalian hepatocyte differentiation requires the transcription factor HNF-4alpha. Genes Dev. 2000; 14:464-474. [PubMed: 10691738]

266. Li X, Low SH, Miura M, Weimbs T. SNARE expression and localization in renal epithelial cells suggest mechanism for variability of trafficking phenotypes. Am J Physiol Renal Physiol. 2002; 283:F1111-F1122. [PubMed: 12372788]

267. Limaye PB, Bowen WC, Orr AV, Luo J, Tseng GC, Michalopoulos GK. Mechanisms of hepatocyte growth factor-mediated and epidermal growth factor-mediated signaling in transdifferentiation of rat hepatocytes to biliary epithelium. Hepatology. 2008; 47:1702-1713. [PubMed: 18398918]

268. Linder MC, Wooten L, Cerveza P, Cotton S, Shulze R, Lomeli N. Copper transport. Am J Clin Nutr. 1998; 67:965S-971S. [PubMed: 9587137]

269. Lisanti MP, Caras IW, Davitz MA, Rodriguez-Boulan E. A glycophospholipid membrane anchor acts as an apical targeting signal in polarized epithelial cells. J Cell Biol. 1989; 109:2145-2156. [PubMed: 2478564]

270. Lisanti MP, Le Bivic A, Sargiacomo M, Rodriguez-Boulan E. Steady-state distribution and biogenesis of endogenous Madin-Darby canine kidney glycoproteins: Evidence for intracellular sorting and polarized cell surface delivery. J Cell Biol. 1989; 109:2117-2127. [PubMed: 2808522]

271. Little JM, Richey JE, Van Thiel DH, Lester R. Taurocholate pool size and distribution in the fetal rat. J Clin Invest. 1979; 63:1042-1049. [PubMed: 447826]

272. Little JM, Smallwood RA, Lester R, Piasecki GJ, Jackson BT. Bile-salt metabolism in the primate fetus. Gastroenterology. 1975; 69:1315-1320. [PubMed: 1193330]

273. Liu J, Guo W. The exocyst complex in exocytosis and cell migration. Protoplasma. 2011; 249:587-597. [PubMed: 21997494]

274. Liu X, LeCluyse EL, Brouwer KR, Gan LS, Lemasters JJ, Stieger B, Meier PJ, Brouwer KL. Biliary excretion in primary rat hepatocytes cultured in a collagen-sandwich configuration. Am J Physiol. 1999; 277:G12-G21. [PubMed: 10409146]

275. Lizcano JM, Goransson O, Toth R, Deak M, Morrice NA, Boudeau J, Hawley SA, Udd L, Makela TP, Hardie DG, Alessi DR. LKB1 is a master kinase that activates 13 kinases of the AMPK subfamily, including MARK/PAR-1. Embo J. 2004; 23:833-843. [PubMed: 14976552]

276. Low SH, Chapin SJ, Weimbs T, Komuves LG, Bennett MK, Mostov KE. Differential localization of syntaxin isoforms in polarized Madin-Darby canine kidney cells. Mol Biol Cell. 1996; 7:2007-2018. [PubMed: 8970161]

277. Low SH, Chapin SJ, Wimmer C, Whiteheart SW, Komuves LG, Mostov KE, Weimbs T. The SNARE machinery is involved in apical plasma membrane trafficking in MDCK cells. J Cell Biol. 1998; 141:1503-1513. [PubMed: 9647644]

278. Low SH, Li X, Miura M, Kudo N, Quinones B, Weimbs T. Syntaxin 2 and endobrevin are required for the terminal step of cytokinesis in mammalian cells. Dev Cell. 2003; 4:753-759. [PubMed: 12737809]

279. Low SH, Roche PA, Anderson HA, van Ijzendoorn SC, Zhang M, Mostov KE, Weimbs T. Targeting of SNAP-23 and SNAP-25 in polarized epithelial cells. J Biol Chem. 1998; 273:34223430. [PubMed: 9452464]

280. Low SH, Wong SH, Tang BL, Subramaniam VN, Hong WJ. Apical cell surface expression of rat dipeptidyl peptidase IV in transfected Madin-Darby canine kidney cells. J Biol Chem. 1991; 266:13391-13396. [PubMed: 1677006]

281. Lozach PY, Lortat-Jacob H, de Lacroix de Lavalette A, Staropoli I, Foung S, Amara A, Houles C, Fieschi F, Schwartz O, Virelizier JL, Arenzana-Seisdedos F, Altmeyer R. DC-SIGN and L-SIGN 
are high affinity binding receptors for hepatitis C virus glycoprotein E2. J Biol Chem. 2003; 278:20358-20366. [PubMed: 12609975]

282. Lozier J, McCright B, Gridley T. Notch signaling regulates bile duct morphogenesis in mice. PLoS One. 2008; 3:e1851. [PubMed: 18365007]

283. Lozoya OA, Wauthier E, Turner RA, Barbier C, Prestwich GD, Guilak F, Superfine R, Lubkin SR, Reid LM. Regulation of hepatic stem/progenitor phenotype by microenvironment stiffness in hydrogel models of the human liver stem cell niche. Biomaterials. 2011; 32:7389-7402. [PubMed: 21788068]

284. Lutsenko S, Gupta A, Burkhead JL, Zuzel V. Cellular multitasking: The dual role of human CuATPases in cofactor delivery and intracellular copper balance. Arch Biochem Biophys. 2008; 476:22-32. [PubMed: 18534184]

285. Madrid R, Aranda JF, Rodriguez-Fraticelli AE, Ventimiglia L, Andres-Delgado L, Shehata M, Fanayan S, Shahheydari H, Gomez S, Jimenez A, Martin-Belmonte F, Byrne JA, Alonso MA. The formin INF2 regulates basolateral-to-apical transcytosis and lumen formation in association with Cdc42 and MAL2. Dev Cell. 2010; 18:814-827. [PubMed: 20493814]

286. Madrid R, Le Maout S, Barrault MB, Janvier K, Benichou S, Merot J. Polarized trafficking and surface expression of the AQP4 water channel are coordinated by serial and regulated interactions with different clathrin-adaptor complexes. Embo J. 2001; 20:7008-7021. [PubMed: 11742978]

287. Magal LG, Yaffe Y, Shepshelovich J, Aranda JF, de Marco Mdel C, Gaus K, Alonso MA, Hirschberg K. Clustering and lateral concentration of raft lipids by the MAL protein. Mol Biol Cell. 2009; 20:3751-3762. [PubMed: 19553470]

288. Maheshwari A, Ray S, Thuluvath PJ. Acute hepatitis C. Lancet. 2008; 372:321-332. [PubMed: 18657711]

289. Manns MP, Wedemeyer H, Cornberg M. Treating viral hepatitis C: Efficacy, side effects, and complications. Gut. 2006; 55:1350-1359. [PubMed: 16905701]

290. Marbet P, Rahner C, Stieger B, Landmann L. Quantitative microscopy reveals 3D organization and kinetics of endocytosis in rat hepatocytes. Microsc Res Tech. 2006; 69:693-707. [PubMed: 16886231]

291. Martin-Belmonte F, Gassama A, Datta A, Yu W, Rescher U, Gerke V, Mostov K. PTENmediated apical segregation of phosphoinositides controls epithelial morphogenesis through Cdc42. Cell. 2007; 128:383-397. [PubMed: 17254974]

292. Martinez-Hernandez A. The hepatic extracellular matrix. II. Electron immunohistochemical studies in rats with CCl4-induced cirrhosis. Lab Invest. 1985; 53:166-186. [PubMed: 3894794]

293. Martinez-Hernandez A, Amenta PS. The hepatic extracellular matrix. I. Components and distribution in normal liver. Virchows Arch A Pathol Anat Histopathol. 1993; 423:1-11. [PubMed: 8212529]

294. Martinez-Hernandez A, Amenta PS. The hepatic extracellular matrix. II. Ontogenesis, regeneration and cirrhosis. Virchows Arch A Pathol Anat Histopathol. 1993; 423:77-84. [PubMed: 8212543]

295. Martinez-Hernandez A, Amenta PS. The extracellular matrix in hepatic regeneration. FASEB J. 1995; 9:1401-1410. [PubMed: 7589981]

296. Martinez-Hernandez A, Delgado FM, Amenta PS. The extracellular matrix in hepatic regeneration. Localization of collagen types I, III, IV, laminin, and fibronectin. Lab Invest. 1991; 64:157-166. [PubMed: 1997730]

297. Matsui T, Kinoshita T, Morikawa Y, Tohya K, Katsuki M, Ito Y, Kamiya A, Miyajima A. K-Ras mediates cytokine-induced formation of E-cadherin-based adherens junctions during liver development. Embo J. 2002; 21:1021-1030. [PubMed: 11867530]

298. Matter A, Orci L, Rouiller C. A study on the permeability barriers between Disse's space and the bile canaliculus. J Ultrastruct Res. 1969; 11:1-71. [PubMed: 4187928]

299. Matter K, Hunziker W, Mellman I. Basolateral sorting of LDL receptor in MDCK cells: The cytoplasmic domain contains two tyrosine-dependent targeting determinants. Cell. 1992; 71:741753. [PubMed: 1423629] 
300. Matter K, Yamamoto EM, Mellman I. Structural requirements and sequence motifs for polarized sorting and endocytosis of LDL and Fc receptors in MDCK cells. J Cell Biol. 1994; 126:9911004. [PubMed: 8051216]

301. Maxfield FR, McGraw TE. Endocytic recycling. Nat Rev Mol Cell Biol. 2004; 5:121-132. [PubMed: 15040445]

302. McCaffrey LM, Macara IG. Widely conserved signaling pathways in the establishment of cell polarity. Cold Spring Harb Perspect Biol. 2009; 1:a001370. [PubMed: 20066082]

303. McClelland R, Wauthier E, Uronis J, Reid L. Gradients in the liver's extracellular matrix chemistry from periportal to pericentral zones: Influence on human hepatic progenitors. Tissue Eng Part A. 2008; 14:59-70. [PubMed: 18333805]

304. McNew JA, Parlati F, Fukuda R, Johnston RJ, Paz K, Paumet F, Sollner TH, Rothman JE. Compartmental specificity of cellular membrane fusion encoded in SNARE proteins. Nature. 2000; 407:153-159. [PubMed: 11001046]

305. McNiven MA, Wolkoff AW, Hubbard A. A stimulus needed for the study of membrane traffic in hepatocytes. Hepatology. 2009; 50:345-348. [PubMed: 19575459]

306. Mee CJ, Farquhar MJ, Harris HJ, Hu K, Ramma W, Ahmed A, Maurel P, Bicknell R, Balfe P, McKeating JA. Hepatitis $\mathrm{C}$ virus infection reduces hepatocellular polarity in a vascular endothelial growth factor-dependent manner. Gastroenterology. 2010; 138:1134-1142. [PubMed: 19944696]

307. Mee CJ, Harris HJ, Farquhar MJ, Wilson G, Reynolds G, Davis C, van ISC, Balfe P, McKeating JA. Polarization restricts hepatitis C virus entry into HepG2 hepatoma cells. J Virol. 2009; 83:6211-6221. [PubMed: 19357163]

308. Meertens L, Bertaux C, Dragic T. Hepatitis C virus entry requires a critical postinternalization step and delivery to early endosomes via clathrin-coated vesicles. J Virol. 2006; 80:1157111578. [PubMed: 17005647]

309. Mellman I, Nelson WJ. Coordinated protein sorting, targeting and distribution in polarized cells. Nat Rev Mol Cell Biol. 2008; 9:833-845. [PubMed: 18946473]

310. Michalopoulos G, Pitot HC. Primary culture of parenchymal liver cells on collagen membranes. Morphological and biochemical observations. Exp Cell Res. 1975; 94:70-78. [PubMed: 243]

311. Michalopoulos GK, Barua L, Bowen WC. Transdifferentiation of rat hepatocytes into biliary cells after bile duct ligation and toxic biliary injury. Hepatology. 2005; 41:535-544. [PubMed: 15726663]

312. Michalopoulos GK, Bowen W, Nussler AK, Becich MJ, Howard TA. Comparative analysis of mitogenic and morphogenic effects of HGF and EGF on rat and human hepatocytes maintained in collagen gels. J Cell Physiol. 1993; 156:443-452. [PubMed: 8360254]

313. Michalopoulos GK, Bowen WC, Mule K, Lopez-Talavera JC, Mars W. Hepatocytes undergo phenotypic transformation to biliary epithelium in organoid cultures. Hepatology. 2002; 36:278283. [PubMed: 12143035]

314. Michalopoulos GK, Bowen WC, Mule K, Stolz DB. Histological organization in hepatocyte organoid cultures. Am J Pathol. 2001; 159:1877-1887. [PubMed: 11696448]

315. Michalopoulos GK, Bowen WC, Zajac VF, Beer-Stolz D, Watkins S, Kostrubsky V, Strom SC. Morphogenetic events in mixed cultures of rat hepatocytes and nonparenchymal cells maintained in biological matrices in the presence of hepatocyte growth factor and epidermal growth factor. Hepatology. 1999; 29:90-100. [PubMed: 9862855]

316. Michalopoulos GK, DeFrances MC. Liver regeneration. Science. 1997; 276:60-66. [PubMed: 9082986]

317. Misfeldt DS, Hamamoto ST, Pitelka DR. Transepithelial transport in cell culture. Proc Natl Acad Sci U S A. 1976; 73:1212-1216. [PubMed: 1063404]

318. Misra S, Ujhazy P, Gatmaitan Z, Varticovski L, Arias IM. The role of phosphoinositide 3-kinase in taurocholate-induced trafficking of ATP-dependent canalicular transporters in rat liver. J Biol Chem. 1998; 273:26638-26644. [PubMed: 9756904]

319. Misra S, Ujhazy P, Varticovski L, Arias IM. Phosphoinositide 3-kinase lipid products regulate ATP-dependent transport by sister of P-glycoprotein and multidrug resistance associated protein 
2 in bile canalicular membrane vesicles. Proc Natl Acad Sci U S A. 1999; 96:5814-5819. [PubMed: 10318967]

320. Misra S, Varticovski L, Arias IM. Mechanisms by which cAMP increases bile acid secretion in rat liver and canalicular membrane vesicles. Am J Physiol Gastrointest Liver Physiol. 2003; 285:G316-G324. [PubMed: 12702492]

321. Miyajima A, Kinoshita T, Tanaka M, Kamiya A, Mukouyama Y, Hara T. Role of Oncostatin M in hematopoiesis and liver development. Cytokine Growth Factor Rev. 2000; 11:177-183. [PubMed: 10817961]

322. Mochizuki K, Kagawa T, Numari A, Harris MJ, Itoh J, Watanabe N, Mine T, Arias IM. Two Nlinked glycans are required to maintain the transport activity of the bile salt export pump (ABCB11) in MDCK II cells. Am J Physiol Gastrointest Liver Physiol. 2007; 292:G818-G828. [PubMed: 17082223]

323. Moens CB, Donn TM, Wolf-Saxon ER, Ma TP. Reverse genetics in zebrafish by TILLING. Brief Funct Genomic Proteomic. 2008; 7:454-459. [PubMed: 19028802]

324. Montesano R, Friend DS, Perrelet A, Orci L. In vivo assembly of tight junctions in fetal rat liver. J Cell Biol. 1975; 67:310-319. [PubMed: 1194351]

325. Mostov KE. Transepithelial transport of immunoglobulins. Annu Rev Immunol. 1994; 12:63-84. [PubMed: 8011293]

326. Motta A, Amodeo P, Fucile P, Castiglione Morelli MA, Bremnes B, Bakke O. A new triplestranded alpha-helical bundle in solution: The assembling of the cytosolic tail of MHC-associated invariant chain. Structure. 1997; 5:1453-1464. [PubMed: 9384561]

327. Mukhopadhyay A, Nieves E, Che FY, Wang J, Jin L, Murray JW, Gordon K, Angeletti RH, Wolkoff AW. Proteomic analysis of endocytic vesicles: Rab1a regulates motility of early endocytic vesicles. J Cell Sci. 2011; 124:765-775. [PubMed: 21303926]

328. Musch A. Microtubule organization and function in epithelial cells. Traffic. 2004; 5:1-9. [PubMed: 14675420]

329. Musch A, Cohen D, Kreitzer G, Rodriguez-Boulan E. cdc42 regulates the exit of apical and basolateral proteins from the trans-Golgi network. Embo J. 2001; 20:2171-2179. [PubMed: 11331583]

330. Musch A, Cohen D, Rodriguez-Boulan E. Myosin II is involved in the production of constitutive transport vesicles from the TGN. J Cell Biol. 1997; 138:291-306. [PubMed: 9230072]

331. Musch A, Xu H, Shields D, Rodriguez-Boulan E. Transport of vesicular stomatitis virus G protein to the cell surface is signal mediated in polarized and nonpolarized cells. J Cell Biol. 1996; 133:543-558. [PubMed: 8636230]

332. Nahmias Y, Berthiaume F, Yarmush ML. Integration of technologies for hepatic tissue engineering. Adv Biochem Eng Biotechnol. 2007; 103:309-329. [PubMed: 17195468]

333. Nakamoto Y, Kaneko S. Mechanisms of viral hepatitis induced liver injury. Curr Mol Med. 2003; 3:537-544. [PubMed: 14527085]

334. Nelson CM, Bissell MJ. Of extracellular matrix, scaffolds, and signaling: Tissue architecture regulates development, homeostasis, and cancer. Annu Rev Cell Dev Biol. 2006; 22:287-309. [PubMed: 16824016]

335. Ng KH, Le Goascogne C, Amborade E, Stieger B, Deschatrette J. Reversible induction of rat hepatoma cell polarity with bile acids. J Cell Sci. 2000; 113(Pt 23):4241-4251. [PubMed: 11069769]

336. Nickel W, Huber LA, Kahn RA, Kipper N, Barthel A, Fasshauer D, Soling HD. ADP ribosylation factor and a 14-kD polypeptide are associated with heparan sulfate-carrying post-trans-Golgi network secretory vesicles in rat hepatocytes. J Cell Biol. 1994; 125:721-732. [PubMed: 8188742]

337. Ning BF, Ding J, Yin C, Zhong W, Wu K, Zeng X, Yang W, Chen YX, Zhang JP, Zhang X, Wang HY, Xie WF. Hepatocyte nuclear factor 4 alpha suppresses the development of hepatocellular carcinoma. Cancer Res. 2010; 70:7640-7651. [PubMed: 20876809]

338. Nitou M, Ishikawa K, Shiojiri N. Immunohistochemical analysis of development of desminpositive hepatic stellate cells in mouse liver. J Anat. 2000; 197(Pt 4):635-646. [PubMed: 11197537] 
339. Nyasae LK, Hubbard AL, Tuma PL. Transcytotic efflux from early endosomes is dependent on cholesterol and glycosphingolipids in polarized hepatic cells. Mol Biol Cell. 2003; 14:2689_ 2705. [PubMed: 12857857]

340. Odin P, Obrink B. Dynamic expression of the cell adhesion molecule cell-CAM 105 in fetal and regenerating rat liver. Exp Cell Res. 1986; 164:103-114. [PubMed: 3514250]

341. Odin P, Obrink B. The cell-surface expression of the cell adhesion molecule cellCAM 105 in rat fetal tissues and regenerating liver. Exp Cell Res. 1988; 179:89-103. [PubMed: 3169152]

342. Odorizzi G, Pearse A, Domingo D, Trowbridge IS, Hopkins CR. Apical and basolateral endosomes of MDCK cells are interconnected and contain a polarized sorting mechanism. J Cell Biol. 1996; 135:139-152. [PubMed: 8858169]

343. Ogawa K, Medline A, Farber E. Sequential analysis of hepatic carcinogenesis: The comparative architecture of preneoplastic, malignant, prenatal, postnatal and regenerating liver. Br J Cancer. 1979; 40:782-790. [PubMed: 41564]

344. Ogawa K, Suzuki J, Mukai H, Mori M. Sequential changes of extracellular matrix and proliferation of Ito cells with enhanced expression of desmin and actin in focal hepatic injury. Am J Pathol. 1986; 125:611-619. [PubMed: 3799820]

345. Ohno H, Stewart J, Fournier MC, Bosshart H, Rhee I, Miyatake S, Saito T, Gallusser A, Kirchhausen T, Bonifacino JS. Interaction of tyrosine-based sorting signals with clathrinassociated proteins. Science. 1995; 269:1872-1875. [PubMed: 7569928]

346. Ohsugi M, Larue L, Schwarz H, Kemler R. Cell-junctional and cytoskeletal organization in mouse blastocysts lacking E-cadherin. Dev Biol. 1997; 185:261-271. [PubMed: 9187087]

347. Ossipova O, Dhawan S, Sokol S, Green JB. Distinct PAR-1 proteins function in different branches of Wnt signaling during vertebrate development. Dev Cell. 2005; 8:829-841. [PubMed: 15935773]

348. Ossipova O, Ezan J, Sokol SY. PAR-1 phosphorylates Mind bomb to promote vertebrate neurogenesis. Dev Cell. 2009; 17:222-233. [PubMed: 19686683]

349. Owen DJ, Evans PR. A structural explanation for the recognition of tyrosine-based endocytotic signals. Science. 1998; 282:1327-1332. [PubMed: 9812899]

350. Oyamada T, Hirata T, Hara M, Kudo M, Yoshikawa H, Yoshikawa T, Suzuki N. Spontaneous larval Gnathostoma nipponicum infection in frogs. J Vet Med Sci. 1998; 60:1029-1031. [PubMed: 9795906]

351. Oztan A, Rondanino C, Apodaca G. Transcytosis of polymeric immunoglobulin a in polarized Madin-Darby canine kidney cells. Methods Mol Biol. 2008; 440:157-170. [PubMed: 18369944]

352. Paladino S, Pocard T, Catino MA, Zurzolo C. GPI-anchored proteins are directly targeted to the apical surface in fully polarized MDCK cells. J Cell Biol. 2006; 172:1023-1034. [PubMed: 16549497]

353. Paladino S, Sarnataro D, Pillich R, Tivodar S, Nitsch L, Zurzolo C. Protein oligomerization modulates raft partitioning and apical sorting of GPI-anchored proteins. J Cell Biol. 2004; 167:699-709. [PubMed: 15557121]

354. Parlati F, McNew JA, Fukuda R, Miller R, Sollner TH, Rothman JE. Topological restriction of SNARE-dependent membrane fusion. Nature. 2000; 407:194-198. [PubMed: 11001058]

355. Parviz F, Matullo C, Garrison WD, Savatski L, Adamson JW, Ning G, Kaestner KH, Rossi JM, Zaret KS, Duncan SA. Hepatocyte nuclear factor 4alpha controls the development of a hepatic epithelium and liver morphogenesis. Nat Genet. 2003; 34:292-296. [PubMed: 12808453]

356. Paulusma CC, Kool M, Bosma PJ, Scheffer GL, ter Borg F, Scheper RJ, Tytgat GN, Borst P, Baas F, Oude Elferink RP. A mutation in the human canalicular multispecific organic anion transporter gene causes the Dubin-Johnson syndrome. Hepatology. 1997; 25:1539-1542. [PubMed: 9185779]

357. Peng X, Grosse B, Le Tiec B, Nicolas V, Delagebeaudeuf C, Bedda T, Decaens C, Cassio D. How to induce non-polarized cells of hepatic origin to express typical hepatocyte polarity: Generation of new highly polarized cell models with developed and functional bile canaliculi. Cell Tissue Res. 2006; 323:233-243. [PubMed: 16231191]

358. Petersen BE, Zajac VF, Michalopoulos GK. Bile ductular damage induced by methylene dianiline inhibits oval cell activation. Am J Pathol. 1997; 151:905-909. [PubMed: 9327722] 
359. Petersen BE, Zajac VF, Michalopoulos GK. Hepatic oval cell activation in response to injury following chemically induced periportal or pericentral damage in rats. Hepatology. 1998; 27:1030-1038. [PubMed: 9537443]

360. Phillips MJ, Poucell S, Oda M. Mechanisms of cholestasis. Lab Invest. 1986; 54:593-608. [PubMed: 2423777]

361. Pinto MA, Marchevsky RS, Baptista ML, de Lima MA, Pelajo-Machado M, Vitral CL, Kubelka CF, Pissurno JW, Franca MS, Schatzmayr HG, Gaspar AM. Experimental hepatitis A virus (HAV) infection in Callithrix jacchus: Early detection of HAV antigen and viral fate. Exp Toxicol Pathol. 2002; 53:413-420. [PubMed: 11930901]

362. Pinzani M. Epithelial-mesenchymal transition in chronic liver disease: Fibrogenesis or escape from death? J Hepatol. 2011; 55:459-465. [PubMed: 21320559]

363. Ploss A, Evans MJ, Gaysinskaya VA, Panis M, You H, de Jong YP, Rice CM. Human occludin is a hepatitis C virus entry factor required for infection of mouse cells. Nature. 2009; 457:882-886. [PubMed: 19182773]

364. Pocard T, Le Bivic A, Galli T, Zurzolo C. Distinct v-SNAREs regulate direct and indirect apical delivery in polarized epithelial cells. J Cell Sci. 2007; 120:3309-3320. [PubMed: 17878240]

365. Polishchuk RS, Polishchuk EV, Marra P, Alberti S, Buccione R, Luini A, Mironov AA. Correlative light-electron microscopy reveals the tubular-saccular ultrastructure of carriers operating between Golgi apparatus and plasma membrane. J Cell Biol. 2000; 148:45-58. [PubMed: 10629217]

366. Pous C, Chabin K, Drechou A, Barbot L, Phung-Koskas T, Settegrana C, Bourguet-Kondracki ML, Maurice M, Cassio D, Guyot M, Durand G. Functional specialization of stable and dynamic microtubules in protein traffic in WIF-B cells. J Cell Biol. 1998; 142:153-165. [PubMed: 9660870]

367. Puertollano R, Martin-Belmonte F, Millan J, de Marco MC, Albar JP, Kremer L, Alonso MA. The MAL proteolipid is necessary for normal apical transport and accurate sorting of the influenza virus hemagglutinin in Madin-Darby canine kidney cells. J Cell Biol. 1999; 145:141151. [PubMed: 10189374]

368. Puertollano R, Martinez-Menarguez JA, Batista A, Ballesta J, Alonso MA. An intact dilysine-like motif in the carboxyl terminus of MAL is required for normal apical transport of the influenza virus hemagglutinin cargo protein in epithelial Madin-Darby canine kidney cells. Mol Biol Cell. 2001; 12:1869-1883. [PubMed: 11408592]

369. Rahner C, Stieger B, Landmann L. Structure-function correlation of tight junctional impairment after intrahepatic and extrahepatic cholestasis in rat liver. Gastroenterology. 1996; 110:15641578. [PubMed: 8613064]

370. Rahner C, Stieger B, Landmann L. Apical endocytosis in rat hepatocytes In situ involves clathrin, traverses a subapical compartment, and leads to lysosomes. Gastroenterology. 2000; 119:16921707. [PubMed: 11113091]

371. Ramadori G, Saile B. Inflammation, damage repair, immune cells, and liver fibrosis: Specific or nonspecific, this is the question. Gastroenterology. 2004; 127:997-1000. [PubMed: 15362057]

372. Ramnarayanan SP, Cheng CA, Bastaki M, Tuma PL. Exogenous MAL reroutes selected hepatic apical proteins into the direct pathway in WIF-B cells. Mol Biol Cell. 2007; 18:2707-2715. [PubMed: 17494867]

373. Reales E, Sharma N, Low SH, Folsch H, Weimbs T. Basolateral sorting of syntaxin 4 is dependent on its $\mathrm{N}$-terminal domain and the AP1B clathrin adaptor, and required for the epithelial cell polarity. PLoS One. 2011; 6:e21181. [PubMed: 21698262]

374. Reinsch S, Karsenti E. Orientation of spindle axis and distribution of plasma membrane proteins during cell division in polarized MDCKII cells. J Cell Biol. 1994; 126:1509-1526. [PubMed: 8089182]

375. Reyes CD, Garcia AJ. Engineering integrin-specific surfaces with a triple-helical collagenmimetic peptide. J Biomed Mater Res A. 2003; 65:511-523. [PubMed: 12761842]

376. Reynolds GM, Harris HJ, Jennings A, Hu K, Grove J, Lalor PF, Adams DH, Balfe P, Hubscher $\mathrm{SG}$, McKeating JA. Hepatitis $\mathrm{C}$ virus receptor expression in normal and diseased liver tissue. Hepatology. 2008; 47:418-427. [PubMed: 18085708] 
377. Robinson MS. Cloning and expression of gamma-adaptin, a component of clathrin-coated vesicles associated with the Golgi apparatus. J Cell Biol. 1990; 111:2319-2326. [PubMed: 2126014]

378. Rodriguez-Boulan E, Kreitzer G, Musch A. Organization of vesicular trafficking in epithelia. Nat Rev Mol Cell Biol. 2005; 6:233-247. [PubMed: 15738988]

379. Rodriguez-Boulan E, Nelson WJ. Morphogenesis of the polarized epithelial cell phenotype. Science. 1989; 245:718-725. [PubMed: 2672330]

380. Rodriguez-Boulan E, Salas PJ. External and internal signals for epithelial cell surface polarization. Annu Rev Physiol. 1989; 51:741-754. [PubMed: 2653203]

381. Rossi JM, Dunn NR, Hogan BL, Zaret KS. Distinct mesodermal signals, including BMPs from the septum transversum mesenchyme, are required in combination for hepatogenesis from the endoderm. Genes Dev. 2001; 15:1998-2009. [PubMed: 11485993]

382. Rowan A, Churchman M, Jefferey R, Hanby A, Poulsom R, Tomlinson I. In situ analysis of LKB1/STK11 mRNA expression in human normal tissues and tumours. J Pathol. 2000; 192:203206. [PubMed: 11004696]

383. Ryan MJ, Bales C, Nelson A, Gonzalez DM, Underkoffler L, Segalov M, Wilson-Rawls J, Cole SE, Moran JL, Russo P, Spinner NB, Kusumi K, Loomes KM. Bile duct proliferation in Jag1/ fringe heterozygous mice identifies candidate modifiers of the Alagille syndrome hepatic phenotype. Hepatology. 2008; 48:1989-1997. [PubMed: 19026002]

384. Sadler KC, Krahn KN, Gaur NA, Ukomadu C. Liver growth in the embryo and during liver regeneration in zebrafish requires the cell cycle regulator, uhrf1. Proc Natl Acad Sci U S A. 2007; 104:1570-1575. [PubMed: 17242348]

385. Sakaguchi TF, Sadler KC, Crosnier C, Stainier DY. Endothelial signals modulate hepatocyte apicobasal polarization in zebrafish. Curr Biol. 2008; 18:1565-1571. [PubMed: 18951027]

386. Salas PJ, Vega-Salas DE, Rodriguez-Boulan E. Collagen receptors mediate early events in the attachment of epithelial (MDCK) cells. J Membr Biol. 1987; 98:223-236. [PubMed: 3681953]

387. Salvarezza SB, Deborde S, Schreiner R, Campagne F, Kessels MM, Qualmann B, Caceres A, Kreitzer G, Rodriguez-Boulan E. LIM kinase 1 and cofilin regulate actin filament population required for dynamin-dependent apical carrier fission from the trans-Golgi network. Mol Biol Cell. 2009; 20:438-451. [PubMed: 18987335]

388. Sapkota GP, Kieloch A, Lizcano JM, Lain S, Arthur JS, Williams MR, Morrice N, Deak M, Alessi DR. Phosphorylation of the protein kinase mutated in Peutz-Jeghers cancer syndrome, LKB1/STK11, at Ser431 by p90(RSK) and cAMP-dependent protein kinase, but not its farnesylation at Cys(433), is essential for LKB1 to suppress cell vrowth. J Biol Chem. 2001; 276:19469-19482. [PubMed: 11297520]

389. Sargiacomo M, Lisanti M, Graeve L, Le Bivic A, Rodriguez-Boulan E. Integral and peripheral protein composition of the apical and basolateral membrane domains in MDCK cells. J Membr Biol. 1989; 107:277-286. [PubMed: 2716048]

390. Sato T, Mushiake S, Kato Y, Sato K, Sato M, Takeda N, Ozono K, Miki K, Kubo Y, Tsuji A, Harada R, Harada A. The Rab8 GTPase regulates apical protein localization in intestinal cells. Nature. 2007; 448:366-369. [PubMed: 17597763]

391. Saucan L, Palade GE. Differential colchicine effects on the transport of membrane and secretory proteins in rat hepatocytes in vivo: Bipolar secretion of albumin. Hepatology. 1992; 15:714-721. [PubMed: 1551647]

392. Saucan L, Palade GE. Membrane and secretory proteins are transported from the Golgi complex to the sinusoidal plasmalemma of hepatocytes by distinct vesicular carriers. J Cell Biol. 1994; 125:733-741. [PubMed: 8188743]

393. Schmitz AA, Govek EE, Bottner B, Van Aelst L. Rho GTPases: Signaling, migration, and invasion. Exp Cell Res. 2000; 261:1-12. [PubMed: 11082269]

394. Schneider D, Greb C, Koch A, Straube T, Elli A, Delacour D, Jacob R. Trafficking of galectin-3 through endosomal organelles of polarized and non-polarized cells. Eur J Cell Biol. 2010; 89:788-798. [PubMed: 20705359]

395. Schohl A, Fagotto F. A role for maternal beta-catenin in early mesoderm induction in Xenopus. EMBO J. 2003; 22:3303-3313. [PubMed: 12839992] 
396. Schuck S, Gerl MJ, Ang A, Manninen A, Keller P, Mellman I, Simons K. Rab10 is involved in basolateral transport in polarized Madin-Darby canine kidney cells. Traffic. 2007; 8:47-60. [PubMed: 17132146]

397. Schulman AN, Dienstag JL, Jackson DR, Hoofnagle JH, Gerety RJ, Purcell RH, Barker LF. Hepatitis A antigen particles in liver, bile, and stool of chimpanzees. J Infect Dis. 1976; 134:8084. [PubMed: 181500]

398. Schuppan D. Structure of the extracellular matrix in normal and fibrotic liver: Collagens and glycoproteins. Semin Liver Dis. 1990; 10:1-10. [PubMed: 2186485]

399. Schwimmer R, Ojakian GK. The alpha 2 beta 1 integrin regulates collagen-mediated MDCK epithelial membrane remodeling and tubule formation. J Cell Sci. 1995; 108(Pt 6):2487-2498. [PubMed: 7673363]

400. Scoazec JY, Maurice M, Moreau A, Feldmann G. Analysis of hepatocyte plasma membrane polarity during rat azo dye hepatocarcinogenesis using monoclonal antibodies directed against domain-associated antigens. Cancer Res. 1988; 48:6882-6890. [PubMed: 3180097]

401. Sebbagh M, Santoni MJ, Hall B, Borg JP, Schwartz MA. Regulation of LKB1/STRAD localization and function by E-cadherin. Curr Biol. 2009; 19:37-42. [PubMed: 19110428]

402. Shanks MR, Cassio D, Lecoq O, Hubbard AL. An improved polarized rat hepatoma hybrid cell line. Generation and comparison with its hepatoma relatives and hepatocytes in vivo. J Cell Sci. 1994; 107(Pt 4):813-825. [PubMed: 8056838]

403. Sharma N, Low SH, Misra S, Pallavi B, Weimbs T. Apical targeting of syntaxin 3 is essential for epithelial cell polarity. J Cell Biol. 2006; 173:937-948. [PubMed: 16785322]

404. Shaw RJ, Lamia KA, Vasquez D, Koo SH, Bardeesy N, Depinho RA, Montminy M, Cantley LC. The kinase LKB1 mediates glucose homeostasis in liver and therapeutic effects of metformin. Science. 2005; 310:1642-1646. [PubMed: 16308421]

405. Sheff DR, Daro EA, Hull M, Mellman I. The receptor recycling pathway contains two distinct populations of early endosomes with different sorting functions. J Cell Biol. 1999; 145:123-139. [PubMed: 10189373]

406. Shen L, Weber CR, Raleigh DR, Yu D, Turner JR. Tight junction pore and leak pathways: A dynamic duo. Annu Rev Physiol. 2011; 73:283-309. [PubMed: 20936941]

407. Shepard CW, Finelli L, Alter MJ. Global epidemiology of hepatitis C virus infection. Lancet Infect Dis. 2005; 5:558-567. [PubMed: 16122679]

408. Shiba M, Shimizu I, Yasuda M, Ii K, Ito S. Expression of type I and type III collagens during the course of dimethylnitrosamine-induced hepatic fibrosis in rats. Liver. 1998; 18:196-204. [PubMed: 9716231]

409. Simmen T, Honing S, Icking A, Tikkanen R, Hunziker W. AP-4 binds basolateral signals and participates in basolateral sorting in epithelial MDCK cells. Nat Cell Biol. 2002; 4:154-159. [PubMed: 11802162]

410. Simon JP, Ivanov IE, Shopsin B, Hersh D, Adesnik M, Sabatini DD. The in vitro generation of post-Golgi vesicles carrying viral envelope glycoproteins requires an ARF-like GTP-binding protein and a protein kinase C associated with the Golgi apparatus. J Biol Chem. 1996; 271:16952-16961. [PubMed: 8663371]

411. Simons K, Ikonen E. Functional rafts in cell membranes. Nature. 1997; 387:569-572. [PubMed: 9177342]

412. Simons K, Wandinger-Ness A. Polarized sorting in epithelia. Cell. 1990; 62:207-210. [PubMed: 2196994]

413. Slimane TA, Trugnan G, Van ISC, Hoekstra D. Raft-mediated trafficking of apical resident proteins occurs in both direct and transcytotic pathways in polarized hepatic cells: Role of distinct lipid microdomains. Mol Biol Cell. 2003; 14:611-624. [PubMed: 12589058]

414. Snooks MJ, Bhat P, Mackenzie J, Counihan NA, Vaughan N, Anderson DA. Vectorial entry and release of hepatitis A virus in polarized human hepatocytes. J Virol. 2008; 82:8733-8742. [PubMed: 18579610]

415. Snykers S, De Kock J, Rogiers V, Vanhaecke T. In vitro differentiation of embryonic and adult stem cells into hepatocytes: State of the art. Stem Cells. 2009; 27:577-605. [PubMed: 19056906] 
416. Soldati T, Schliwa M. Powering membrane traffic in endocytosis and recycling. Nat Rev Mol Cell Biol. 2006; 7:897-908. [PubMed: 17139330]

417. Sollner TH, Rothman JE. Molecular machinery mediating vesicle budding, docking and fusion. Experientia. 1996; 52:1021-1025. [PubMed: 8988241]

418. Son S, Kojima T, Decaens C, Yamaguchi H, Ito T, Imamura M, Murata M, Tanaka S, Chiba H, Hirata K, Sawada N. Knockdown of tight junction protein claudin-2 prevents bile canalicular formation in WIF-B9 cells. Histochem Cell Biol. 2009; 131:411-424. [PubMed: 19084987]

419. Spano D, Russo R, Di Maso V, Rosso N, Terracciano LM, Roncalli M, Tornillo L, Capasso M, Tiribelli C, Iolascon A. Galectin-1 and its involvement in hepatocellular carcinoma aggressiveness. Mol Med. 2010; 16:102-115. [PubMed: 20200618]

420. Spath GF, Weiss MC. Hepatocyte nuclear factor 4 provokes expression of epithelial marker genes, acting as a morphogen in dedifferentiated hepatoma cells. J Cell Biol. 1998; 140:935-946. [PubMed: 9472044]

421. St Johnston D, Sanson B. Epithelial polarity and morphogenesis. Curr Opin Cell Biol. 2011; 23:540-546. [PubMed: 21807488]

422. Stamatoglou SC, Enrich C, Manson MM, Hughes RC. Temporal changes in the expression and distribution of adhesion molecules during liver development and regeneration. J Cell Biol. 1992; 116:1507-1515. [PubMed: 1531833]

423. Stamatoglou SC, Manson MM, Green JA, Mayol X, Hughes RC. Distribution of fibronectin and fibronectin-binding proteins, AGp1 10 and integrin alpha 5 beta 1, during chemically induced hepatocarcinogenesis in adult rats. J Cell Sci. 1991; 100(Pt 3):599-604. [PubMed: 1839682]

424. Stechly L, Morelle W, Dessein AF, Andre S, Grard G, Trinel D, Dejonghe MJ, Leteurtre E, Drobecq H, Trugnan G, Gabius HJ, Huet G. Galectin-4-regulated delivery of glycoproteins to the brush border membrane of enterocyte-like cells. Traffic. 2009; 10:438-450. [PubMed: 19192249]

425. Steinman RM, Mellman IS, Muller WA, Cohn ZA. Endocytosis and the recycling of plasma membrane. J Cell Biol. 1983; 96:1-27. [PubMed: 6298247]

426. Stepanenko OV, Shcherbakova DM, Kuznetsova IM, Turoverov KK, Verkhusha VV. Modern fluorescent proteins: From chromophore formation to novel intracellular applications. Biotechniques. 2011; 51:313-314. 316, 318. passim. [PubMed: 22054544]

427. Stieger B, Meier PJ, Landmann L. Effect of obstructive cholestasis on membrane traffic and domain-specific expression of plasma membrane proteins in rat liver parenchymal cells. Hepatology. 1994; 20:201-212. [PubMed: 7517382]

428. Strautnieks SS, Bull LN, Knisely AS, Kocoshis SA, Dahl N, Arnell H, Sokal E, Dahan K, Childs S, Ling V, Tanner MS, Kagalwalla AF, Nemeth A, Pawlowska J, Baker A, Mieli-Vergani G, Freimer NB, Gardiner RM, Thompson RJ. A gene encoding a liver-specific ABC transporter is mutated in progressive familial intrahepatic cholestasis. Nat Genet. 1998; 20:233-238. [PubMed: 9806540]

429. Suzuki A, Hirata M, Kamimura K, Maniwa R, Yamanaka T, Mizuno K, Kishikawa M, Hirose H, Amano Y, Izumi N, Miwa Y, Ohno S. aPKC acts upstream of PAR-1b in both the establishment and maintenance of mammalian epithelial polarity. Curr Biol. 2004; 14:1425-1435. [PubMed: 15324659]

430. Tai AW, Chuang JZ, Bode C, Wolfrum U, Sung CH. Rhodopsin's carboxy-terminal cytoplasmic tail acts as a membrane receptor for cytoplasmic dynein by binding to the dynein light chain Tctex-1. Cell. 1999; 97:877-887. [PubMed: 10399916]

431. Taipale J, Keski-Oja J. Growth factors in the extracellular matrix. FASEB J. 1997; 11:51-59. [PubMed: 9034166]

432. Takahara T, Furui K, Yata Y, Jin B, Zhang LP, Nambu S, Sato H, Seiki M, Watanabe A. Dual expression of matrix metalloproteinase-2 and membrane-type 1-matrix metalloproteinase in fibrotic human livers. Hepatology. 1997; 26:1521-1529. [PubMed: 9397993]

433. Takaki Y, Hirai S, Manabe N, Izumi Y, Hirose T, Nakaya M, Suzuki A, Mizuno K, Akimoto K, Tsukita S, Shuin T, Ohno S. Dynamic changes in protein components of the tight junction during liver regeneration. Cell Tissue Res. 2001; 305:399-409. [PubMed: 11572093] 
434. Takeichi M. Cadherin cell adhesion receptors as a morphogenetic regulator. Science. 1991; 251:1451-1455. [PubMed: 2006419]

435. Tanos B, Rodriguez-Boulan E. The epithelial polarity program: Machineries involved and their hijacking by cancer. Oncogene. 2008; 27:6939-6957. [PubMed: 19029936]

436. Taub R. Liver regeneration: From myth to mechanism. Nat Rev Mol Cell Biol. 2004; 5:836-847. [PubMed: 15459664]

437. Taura K, Miura K, Iwaisako K, Osterreicher CH, Kodama Y, Penz-Osterreicher M, Brenner DA. Hepatocytes do not undergo epithelial-mesenchymal transition in liver fibrosis in mice. Hepatology. 2010; 51:1027-1036. [PubMed: 20052656]

438. Tee AR, Blenis J. mTOR, translational control and human disease. Semin Cell Dev Biol. 2005; 16:29-37. [PubMed: 15659337]

439. ter Beest MB, Chapin SJ, Avrahami D, Mostov KE. The role of syntaxins in the specificity of vesicle targeting in polarized epithelial cells. Mol Biol Cell. 2005; 16:5784-5792. [PubMed: 16207812]

440. Terada K, Nakako T, Yang XL, Iida M, Aiba N, Minamiya Y, Nakai M, Sakaki T, Miura N, Sugiyama T. Restoration of holoceruloplasmin synthesis in LEC rat after infusion of recombinant adenovirus bearing WND cDNA. J Biol Chem. 1998; 273:1815-1820. [PubMed: 9430732]

441. Theard D, Steiner M, Kalicharan D, Hoekstra D, van Ijzendoorn SC. Cell polarity development and protein trafficking in hepatocytes lacking E-cadherin/beta-catenin-based adherens junctions. Mol Biol Cell. 2007; 18:2313-2321. [PubMed: 17429067]

442. Thiberge S, Blazquez S, Baldacci P, Renaud O, Shorte S, Menard R, Amino R. In vivo imaging of malaria parasites in the murine liver. Nat Protoc. 2007; 2:1811-1818. [PubMed: 17641649]

443. Thompson A, Nessler R, Wisco D, Anderson E, Winckler B, Sheff D. Recycling endosomes of polarized epithelial cells actively sort apical and basolateral cargos into separate subdomains. Mol Biol Cell. 2007; 18:2687-2697. [PubMed: 17494872]

444. Timm T, Li XY, Biernat J, Jiao J, Mandelkow E, Vandekerckhove J, Mandelkow EM. MARKK, a Ste20-like kinase, activates the polarity-inducing kinase MARK/PAR-1. Embo J. 2003; 22:5090-5101. [PubMed: 14517247]

445. Tiollais P, Pourcel C, Dejean A. The hepatitis B virus. Nature. 1985; 317:489-495. [PubMed: 2995835]

446. Tolleshaug H, Hobgood KK, Brown MS, Goldstein JL. The LDL receptor locus in familial hypercholesterolemia: Multiple mutations disrupt transport and processing of a membrane receptor. Cell. 1983; 32:941-951. [PubMed: 6299582]

447. Tomasek JJ, Gabbiani G, Hinz B, Chaponnier C, Brown RA. Myofibroblasts and mechanoregulation of connective tissue remodelling. Nat Rev Mol Cell Biol. 2002; 3:349-363. [PubMed: 11988769]

448. Tomoyori T, Ogawa K, Mori M, Onoe T. Ultrastructural changes in the bile canaliculi and the lateral surfaces of rat hepatocytes during restorative proliferation. Virchows Arch B Cell Pathol Incl Mol Pathol. 1983; 42:201-211. [PubMed: 6133392]

449. Tooze SA, Huttner WB. Cell-free protein sorting to the regulated and constitutive secretory pathways. Cell. 1990; 60:837-847. [PubMed: 2138058]

450. Torok NJ, Larusso EM, McNiven MA. Alterations in vesicle transport and cell polarity in rat hepatocytes subjected to mechanical or chemical cholestasis. Gastroenterology. 2001; 121:11761184. [PubMed: 11677210]

451. Trauner M, Meier PJ, Boyer JL. Molecular pathogenesis of cholestasis. N Engl J Med. 1998; 339:1217-1227. [PubMed: 9780343]

452. Treichel U, Meyer zum Buschenfelde KH, Dienes HP, Gerken G. Receptor-mediated entry of hepatitis B virus particles into liver cells. Arch Virol. 1997; 142:493-498. [PubMed: 9349295]

453. Troxell ML, Gopalakrishnan S, McCormack J, Poteat BA, Pennington J, Garringer SM, Schneeberger EE, Nelson WJ, Marrs JA. Inhibiting cadherin function by dominant mutant Ecadherin expression increases the extent of tight junction assembly. J Cell Sci. 2000; 113(Pt 6): 985-996. [PubMed: 10683147] 
454. Tuma PL, Nyasae LK, Hubbard AL. Nonpolarized cells selectively sort apical proteins from cell surface to a novel compartment, but lack apical retention mechanisms. Mol Biol Cell. 2002; 13:3400-3415. [PubMed: 12388745]

455. Urban J, Parczyk K, Leutz A, Kayne M, Kondor-Koch C. Constitutive apical secretion of an 80$\mathrm{kD}$ sulfated glycoprotein complex in the polarized epithelial Madin-Darby canine kidney cell line. J Cell Biol. 1987; 105:2735-2743. [PubMed: 3693398]

456. Van Aken E, De Wever O, Correia da Rocha AS, Mareel M. Defective E-cadherin/catenin complexes in human cancer. Virchows Arch. 2001; 439:725-751. [PubMed: 11787845]

457. van de Graaf SF, Hoenderop JG, Gkika D, Lamers D, Prenen J, Rescher U, Gerke V, Staub O, Nilius B, Bindels RJ. Functional expression of the epithelial Ca(2+) channels (TRPV5 and TRPV6) requires association of the S100A10-annexin 2 complex. EMBO J. 2003; 22:14781487. [PubMed: 12660155]

458. van der Wouden JM, van ISC, Hoekstra D. Oncostatin M regulates membrane traffic and stimulates bile canalicular membrane biogenesis in HepG2 cells. Embo J. 2002; 21:6409-6418. [PubMed: 12456648]

459. Van Eyken P, Sciot R, Callea F, Van der Steen K, Moerman P, Desmet VJ. The development of the intrahepatic bile ducts in man: A keratin-immunohistochemical study. Hepatology. 1988; 8:1586-1595. [PubMed: 2461337]

460. van Hengel J, D’Hooge P, Hooghe B, Wu X, Libbrecht L, De Vos R, Quondamatteo F, Klempt M, Brakebusch C, van Roy F. Continuous cell injury promotes hepatic tumorigenesis in cdc42deficient mouse liver. Gastroenterology. 2008; 134:781-792. [PubMed: 18325391]

461. van ISC, Hoekstra D. (Glyco)sphingolipids are sorted in sub-apical compartments in HepG2 cells: A role for non-Golgi-related intracellular sites in the polarized distribution of (glyco)sphingolipids. J Cell Biol. 1998; 142:683-696. [PubMed: 9700158]

462. Van ISC, Theard D, Van Der Wouden JM, Visser W, Wojtal KA, Hoekstra D. Oncostatin Mstimulated apical plasma membrane biogenesis requires p27(Kip1)-regulated cell cycle dynamics. Mol Biol Cell. 2004; 15:4105-4114. [PubMed: 15240818]

463. van ISC, Zegers MM, Kok JW, Hoekstra D. Segregation of glucosylce-ramide and sphingomyelin occurs in the apical to basolateral transcytotic route in HepG2 cells. J Cell Biol. 1997; 137:347357. [PubMed: 9128247]

464. van Meer G, Simons K. Lipid polarity and sorting in epithelial cells. J Cell Biochem. 1988; 36:51-58. [PubMed: 3277985]

465. Vega-Salas DE, Salas PJ, Gundersen D, Rodriguez-Boulan E. Formation of the apical pole of epithelial (Madin-Darby canine kidney) cells: Polarity of an apical protein is independent of tight junctions while segregation of a basolateral marker requires cell-cell interactions. J Cell Biol. 1987; 104:905-916. [PubMed: 3558485]

466. Vega-Salas DE, Salas PJ, Rodriguez-Boulan E. Modulation of the expression of an apical plasma membrane protein of Madin-Darby canine kidney epithelial cells: Cell-cell interactions control the appearance of a novel intracellular storage compartment. J Cell Biol. 1987; 104:1249-1259. [PubMed: 3553208]

467. Vega-Salas DE, Salas PJ, Rodriguez-Boulan E. Exocytosis of vacuolar apical compartment (VAC): A cell-cell contact controlled mechanism for the establishment of the apical plasma membrane domain in epithelial cells. J Cell Biol. 1988; 107:1717-1728. [PubMed: 3053735]

468. Vieira OV, Verkade P, Manninen A, Simons K. FAPP2 is involved in the transport of apical cargo in polarized MDCK cells. J Cell Biol. 2005; 170:521-526. [PubMed: 16103222]

469. Wagner M, Halilbasic E, Marschall HU, Zollner G, Fickert P, Langner C, Zatloukal K, Denk H, Trauner M. CAR and PXR agonists stimulate hepatic bile acid and bilirubin detoxification and elimination pathways in mice. Hepatology. 2005; 42:420-430. [PubMed: 15986414]

470. Wakabayashi Y, Dutt P, Lippincott-Schwartz J, Arias IM. Rab11a and myosin Vb are required for bile canalicular formation in WIF-B9 cells. Proc Natl Acad Sci U S A. 2005; 102:15087-15092. [PubMed: 16214890]

471. Wakabayashi Y, Kipp H, Arias IM. Transporters on demand: Intracellular reservoirs and cycling of bile canalicular ABC transporters. J Biol Chem. 2006; 281:27669-27673. [PubMed: 16737964] 
472. Walker JM, Tsivkovskii R, Lutsenko S. Metallochaperone Atox1 transfers copper to the NH2terminal domain of the Wilson's disease protein and regulates its catalytic activity. J Biol Chem. 2002; 277:27953-27959. [PubMed: 12029094]

473. Wandinger-Ness A, Bennett MK, Antony C, Simons K. Distinct transport vesicles mediate the delivery of plasma membrane proteins to the apical and basolateral domains of MDCK cells. J Cell Biol. 1990; 111:987-1000. [PubMed: 2202740]

474. Wang AZ, Ojakian GK, Nelson WJ. Steps in the morphogenesis of a polarized epithelium. I. Uncoupling the roles of cell-cell and cell-substratum contact in establishing plasma membrane polarity in multicellular epithelial (MDCK) cysts. J Cell Sci. 1990; 95(Pt 1):137-151. [PubMed: 2351699]

475. Wang D, Dou K, Xiang H, Song Z, Zhao Q, Chen Y, Li Y. Involvement of RhoA in progression of human hepatocellular carcinoma. J Gastroenterol Hepatol. 2007; 22:1916-1920. [PubMed: 17914970]

476. Wang E, Brown PS, Aroeti B, Chapin SJ, Mostov KE, Dunn KW. Apical and basolateral endocytic pathways of MDCK cells meet in acidic common endosomes distinct from a nearlyneutral apical recycling endosome. Traffic. 2000; 1:480-493. [PubMed: 11208134]

477. Wang P, Wang JJ, Xiao Y, Murray JW, Novikoff PM, Angeletti RH, Orr GA, Lan D, Silver DL, Wolkoff AW. Interaction with PDZK1 is required for expression of organic anion transporting protein 1A1 on the hepatocyte surface. J Biol Chem. 2005; 280:30143-30149. [PubMed: 15994332]

478. Wang Q, Margolis B. Apical junctional complexes and cell polarity. Kidney Int. 2007; 72:14481458. [PubMed: 17914350]

479. Wang X, Kumar R, Navarre J, Casanova JE, Goldenring JR. Regulation of vesicle trafficking in madin-darby canine kidney cells by Rab11a and Rab25. J Biol Chem. 2000; 275:29138-29146. [PubMed: 10869360]

480. Watabe M, Nagafuchi A, Tsukita S, Takeichi M. Induction of polarized cell-cell association and retardation of growth by activation of the E-cadherin-catenin adhesion system in a dispersed carcinoma line. J Cell Biol. 1994; 127:247-256. [PubMed: 7929567]

481. Watanabe S, Horie Y, Suzuki A. Hepatocyte-specific Pten-deficient mice as a novel model for nonalcoholic steatohepatitis and hepatocellular carcinoma. Hepatol Res. 2005; 33:161-166. [PubMed: 16214396]

482. Weber T, Zemelman BV, McNew JA, Westermann B, Gmachl M, Parlati F, Sollner TH, Rothman JE. SNAREpins: Minimal machinery for membrane fusion. Cell. 1998; 92:759-772. [PubMed: 9529252]

483. Webster CR, Anwer MS. Role of the PI3K/PKB signaling pathway in cAMP-mediated translocation of rat liver Ntcp. Am J Physiol. 1999; 277:G1165-G1172. [PubMed: 10600813]

484. Weibel ER, Staubli W, Gnagi HR, Hess FA. Correlated morphometric and biochemical studies on the liver cell. I. Morphometric model, stereologic methods, and normal morphometric data for rat liver. J Cell Biol. 1969; 42:68-91. [PubMed: 4891915]

485. Weisz OA, Machamer CE, Hubbard AL. Rat liver dipeptidylpeptidase IV contains competing apical and basolateral targeting information. J Biol Chem. 1992; 267:22282-22288. [PubMed: 1358878]

486. Weisz OA, Rodriguez-Boulan E. Apical trafficking in epithelial cells: Signals, clusters and motors. J Cell Sci. 2009; 122:4253-4266. [PubMed: 19923269]

487. Wells RG. The role of matrix stiffness in regulating cell behavior. Hepatology. 2008; 47:13941400. [PubMed: 18307210]

488. Wells RG. The epithelial-to-mesenchymal transition in liver fibrosis: Here today, gone tomorrow? Hepatology. 2010; 51:737-740. [PubMed: 20198628]

489. Wewer UM, Engvall E, Paulsson M, Yamada Y, Albrechtsen R. Laminin A, B1, B2, S and M subunits in the postnatal rat liver development and after partial hepatectomy. Lab Invest. 1992; 66:378-389. [PubMed: 1538591]

490. Wilkins T, Malcolm JK, Raina D, Schade RR. Hepatitis C: Diagnosis and treatment. Am Fam Physician. 2010; 81:1351-1357. [PubMed: 20521755] 
491. Wisse E, De Zanger RB, Charels K, Van Der Smissen P, McCuskey RS. The liver sieve: Considerations concerning the structure and function of endothelial fenestrae, the sinusoidal wall and the space of Disse. Hepatology. 1985; 5:683-692. [PubMed: 3926620]

492. Wojtal KA, de Vries E, Hoekstra D, van Ijzendoorn SC. Efficient trafficking of MDR1/Pglycoprotein to apical canalicular plasma membranes in HepG2 cells requires PKA-RIIalpha anchoring and glucosyl-ceramide. Mol Biol Cell. 2006; 17:3638-3650. [PubMed: 16723498]

493. Wojtal KA, Diskar M, Herberg FW, Hoekstra D, van Ijzendoorn SC. Regulatory subunit Icontrolled protein kinase A activity is required for apical bile canalicular lumen development in hepatocytes. J Biol Chem. 2009; 284:20773-20780. [PubMed: 19465483]

494. Wood RL. An electron microscope study of developing bile canaliculi in the rat. Anat Rec. 1965; 151:507-529. [PubMed: 14326981]

495. Woods A, Heslegrave AJ, Muckett PJ, Levene AP, Clements M, Mobberley M, Ryder TA, AbuHayyeh S, Williamson C, Goldin RD, Ashworth A, Withers DJ, Carling D. LKB1 is required for hepatic bile acid transport and canalicular membrane integrity in mice. Biochem J. 2011; 434:4960. [PubMed: 21118154]

496. Wu H, Chen P, Liao R, Li YW, Yi Y, Wang JX, Sun TW, Zhou J, Shi YH, Yang XR, Jin JJ, Cheng YF, Fan J, Qiu SJ. Overexpression of galectin-1 associates with poor prognosis in human hepatocellular carcinoma following resection. J Gastroenterol Hepatol. 2012; 27(8):13121319.10.1111/j.1440-1746.2012.07130.x [PubMed: 22432916]

497. Wu JC, Merlino G, Fausto N. Establishment and characterization of differentiated, nontransformed hepatocyte cell lines derived from mice transgenic for transforming growth factor alpha. Proc Natl Acad Sci U S A. 1994; 91:674-678. [PubMed: 7904757]

498. Xie M, Zhang D, Dyck JR, Li Y, Zhang H, Morishima M, Mann DL, Taffet GE, Baldini A, Khoury DS, Schneider MD. A pivotal role for endogenous TGF-beta-activated kinase-1 in the LKB1/AMP-activated protein kinase energy-sensor pathway. Proc Natl Acad Sci U S A. 2006; 103:17378-17383. [PubMed: 17085580]

499. Yang Y, Pan X, Lei W, Wang J, Song J. Transforming growth factor-beta1 induces epithelial-tomesenchymal transition and apoptosis via a cell cycle-dependent mechanism. Oncogene. 2006; 25:7235-7244. [PubMed: 16799646]

500. Yee HF Jr. Rho directs activation-associated changes in rat hepatic stellate cell morphology via regulation of the actin cytoskeleton. Hepatology. 1998; 28:843-850. [PubMed: 9731582]

501. Yin L, Lynch D, Ilic Z, Sell S. Proliferation and differentiation of ductular progenitor cells and littoral cells during the regeneration of the rat liver to CCl4/2-AAF injury. Histol Histopathol. 2002; 17:65-81. [PubMed: 11813887]

502. Ylikorkala A, Rossi DJ, Korsisaari N, Luukko K, Alitalo K, Henkemeyer M, Makela TP. Vascular abnormalities and deregulation of VEGF in Lkb1-deficient mice. Science. 2001; 293:1323-1326. [PubMed: 11509733]

503. Yuan H, Zhang H, Wu X, Zhang Z, Du D, Zhou W, Zhou S, Brakebusch C, Chen Z. Hepatocytespecific deletion of $\mathrm{Cdc} 42$ results in delayed liver regeneration after partial hepatectomy in mice. Hepatology. 2009; 49:240-249. [PubMed: 19085966]

504. Zaal KJ, Kok JW, Sormunen R, Eskelinen S, Hoekstra D. Intracellular sites involved in the biogenesis of bile canaliculi in hepatic cells. Eur J Cell Biol. 1994; 63:10-19. [PubMed: 8005096]

505. Zegers MM, Hoekstra D. Sphingolipid transport to the apical plasma membrane domain in human hepatoma cells is controlled by PKC and PKA activity: A correlation with cell polarity in HepG2 cells. J Cell Biol. 1997; 138:307-321. [PubMed: 9230073]

506. Zegers MM, Zaal KJ, van ISC, Klappe K, Hoekstra D. Actin filaments and microtubules are involved in different membrane traffic pathways that transport sphingolipids to the apical surface of polarized HepG2 cells. Mol Biol Cell. 1998; 9:1939-1949. [PubMed: 9658181]

507. Zeisberg M, Yang C, Martino M, Duncan MB, Rieder F, Tanjore H, Kalluri R. Fibroblasts derive from hepatocytes in liver fibrosis via epithelial to mesenchymal transition. J Biol Chem. 2007; 282:23337-23347. [PubMed: 17562716] 
508. Zhang L, Li J, Young LH, Caplan MJ. AMP-activated protein kinase regulates the assembly of epithelial tight junctions. Proc Natl Acad Sci U S A. 2006; 103:17272-17277. [PubMed: 17088526]

509. Zheng B, Cantley LC. Regulation of epithelial tight junction assembly and disassembly by AMPactivated protein kinase. Proc Natl Acad Sci U S A. 2007; 104:819-822. [PubMed: 17204563]

510. Zorn, AM. Liver development. In: Schier, AF., editor. StemBook. The Stem Cell Research Community, StemBook, in collaboration with the Harvard Stem Cell Institute; Cambridge, MA: 2008. http://www.hsci.harvard.edu/doi/10.3824/stembook.1.25.1http://www.stembook.org

511. Zurzolo C, Lisanti MP, Caras IW, Nitsch L, Rodriguez-Boulan E. Glycosylphosphatidylinositolanchored proteins are preferentially targeted to the basolateral surface in Fischer rat thyroid epithelial cells. J Cell Biol. 1993; 121:1031-1039. [PubMed: 7684737]

512. Zurzolo C, van't Hof W, van Meer G, Rodriguez-Boulan E. VIP21/caveolin, glycosphingolipid clusters and the sorting of glycosylphosphatidylinositol-anchored proteins in epithelial cells. Embo J. 1994; 13:42-53. [PubMed: 8306971] 
(A) The Liver lobe

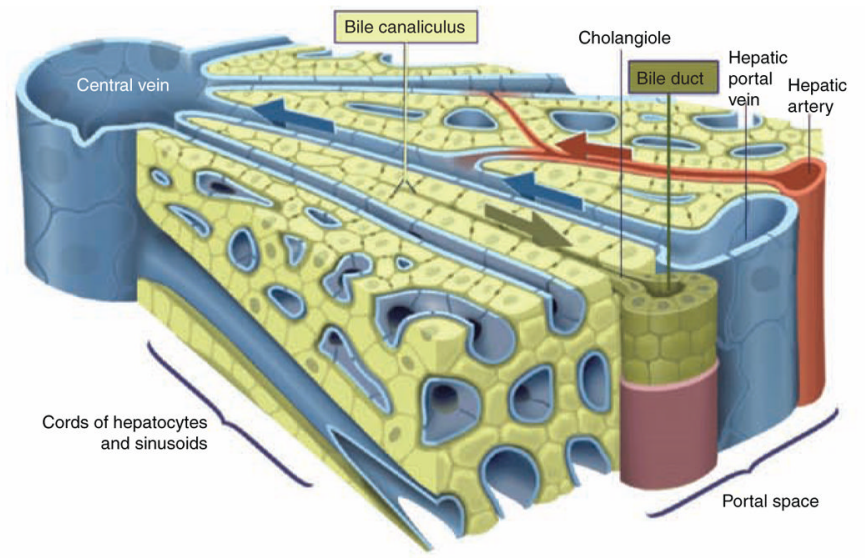

(B) Hepatocyte and Cholangiocyte Polarity

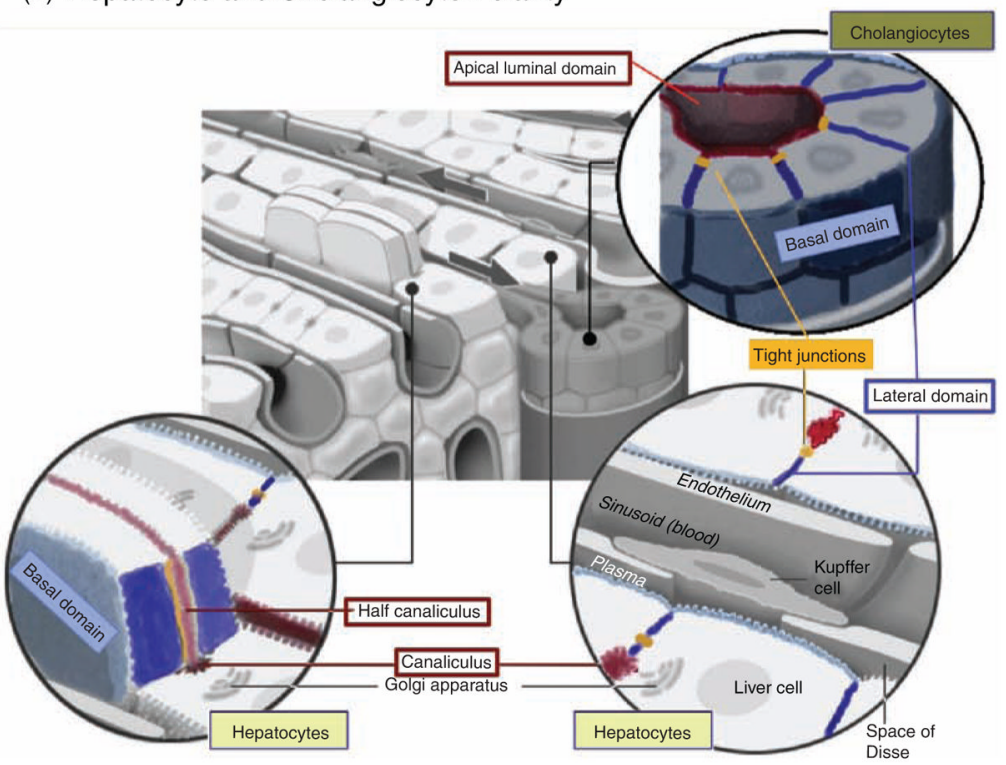

Figure 1. The two epithelial cell types in the liver

(A) The mammalian biliary tree is characterized by a network of bile canaliculi, the luminal domains of adjacent hepatocytes, which are organized in one or two-cell-thick cords. The bile canaliculi connect to the bile ducts located in the portal triad that also encompasses the hepatic artery and portal vein. Ducts are composed of biliary epithelial cells that exhibit columnar polarity. (B) The domain organization of hepatocytes and cholangiocytes. Red: luminal domains, dark blue: lateral domains engaged in cell-cell adhesion, gray: basal domain in contact with a basal lamina (cholagiocytes) or facing the space of Disse (hepatocytes). Adapted, with permission, from Color Textbook of Histology by Leslie Gartner and James Hiatt, $2^{\text {nd }}$ Edition, Chapter 18: Digestive System III. Glands (140), Copyright Elsevier (2001). 

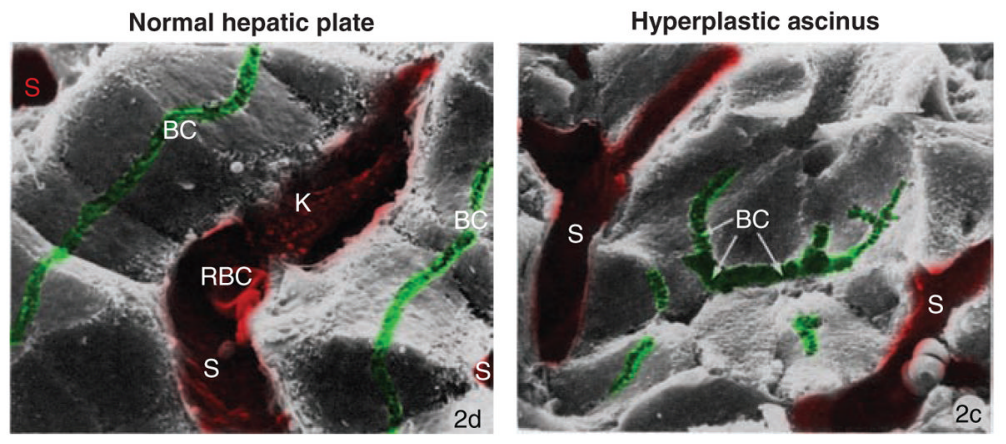

Figure 2. The organization of hepatocytes in the injured liver

Scanning electron micrographs of left: normal hepatic plate. Note the continuous, linear and lateral canaliculi (BC); Sinusoids (S) are separated by single-cell thick plates of hexagonal hepatocytes. Right: hyperplastic acinus. Notice a prominent central lumen (BC with arrows) shared by several neighboring hepatocytes; other canaliculi are short and discontinuous; sinusoids (S) are separated by multiple cells. K, Kupffer cell; RBC, red blood cell; x1530. Adapted by permission from Macmillan Publishers Ltd. on behalf of Cancer Research UK: [Br J Cancer] (Ogawa et al., Vol. 40: 782-90) (343), copyright (1979). 


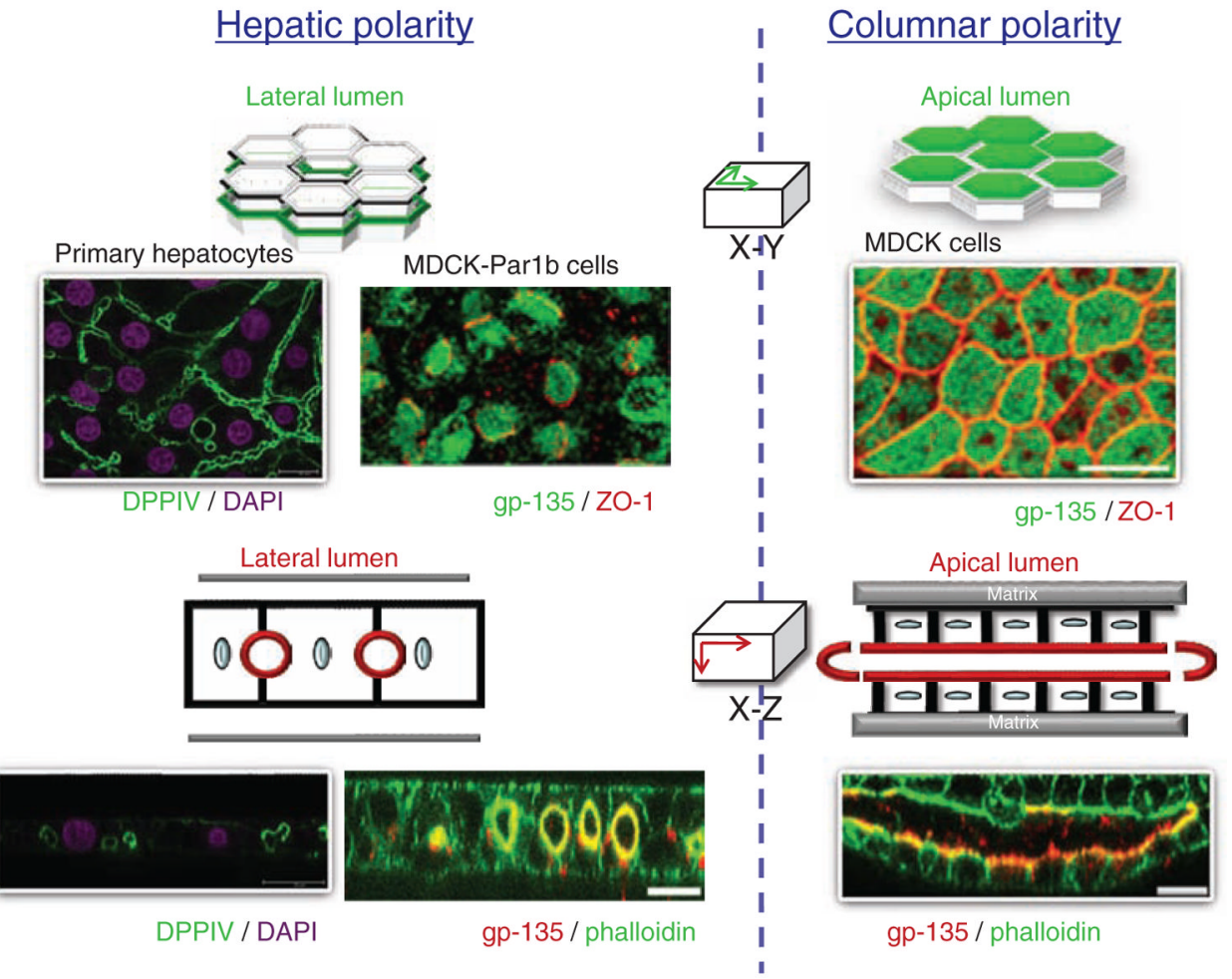

Figure 3. The hepatic and columnar polarity phenotypes

columnar epithelia, for example, kidney-derived Mardin Darby Canine kidney (MDCK) cells establish their luminal domains at the apex. When cultured in three-dimensional (3D) collagen matrices, they organize a luminal domain (labeled by the apical marker gp135) between two layers of cells. Phalloidin, an actin filament label, outlines all cell surfaces. Hepatocyte luminal domains are grooves interrupting the lateral surfaces of neighboring cells. When cultured in collagen sandwiches, primary rat hepatocytes remain monolayered and form an elaborate network of bile canaliculi labeled by the luminal protein DPPIV. MDCK cells overexpressing the kinase Parlb organize with hepatic polarity, they form their gp135-positive luminal surface between neighboring cells and remain monolayered in 3D collagen matrices. Unlike in hepatocytes, however, MDCK-Par1b lumina do not align to form interconnected bile canaliculi but remain cyst-like extracellular spheres between two cells. MDCK, MDCK-Par1b images are, with permission, from Cohen D et al., originally published in J Cell Biol. 164(5):717-27 (81). 
(A) Two step polarization of WIFB cells

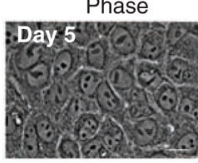

Phase

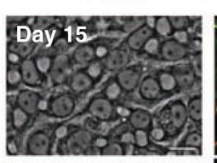

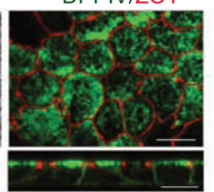

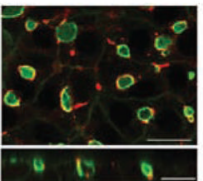

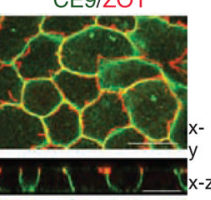

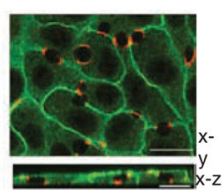

(B) Canaliculi in Can-10 cells
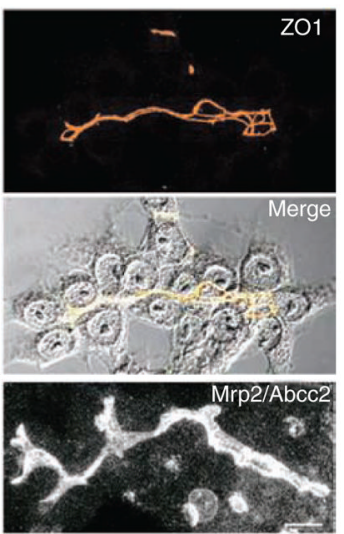

Figure 4. Examples of hepatic cell culture models

(A) In two-dimensional (2D) cultures, WIFB cells initially acquire columnar polarity (day 5 after plating) with apical DPPIV and with a "chickenwire" tight junction belt (ZO1). The lateral protein CE9 lines the sites of cell-cell contacts. Cells subsequently repolarize with hepatic lumen organization over a time course of 10 days. The spherical luminal domains between neighboring cells appear as translucent holes in phase images and are surrounded by the tight junction marker ZO1. Note also that CE9 remains present at the cell-contacting surfaces but is absent where they are interrupted by the lumina. Adapted, with permission, from Cohen D et al. 2004; originally published in J Cell Biol. 164(5): 717-27 (81). (B) In 2D cultures of Can10, the luminal domains of adjacent cells align to form elaborate canalicular networks that label for the bile acid transporter MRP2 and the tight junction marker ZO1. Adapted, with permission, from Peng X et al. Cell Tissue Res 2006; 323:233243 (357); reproduced, with permission, from Springer Verlag. 


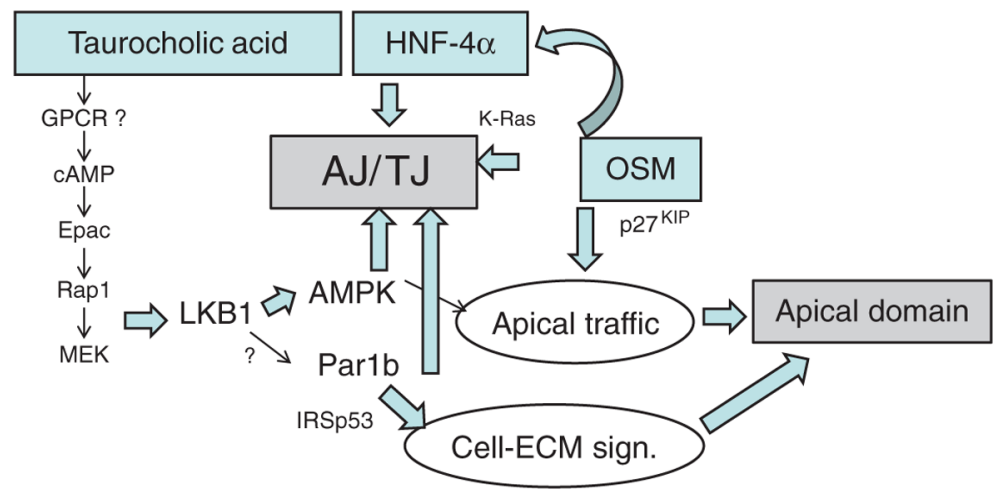

Figure 5. Signaling Pathways that determine hepatocyte polarization

Bile acids, the transcription factor HNF-4a and the cytokine Oncostatin M (OSM) have all been linked to two main aspects of hepatocyte polarization, the formation of tight (TJ) and adherens (AJ) junctions and the generation of an apical domain. The kinase LKB1 and its downstream target adenosine monophosphate kinase (AMPK) have evolved as key effecters of taurocholic acid signaling to promote both polarity features. LKB1 can also act as activating kinase for Par1 paralogues but has not yet been shown to do so in hepatocytes. Par1b regulates cell-cell adhesion and promotes a hepatic polarity phenotype in MDCK cells, in part by inhibiting the rho-GTPase adaptor protein IRSp53 in its role in cell-matrix signaling. For details, see text. 
(A)

Columnar
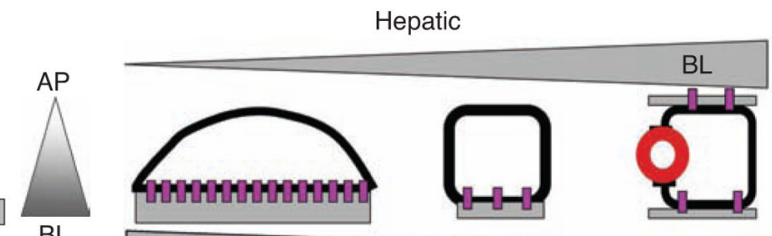

ECM signaling

(B)

Columnar

1. E-cadherin clustering

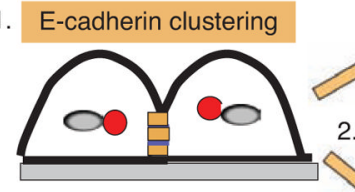

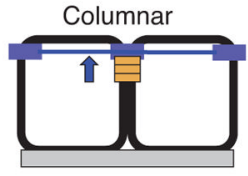

2. Tight junction organization

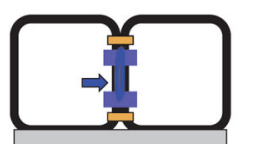

Hepatic

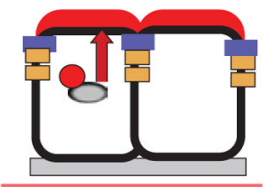

3. AP surface formation

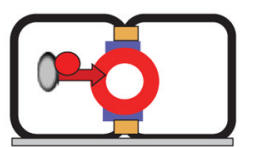

Figure 6. Models for the role of cell adhesion and E-cadherin-mediated junction formation in epithelial polarization

(A) In cultured columnar epithelial cells, the basal lamina provides a polarity cue to establish the apical (AP) domain on the free surface. In cultured hepatic cells, strong asymmetric integrin signaling on collagen or matrigel causes a nonpolarized, spread phenotype; on adhesive nonextracellular matrix (ECM) substrates and even more so in spheroid culture without any substrate contact, hepatic cells acquire a cuboidal cell shape and might develop luminal domains; best lumen polarity is achieved in ECM sandwich cultures. (B) In the absence of E-cadherin-mediated adhesion, cultured nonpolarized columnar and hepatic cells maintain luminal proteins in an intracellular organelle. In polarizing cells, adhesion (brown) and tight junction (blue) proteins are not yet separated (1). Strong E-cadherin clustering, induced by myosin II, promotes tight junction maturation with a chickenwire phenotype, parallel to the basal domain (columnar). Weak E-cadherin clustering results in a tight junction belt parallel to the cell-cell contacting surface (hepatic) (2). Apical surface formation follows the established tight junction pattern (3). AP, apical; BL, basolateral. 


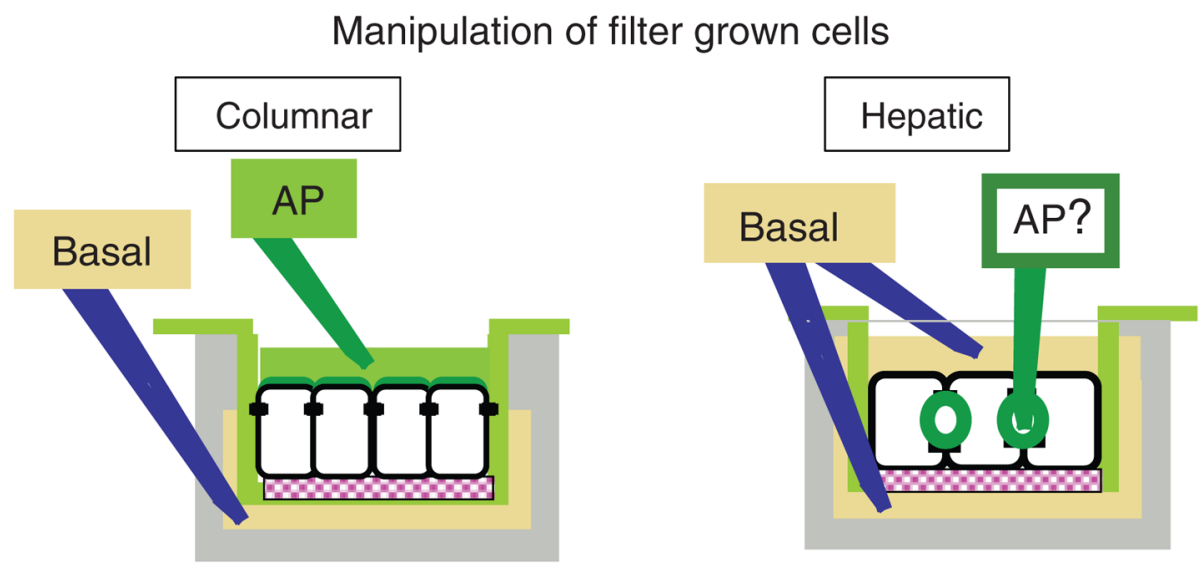

Figure 7. Experimental access to the apical and basolateral domain and secretory compartments in columnar and hepatic cells

Columnar: when grown on polycarbonate filter inserts that are suspended in clusterwell culture dishes, the tight junctions of Mardin Darby Canine kidney cells provide a diffusion barrier for small molecules that generate separate apical and basal chambers. These culture conditions allow for the quantitative study of apical (AP) and basolateral membrane and secretory proteins. Hepatic: filter cultures allow experimental access to the entire basolateral but not apical domain, but the luminal/apical domain is sequestered from experimental access. 


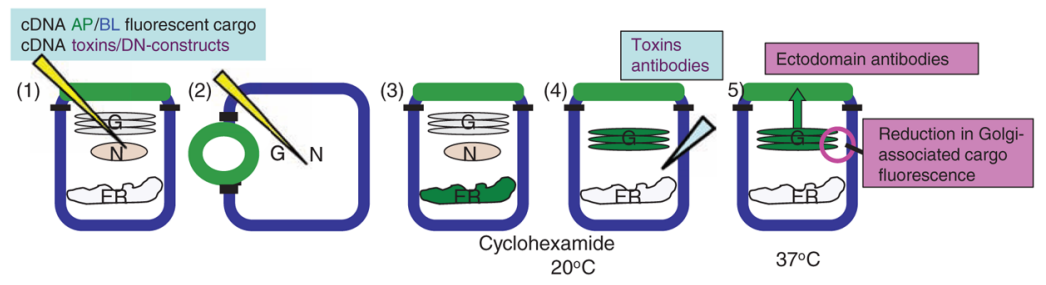

Figure 8. Studying protein targeting by live cell imaging

Microinjection of cDNAs encoding interfering cDNAs and proteins into individual cells to study their effect on cargo protein transport has proven an extremely effective strategy for the discovery of the apical and basolateral protein targeting machinery in Mardin Darby Canine kidney cells. To set a pulse of newly synthesized apical and/or basolateral proteins, cDNAs encoding fluorescent cargo proteins are comicroinjected with the interfering cDNAs into the nucleus [(1) for columnar or (2) for hepatic cells]. Upon protein expression from the cDNAs 1 to $3 \mathrm{~h}$ postmicroinjection (3), the cargo protein (an apical marker is shown here in green) is chased to the trans-Golgi network (TGN) in the presence of cyclohexamide to prevent further protein synthesis (4). At this point, toxins or function-blocking antibodies can be injected into the cytosol of cells. Protein exit from the TGN and arrival at the cell surface are determined after release of the TGN block (4). Cargo exit from the TGN is measured as decrease of Golgi-associated cargo (5). A fluorescent Golgi marker serves to define the Golgi area. Arrival at the cell surface is assessed with antibodies to the extracellular domain of the apical protein, added to unpermeabilized cells (5). 


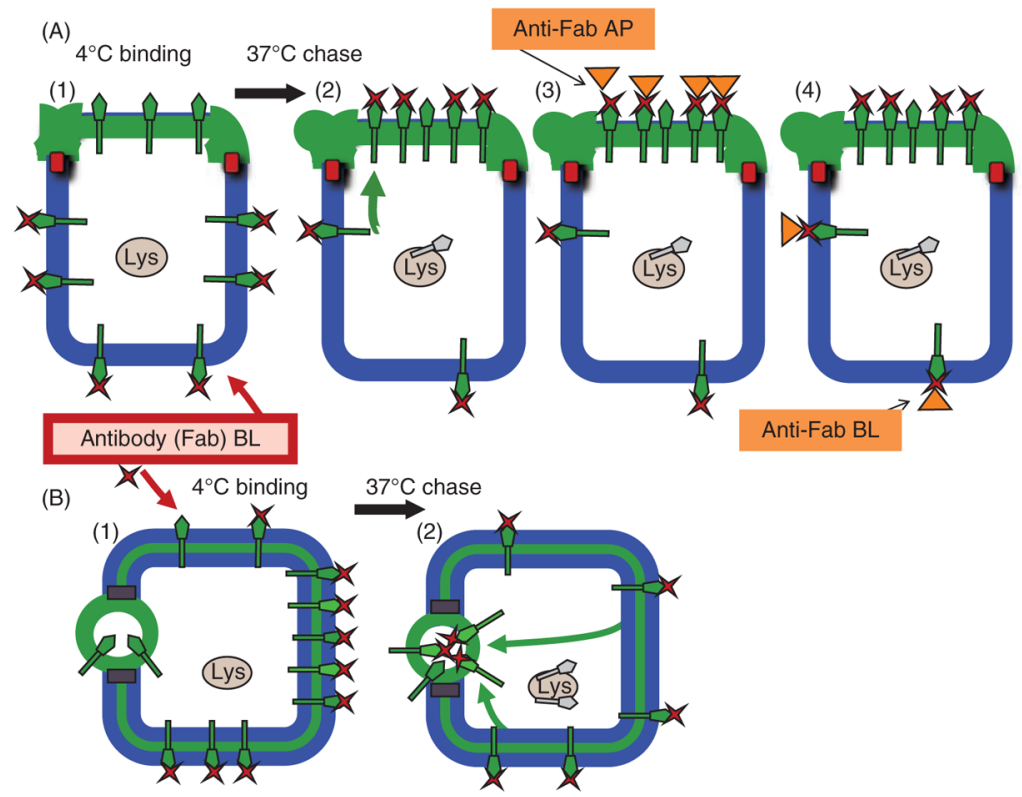

Figure 9. Example of a domain-selective targeting experiment in filter-grown columnar Mardin Darby Canine kidney cells

(A) Monovalent antibodies (Fab) to the extracellular domain of a membrane protein are bound to its basolateral population at $4^{\circ} \mathrm{C}(1)$. The fate of the labeled membrane protein after a chase period at $37^{\circ} \mathrm{C}(2)$ is determined by the addition of anti-Fab antibodies to either the apical (3) or basolateral (4) domain. (B) In hepatic cells, a similar quantitative assessment cannot be performed. Basolateral-to-apical transcytosis has only been documented in a qualitative manner by the appearance of basolaterally added antibodies in the luminal domain. 


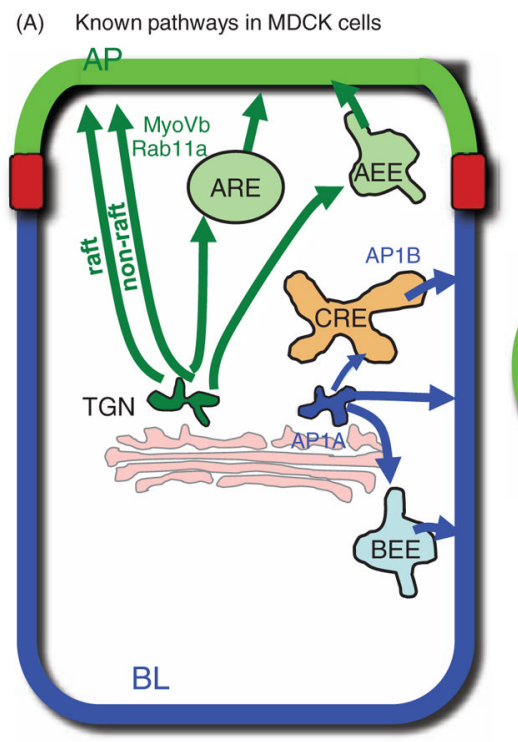

(B) Known and hypothetical pathways in hepatic cells

Figure 10. Targeting pathways from the trans-Golgi network (TGN) to the apical/canalicular and basolateral surfaces in Mardin Darby Canine kidney (MDCK) and hepatic cells

(A) Known pathways in MDCK cells. Apical (AP) pathways (green arrows): Depending on their presence in detergent-insoluble microdomains, raft-dependent and independent apical routes have been distinguished. Membrane and secretory proteins have been shown to traverse the apical recycling endosome (ARE) (in a MyoVb and Rab11-dependent manner) or the apical early endosome (AEE) before reaching the apical domain. Basolateral (BL) pathways (blue arrows): basolateral protein exit from the TGN is clathrin and AP-1A mediated. Multiple pathways have been distinguished: some basolateral proteins reach the basolateral domain without intermediate, others traversing either the basolateral early endosome (BEE) or the common recycling endosome (CRE) (in an AP-1B-dependent manner) prior to arriving at the basolateral domain. (B) Known and hypothetical pathways in hepatic cells. Two classes of apical proteins have been distinguished: those traveling from the TGN to the apical domain directly and those that first reach the basolateral domain. It is likely that, as in MDCK cells additional distinctions apply. Thus, some proteins might pass the ARE en route to the apical domain and there is evidence for raft and nonraft association in the TGN of apical proteins that take the transcytotic route. It is not resolved whether (A) apical and basolateral proteins are sorted into distinct transport carriers in the TGN and if so, whether basolateral proteins follow the same pathways as in MDCK cells, or (B) whether apical and basolateral proteins travel in common carriers to the basolateral domain. 
Hepatocyte targeting pathways from the plasma membrane Model 1 Model 2

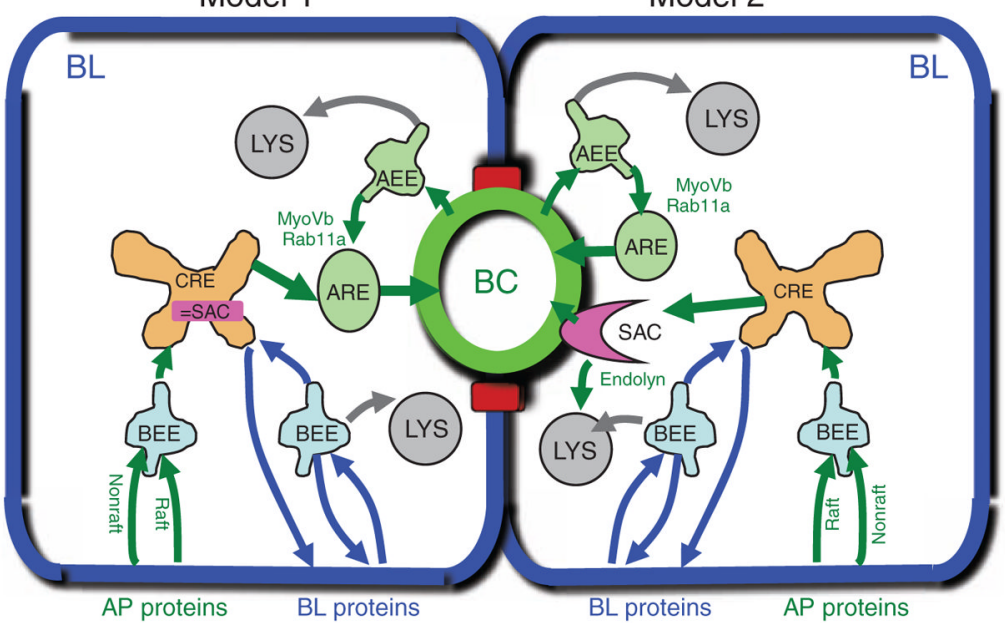

Figure 11. Proposed targeting pathways from the apical proteins (AP) and basolateral (BL) plasma membrane in hepatocytes

Model 1: upon endocytosis from the canalicular domain APs are sorted in the apical early endosome (AEE) into either the late endosomal/lysosomal pathway or for recycling to the apical recycling endosome (ARE). Apical proteins that have reached the basolateral surface from the trans-Golgi network are internalized via clathrin-coated vesicles (nonraft) or in a clathrin-independent, flotillin-dependent manner (raft), and reach the (subapical endosome) $\mathrm{SAC}$ via basolateral early endosomes (BEE). From the SAC they are targeted to the apical surface via the ARE (green arrows). BL resident proteins (blue arrows) undergo fast recycling from the BEE directly or via the SAC where they are sorted from apical proteins that reach the SAC in the transcytotic pathway. As the AEE, the BEE also sorts proteins for degradation to the lysosome (LYS). Pathways similar to model 1 have been described in MDCK cells. Model 2: differs from model 1 in the definition of the SAC and in the itinerary of apical proteins undergoing basolateral-to-apical transcytosis. Apical proteins reach the bile canalicular membrane via the SAC after being sorted from basolateral proteins in the CRE. The SAC is also involved in the targeting of some lysosomal proteins such as endolyn-78. It is distinct from the ARE, which handles apical protein recycling. 
Table 1

List of Selected Membrane Proteins that are Targeted to Either the Canalicular or Sinusoidal Membrane of Hepatocytes

\begin{tabular}{|c|c|c|}
\hline Abbreviation & Name & Function \\
\hline \multicolumn{3}{|c|}{ Basolaterally targeted and simusoidal membrane proteins } \\
\hline NTCP & Sodium-taurocholate cotransporter & Principal carrier for bile salt uptake from portal vein \\
\hline OATPs & Organic anion transporting proteins & Uptake of organic solutes from portal vein \\
\hline OCT-1 & Organic cation transporter-1 & Uptake of small organic cations \\
\hline OCT-2 & Organic cation transporter- 2 & Uptake of drugs and prostaglandins \\
\hline MRP6 & Multidrug-resistance-associated protein- 6 & ATP-dependent transport of small peptides and organic anions \\
\hline MRP3 & Multidrug-resistance-associated protein-3 & $\begin{array}{l}\text { ATP-dependent transport of small peptides and organic } \\
\text { anions; induced in cholestasis }\end{array}$ \\
\hline $\mathrm{Na}^{+} / \mathrm{K}^{+}$ATPase & Sodium-potassium ATPase & Pumps out $\mathrm{Na}^{+}$and exchange for $\mathrm{K}^{+}$ \\
\hline NHE-1 & $\mathrm{Na}^{+} / \mathrm{H}^{+}$-exchanger isoform 1 & Regulates intracellular $\mathrm{pH}$ \\
\hline ASOR & Asialoglycoprotein receptor & $\begin{array}{l}\text { Lectin that removes glycoprotein without sialic acid from the } \\
\text { circulation via receptor-mediated endocytosis }\end{array}$ \\
\hline $\mathrm{pIgR}$ & Polymeric immunoglobulin receptor & $\begin{array}{l}\text { Transcellular transport of } \operatorname{IgA} \text { and } \operatorname{IgM} \text { from the bood into the } \\
\text { bile }\end{array}$ \\
\hline Tf-R & Transferrin receptor & Iron import via receptor-mediated endocytosis \\
\hline LDL-R & Low-density lipoprotein receptor & Endocytosis of cholesterol-rich LDL \\
\hline HA321 & HA321 & Lateral membrane protein of unknown function \\
\hline CE9/EMMPRIN/CD147 & $\begin{array}{l}\text { Rat CE-9, cluster of differentiation } 147, \\
\text { EMMPRIN }\end{array}$ & Matrix metalloprotein inducer \\
\hline \multicolumn{3}{|c|}{ Apical/luminal membrane proteins } \\
\hline MDR1 & $\begin{array}{l}\text { Multidrug-resistance-1 } \\
\text { P-glycoprotein }\end{array}$ & $\begin{array}{l}\text { ATP-dependent excretion of organic cations, xenobiotics, and } \\
\text { cytotoxins into bile }\end{array}$ \\
\hline MDR3 & $\begin{array}{l}\text { Multidrug-resistance-3 } \\
\text { Phospholipid transporter }\end{array}$ & $\begin{array}{l}\text { Canalicular phospholipid flippase that mediates excretion of } \\
\text { phospholipids }\end{array}$ \\
\hline BSEP/SPGS & Bile salt export pump/sister of P-glycoprotein & $\begin{array}{l}\text { ATP-dependent bile salt transport into bile, stimulates bile } \\
\text { salt-dependent bile flow }\end{array}$ \\
\hline MRP2 & Multidrug-resistance-associated protein 2 & $\begin{array}{l}\text { ATP-dependent multispecific organic anion transport (e.g., } \\
\text { bilirubin and diglycoronide) into bile }\end{array}$ \\
\hline $\mathrm{BRCP}$ & Breast cancer resistance protein & ATP-dependent multispecific drug transporter \\
\hline ABCG5/G8 & Sterolin-1/2 & Heteromeric ATP-dependent cholesterol transporter \\
\hline AE-2 & Anion exchanger-2 & $\begin{array}{l}\text { Sodium-independent chloride-bicarbonate anion exchanger; } \\
\text { generates hydroionic fluxes into secretion }\end{array}$ \\
\hline MATE-1 & Multidrug and toxin extrusion protein-1 & Organic cation $/ \mathrm{H}^{+}$exchanger, excretes xenobiotics \\
\hline HA4/cCAM105 & Cell-cell adhesion molecule 105 kD & Homophilic cell-cell adhesion molecule and ecto-ATPase \\
\hline DPPIV/Cd26 & Dipeptidyl peptidase IV & $\begin{array}{l}\text { Ectopeptidase; regulates extracellular concentration of } \\
\text { biologically active peptides, function at the BC not clear }\end{array}$ \\
\hline APN/CD13 & Amino peptidase $\mathrm{N}$ & Metallo exoprotease, function at BC not clear \\
\hline LAP & Leucine aminopeptidase & Metallo exopeptidase, function at BC not clear \\
\hline GGT & Gamma-glutamyltranspeptidase & $\begin{array}{l}\text { Catalyzes the transfer of the gluthatione gamma-glutamyl } \\
\text { moiety to an acceptor; drug and xenobiotic detoxification, } \\
\text { elevated in HCC and alcoholic liver disease }\end{array}$ \\
\hline $5^{\prime}-\mathrm{NT}$ & $5^{\prime}$-ribonucleotide phosphohydrolase & $\begin{array}{l}\text { GPI-anchored ectonucleotidase; catalyzes the hydrolysis of } \\
\text { nucleotides; mediates extracellular adenosine formation from } \\
\text { AMP in injured cells, which promotes fibrosis }\end{array}$ \\
\hline
\end{tabular}

Compr Physiol. Author manuscript; available in PMC 2013 July 01. 


\begin{tabular}{lll}
\hline Abbreviation & Name & Function \\
\hline ALP & Liver alkaline phosphatase & $\begin{array}{l}\text { GPI-anchored ectophosphatase; dephosphorylates nucleotides, } \\
\text { proteins, alkaloids }\end{array}$ \\
\hline
\end{tabular}

